San Jose State University

SJSU ScholarWorks

Master's Theses

Master's Theses and Graduate Research

Spring 2013

\title{
Immobilization of Rhodococcus Erythropolis as a Potential Treatment for Atherosclerosis
}

Srikanth Darbha

San Jose State University

Follow this and additional works at: https://scholarworks.sjsu.edu/etd_theses

\section{Recommended Citation}

Darbha, Srikanth, "Immobilization of Rhodococcus Erythropolis as a Potential Treatment for Atherosclerosis" (2013). Master's Theses. 4268.

DOI: https://doi.org/10.31979/etd.nuv9-sgs4

https://scholarworks.sjsu.edu/etd_theses/4268

This Thesis is brought to you for free and open access by the Master's Theses and Graduate Research at SJSU ScholarWorks. It has been accepted for inclusion in Master's Theses by an authorized administrator of SJSU ScholarWorks. For more information, please contact scholarworks@sjsu.edu. 

TREATMENT FOR ATHEROSCLEROSIS

\author{
A Thesis \\ Presented to \\ The Faculty of the Department of General Engineering \\ San José State University
}

\author{
In Partial Fulfillment \\ of the Requirements for the Degree \\ Master of Science
}

by

Srikanth Vivek Darbha

May 2013 
(C) 2013

Srikanth Vivek Darbha

ALL RIGHTS RESERVED 
The Designated Thesis Committee Approves the Thesis Titled IMMOBILIZATION OF RHODOCOCCUS ERYTHROPOLIS AS A POTENTIAL TREATMENT FOR ATHEROSCLEROSIS

\author{
by \\ Srikanth Vivek Darbha

\section{APPROVED FOR THE DEPARTMENT OF GENERAL ENGINEERING}

San José State University

May 2013
Dr. Maryam Mobed-Miremadi Department of General Engineering
Dr. Bradley Stone
Department of Chemistry
Dr. Guna Selvaduray
Department of Biomedical, Chemical \& Materials Engineering




\title{
ABSTRACT \\ IMMOBILIZATION OF RHODOCOCCUS ERYTHROPOLIS AS A POTENTIAL TREATMENT FOR ATHEROSCLEROSIS
}

\author{
by Srikanth Vivek Darbha
}

Cardiovascular disease is the leading cause of death in the United States and is primarily due to hypercholesterolemia. The novel approach of combatting atherosclerosis presented in this research entails delivery of microencapsulated Rhodococcus erythropolis immobilized in biodegradable alginate-based microcapsules and utilizing the bacterium's cholesterol oxidase enzyme pathway to degrade cholesterol from intermediate-stage arterial plaque. The bacterial growth medium was optimized using Taguchi design methods to enable growth characterizations hindered by biosurfactant by-product. Methodologies for extraction and quantification of biosurfactant and cholesterol were developed and conducted simultaneous to bacterial growth assessment. Bacteria were encapsulated using atomization $(850 \pm 50 \mu \mathrm{m})$ and inkjet bioprinting $(32 \pm 5 \mu \mathrm{m})$ to study the effects of cell density and capsule miniaturization on the rate of cholesterol degradation. The cholesterol degradation rate was determined to be independent of cell density, and capsule miniaturization led to a near 4-fold increase in cholesterol degradation, thus allowing for $61.8 \%$ cholesterol in an intermediate-stage lesion to be degraded. 


\section{ACKNOWLEDGMENTS}

The author would like to thank his advisor, Dr. Maryam Mobed-Miremadi, Professor, Department of Biomedical, Chemical \& Materials Engineering, San Jose State University, for her support and guidance throughout this project. The author would also like to thank Dr. Guna Selvaduray, Professor, Department of Biomedical, Chemical and Materials Engineering, and Dr. Bradley Stone, Professor, Department of Chemistry, for their guidance and critical reviews for ensuring that this research effort was successful. The author would also like to thank his fellow students, Yiming Shan, Sahar Roshan, and Justin Win, for their help in completing the research experiments in a timely manner.

This thesis is dedicated to the author's family who has made possible the completion of this thesis through their encouragement, support, and inspiration. 


\section{TABLE OF CONTENTS}

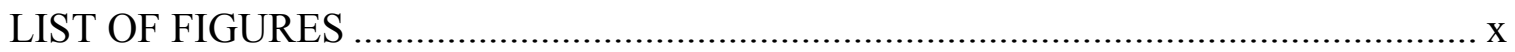

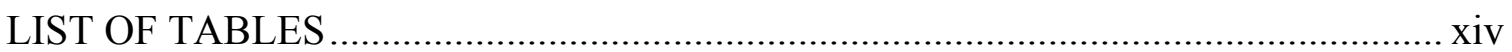

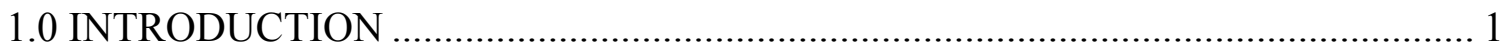

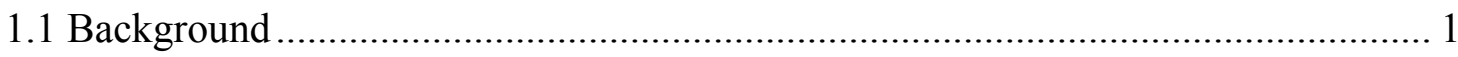

1.2 Physiology of Atherosclerotic Plaque ........................................................ 2

1.3 Current Treatment Methods for Atherosclerosis ............................................... 4

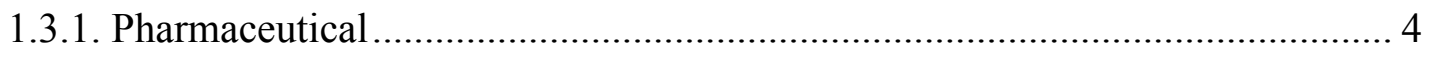

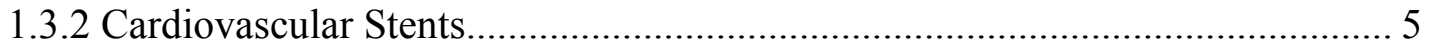

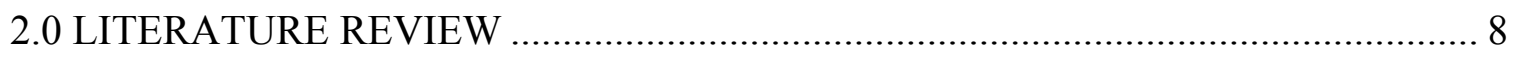

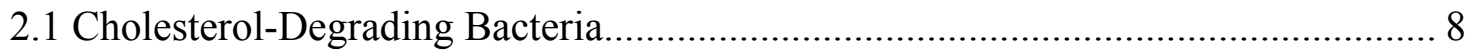

2.1.1 Bacteria Growth Curve Theory .............................................................. 11

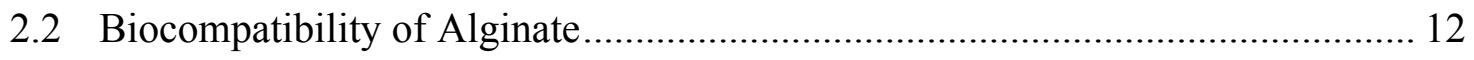

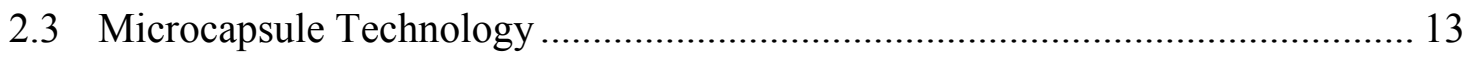

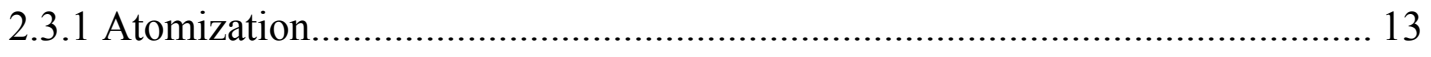

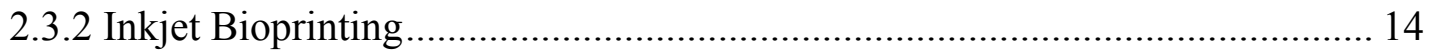

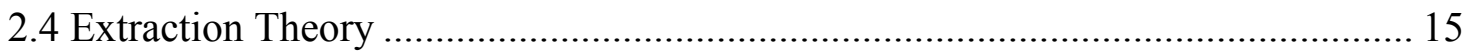

2.5 Prior Studies with Cholesterol-Degrading Bacteria........................................ 17

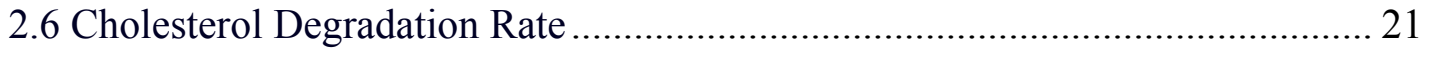

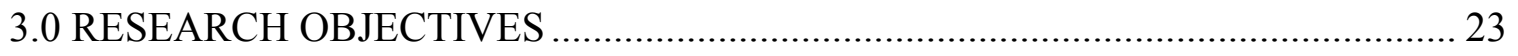




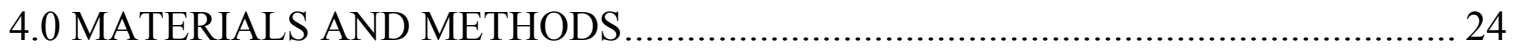

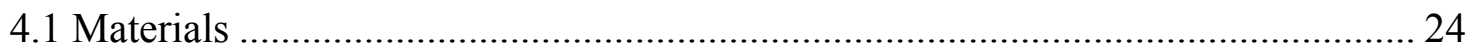

4.1.1 Bacterial Cell Culture .......................................................................... 24

4.1.2 Preparation of LB Broth Medium .................................................................. 25

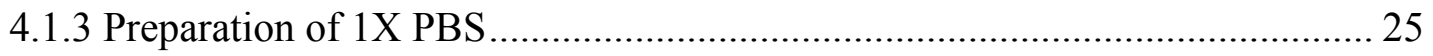

4.1.4 Preparation of 3\% (w/v) Sodium Citrate ............................................... 26

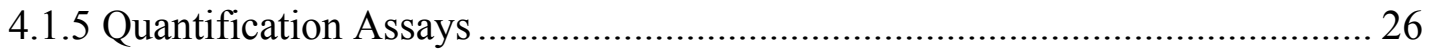

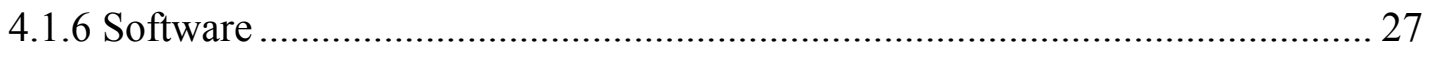

4.2 Bacterial Growth Medium Optimization ................................................... 27

4.2.1 Challenge with Bacterial Growth Measurements ....................................... 27

4.2.2 Design of Experiments (DOE) using Taguchi Screening Designs ................. 28

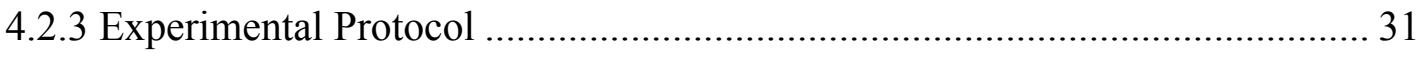

4.3 Growth Curve of Free and Encapsulated Bacteria............................................ 37

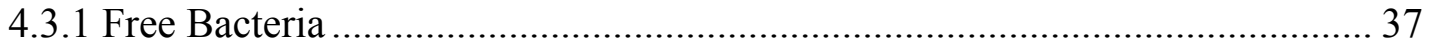

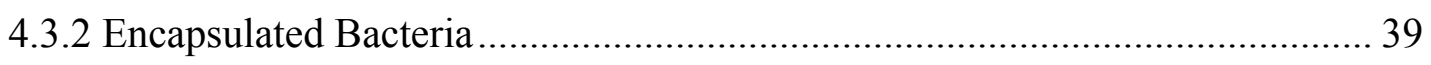

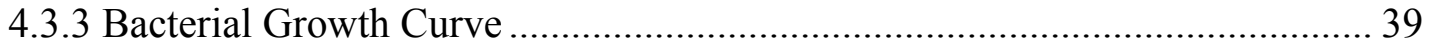

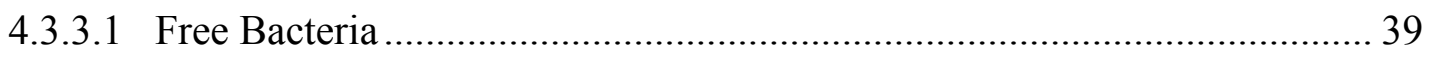

4.4 Encapsulation of Bacteria via Atomization and Inkjet Bioprinting ..................... 40

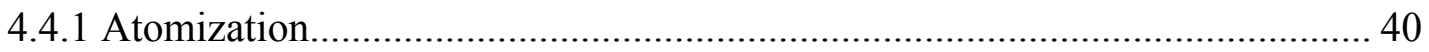

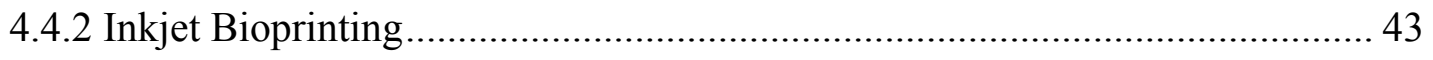

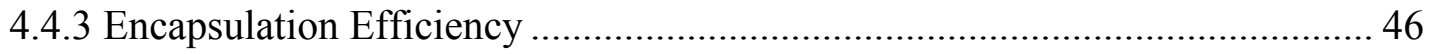

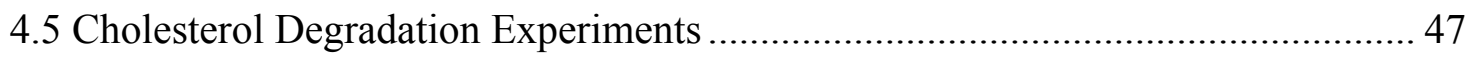




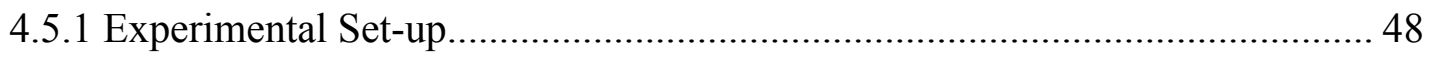

4.5.2 Cholesterol Layer Identification .................................................................. 49

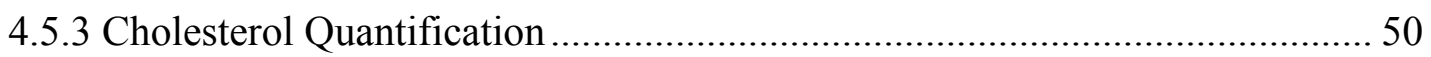

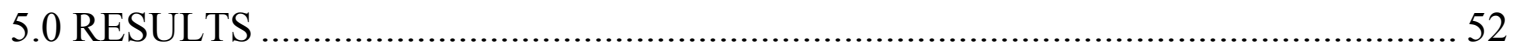

5.1 Growth medium Optimization and Validation ……………………................... 52

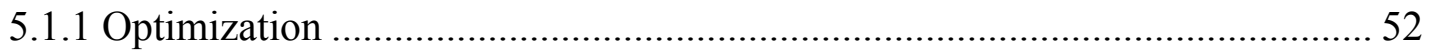

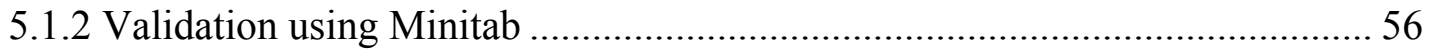

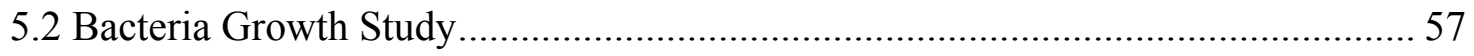

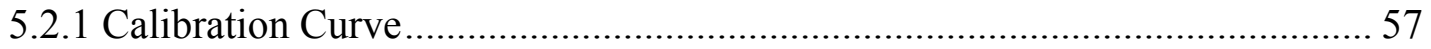

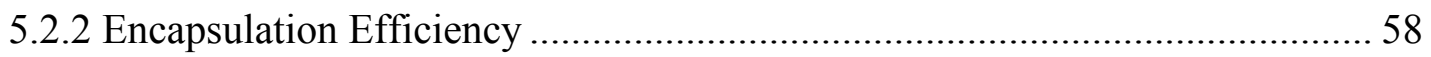

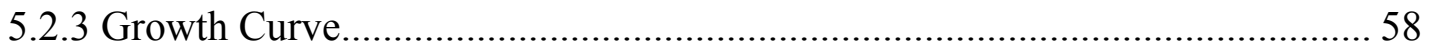

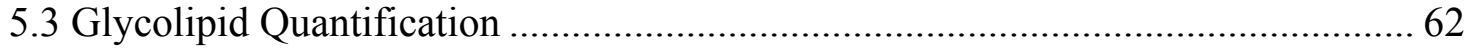

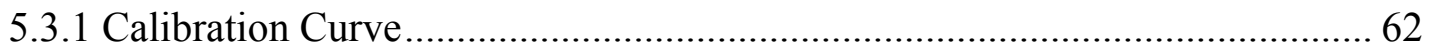

5.3.2 Glycolipid Profile For Encapsulated Bacteria ……......................................... 63

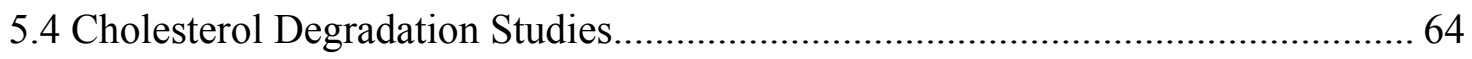

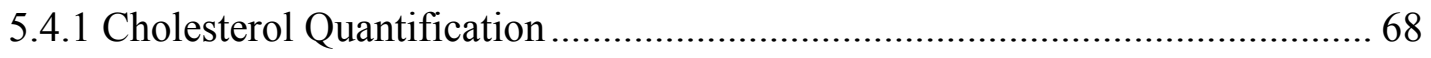

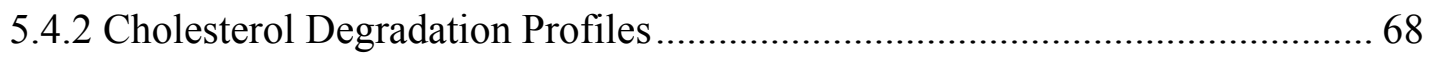

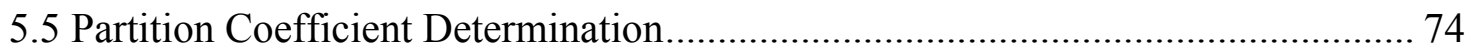

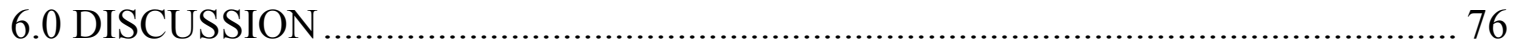

7.0 POSSIBLE CONTRIBUTIONS TO KNOWLEDGE _.............................................. 79

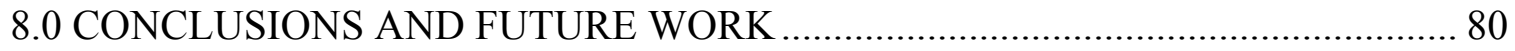




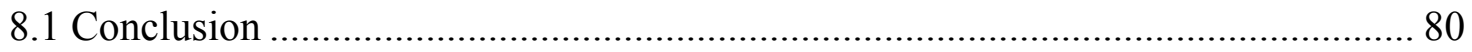

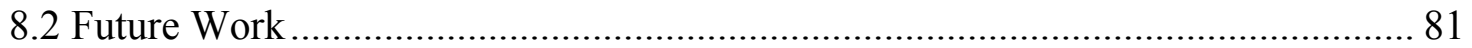

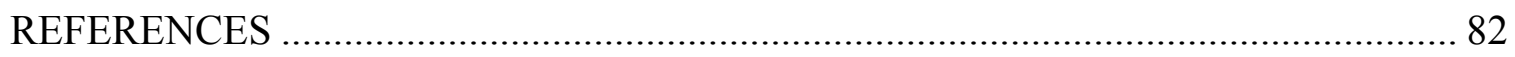

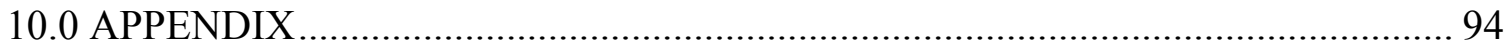

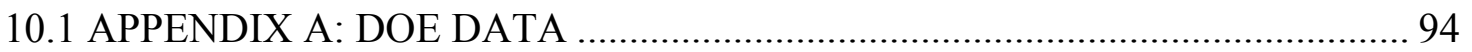

10.2 APPENDIX B: CHOLESTEROL DEGRADATION PROFILES ..................... 98 


\section{LIST OF FIGURES}

Figure 1. Chemical structure of rhodococcus sp. Trehalose lipid................................. 9

Figure 2. Bacterial growth curve...................................................................... 12

Figure 3. Design of atomization needle (drawing not to scale)................................... 14

Figure 4. Cross-sectional view of inkjet printhead (drawing not to scale)..................... 15

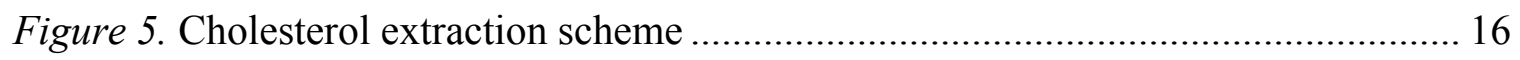

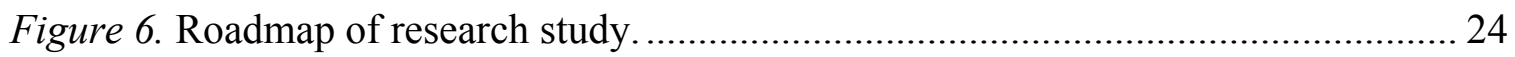

Figure 7. Growth curve of free (shown in blue) and encapsulated bacteria

(shown in red) in regular growth medium (lb and bsa)................................... 27

Figure $8 a$. Experimental flow diagram for biosurfactant quantification and

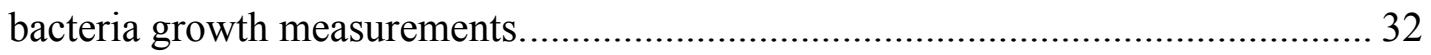

Figure $8 b$. Experimental flow diagram for for cholesterol quantification...................... 33

Figure 9. Biphasic separation of glycolipid biosurfactant........................................ 35

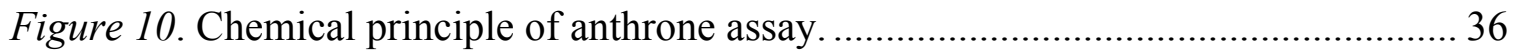

Figure 11. Cell counting chambers of cbc hemacytometer (drawing not

to scale). Chambers circled at regions where used for cell counting....................... 38

Figure 12. Cell counting chamber of a cbc hemacytometer with live

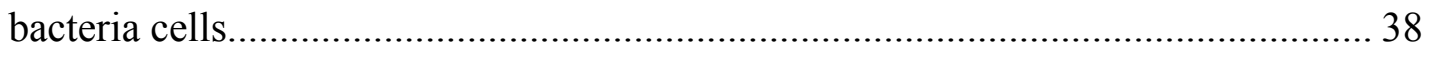

Figure 13. Experimental setup for alginate bead fabrication. .................................. 42

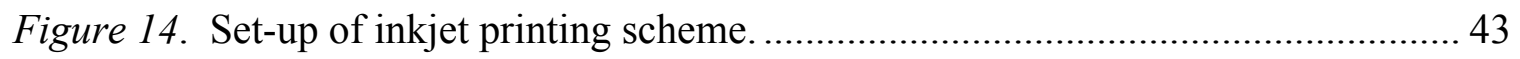

Figure 15. Input parameters for inkjet bioprinting system using

Microfab Jetserver TM . .................................................................................. 45 
Figure 16. Close-up view of inkjet printhead ejecting encapsulated bacteria. 46

Figure 17. Cholesterol phase identification using salkowski's method

(1-cholesterol powder, 2-sulfuric acid, 3-chloroform, 4-culture broth,

5-capsules, 6-methanol, 7-water). 50

Figure 18. Sensitivity plot for bsa, lb, pbs, cholesterol, and temperature

on biosurfactant production. 52

Figure 19. Signal-to-noise ratio plot for bsa, lb, pbs, cholesterol, and temperature on biosurfactant production

Figure 20. Sensitivity plot for bsa, lb, pbs, cholesterol, and temperature on bacteria growth. 53

Figure 21. Signal-to-noise ratio plot for bsa, lb, pbs, cholesterol, and temperature on bacteria growth. 54

Figure 22. Main effects plot for means of glycolipid biosurfactant for $\mathrm{t}=48 \mathrm{~h}$ 56

Figure 23. Main effects plot for signal-to-noise ratios of glycolipid biosurfactant for $\mathrm{t}=48 \mathrm{~h}$. 57

Figure 24. Calibration curve of bacterial cell count in optimized medium 58

Figure 25. Growth curve of free (shown in blue) and encapsulated bacteria (shown in red) in regular growth medium (lb and bsa) 59

Figure 26. Growth curve of free (shown in red) and encapsulated bacteria (shown in blue) in optimized medium. 61

Figure 28. Calibration curve of anthrone carbohydrate assay against 
glucose standard.

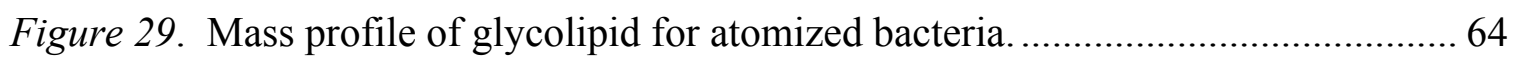

Figure 30. Atomized bacteria (at 10x) used throughout the study

(before experiment).

Figure 31. Atomized bacteria (at $4 \mathrm{x}$ ) in culture broth after $\mathrm{t}=8$ days

of incubation (before extraction). 66

Figure 32. Atomized bacteria (at 10x) after 8 days of incubation

(after extraction)

Figure 33. A) encapsulated bacteria (at 20x) fabricated by way of inkjet printing, 67

Figure 34. Calibration curve for abcam cholesterol quantitation kit 68

Figure 35. Normalized cholesterol concentration profile as a function of time for free bacteria $\left(\mathrm{n}_{\text {low }}\right)$ 71

Figure 36. Cholesterol degradation profiles for free and immobilized bacteria as a function of time for $\mathrm{n}_{\text {low }}=4.53 \times 10^{8}$. 72

Figure 37. Experimentally determined partition coefficient of cholesterol extracted from water into chloroform. 75

Figure 38. Main effects plot for means for bacteria growth for $\mathrm{t}=24 \mathrm{~h}$. 94

Figure 39. Main effects plot for signal-to-noise ratios for $\mathrm{t}=24 \mathrm{~h}$. 94

Figure 40. Main effects plot for means for bacteria growth for $\mathrm{t}=48 \mathrm{~h}$. 95

Figure 41. Main effects plot for signal-to-noise ratios for bacteria growth for $\mathrm{t}=48 \mathrm{~h}$. 95 
Figure 42. Main effects plot for means for glycolipid biosurfactant for $\mathrm{t}=24 \mathrm{~h}$. 96

Figure 43. Main effects plot for signal-to-noise ratios for glycolipid biosurfactant for $\mathrm{t}=24 \mathrm{~h}$. 96

Figure 44. Cholesterol profile of free bacteria with medium cell count. 98

Figure 45. Cholesterol profile of free bacteria with high cell count. 98

Figure 46. Cholesterol profile of atomized bacteria with medium cell count. 99

Figure 47. Cholesterol profile of atomized bacteria with high cell count. 99 


\section{LIST OF TABLES}

Table 1. Bacteria information and availability (ATCC, 2010)..................................... 8

Table 2. Summary of literature survey to-date of prior cholesterol degradation studies using bacteria..................................................................... 18

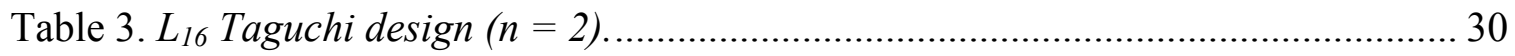

Table 4. Optimizations type by response .................................................................... 30

Table 5. $L_{16}$ (5 variables, 4 levels) taguchi matrix for biosurfactant

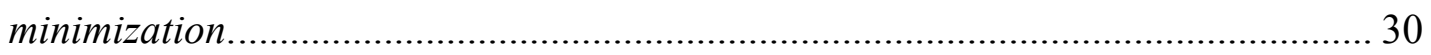

Table 6. Volumetric measurements for set-up of calibration curve for

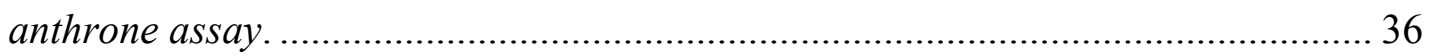

Table 7. Set-up parameters of cholesterol degradation experiment $(n=3)$................... 48

Table 8. Volumetric measurements of set-up for calibration curve of

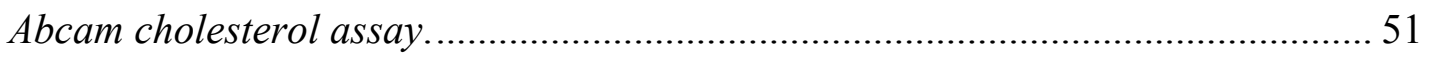

Table 9. Summary of Taguchi analysis of biosurfactant production using

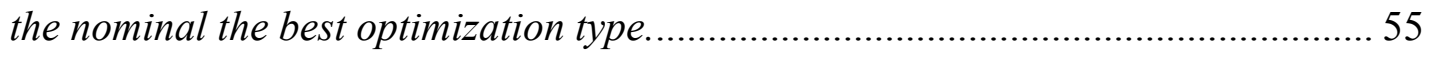

Table 10. Summary of taguchi analysis of bacterial growth using the nominal the best optimization type.

Table 11. Degradation rates of cholesterol by free, atomized, and inkjet bacteria for the free diffusion phase at $n_{\text {low }}\left(4.53 \times 10^{8}\right)$.

Table 12. Degradation rates of free, atomized, and inkjet bacteria for the glycolipid-mediated transport phase at $n_{\text {low. }}\left(4.53 \times 10^{8}\right)$. 69

Table 13. Significance testing summary comparing the effect of cell count 
to cholesterol degradation for the free bacteria.

Table 14. Summary of t-test significance testing for the effect of capsule miniaturization on cholesterol degradation rates at $n_{\text {low }}=4.53 \times 10^{8}$

Table 15. Percentage degradation of cholesterol mass for free, atomized, and inkjet bacteria in optimized medium 73

Table 16. Estimated time to fully degrade cholesterol from intermediate-stage plaque lesion. 74

Table 17. Average partition coefficients of cholesterol extracted from water into chloroform $(n=3)$.... 75

Table 18. Doe raw data for biosurfactant mass and bacteria growth at $t=48 h$ 


\subsection{INTRODUCTION}

\subsection{Background}

Atherosclerosis is considered to be an inflammatory condition of the artery and is characterized by the narrowing due to buildup of a substance known as plaque. It is one of the leading causes of death for men and women in the United States (Moses, 2007; Fontos, 2006; Sutton, 2005; Arjomand, 2003; Jenkins, 2002; Bitl, 1995; Serruys, 1994), and a wide variety of common ailments are associated directly with it, including cardiovascular disease (CVD), coronary heart disease (CHD), hyperlipidemia, and hypercholesterolemia.

Hyperlipidemia is the leading cause of cardiac illness and death (Rosamund, 1998; Murray, 1997), specifically CHD, ischemic cerebrovascular disease, and peripheral vascular disease (Jain, 2007). It had been established in 1984 that cholesterol was directly linked to CHD (McGill, 1968) such that a 1\% drop in blood cholesterol levels led to a 2-3\% reduced risk for CHD (AHA, 2001). This is a significant statistic because CHD accounts for twice as many cancer-related deaths and ten times as many accidentrelated deaths (McGill, 1968). According to the World Health Organization (WHO), high cholesterol levels accounted for over $60 \%$ of CHD cases (Yusuf, 2004). Cholesterol is also known to lead to damage in endothelial (arterial) tissue (McGill, 1968). This was apparent in Europe where $45 \%$ of heart attacks in Western Europe and 35\% in Central and Eastern Europe were due to high cholesterol (Yusuf, 2004).

Along with CHD and hypercholesterolemia, CVD assumes a large portion of the cardiovascular market. Some major risk factors for CVD include health conditions of 
large markets, including diabetes and hypertension, for example (George, 2010). In 2002, over 62 million patients suffered from CVD in the U.S. alone, and the total costs of treatment amounted to over $\$ 110$ billion (du Souich, 2004). It has been projected that by year 2030, CVD will remain the leading cause of death in the world (WHO, 2009). In Europe especially, CVD takes its toll with over 4 million deaths per year, $38 \%$ of which occur in the UK (WHO, 2009).

One must also consider the corresponding market of cardiovascular stents, in particular the drug-eluting stents (DES). In 2005, it was estimated that DESs constituted a market of approximately $\$ 5$ billion (Congress, 2010). In 2006, DESs accounted for over $70 \%$ of the stent market in the U.S. and $40 \%$ in Europe (Ong, 2006). In 2009, approximately $80 \%$ of stents in the U.S. were of the DES subset (Maisel, 2007), and healthcare spending amounted to over $\$ 400$ billion in the U.S. (Mensah, 2007). It is projected that the market for DESs will amount to over $\$ 6$ billion annually in the U.S. (Bischof, 2009).

\subsection{Physiology of Atherosclerotic Plaque}

Plaque is composed of cholesterol-filled macrophages, smooth muscle cells (SMC), glycosaminoglycans (GAG), collagen, fibrin, and cholesterol (Ross, 1976). What causes atherosclerosis to progress is the formation of an atherosclerotic lesion, which occurs when low-density lipoprotein (LDL) breaches the damaged intima of the blood vessel (Brown, 1983). The LDL is then oxidized, which causes the release of adhesion factors and chemotactic molecules (Moubayed, 2007). These adhesions molecules in turn allow for freely flowing blood monocytes to adhere and bind to the endothelial layer 
of the vessel wall (Moubayed, 2007). Specifically, the monocytes appear at the intima and subintima of the vessel wall (Imhof, 2004; Ley, 2007).

Blood monocytes are an unbound species naturally present in blood and circulate to regions of inflammation in order to produce cytokines (Woollard, 2010). They are also capable of differentiating into macrophages and even foam cells (Tacke, 2006; Varol, 2009) they can consume oxidized LDL (Woollard, 2010) by way of receptor-mediated endocytosis (Goldstein, 1979; Basu, 1979; Goldstein, 1980; Goldstein, 1981). Next, is that the monocytes/macrophages consume oxidized LDL (Greaves, 2009) and then differentiate into foam cells, so named due to their foamy appearance similar to soapy lather. It is the cholesterol that is stored as cholesteryl ester droplets within the macrophages/monocytes that contributes to the foamy appearance (Greaves, 2009). Also, the cholesterol that is endocytosed undergoes a continuous cycle of hydrolysis and reesterification by various lysosomal enzymes (Brown, 1980). The accumulation of these foam cells, also known as fatty streaks, is the early stage of plaque that is incorporated in the intima layer of the vessel (Galkina, 2009). It is important to note that fatty streaks usually develop in those regions that have arterial branching (Hahn, 2009).

The fatty streaks then accumulate and mature into a plaque core that is eventually surrounded by a cap of smooth muscle cells and a collagen cellular matrix (Woollard, 2010). During this time, a plethora of inflammatory cytokines and growth factors is secreted and furthers the progression of the plaque, which can eventually lead to thrombosis and even stenosis (Woollard, 2010). Consequently, the plaque core becomes necrotic and can cause new blood vessels to form (Woollard, 2010). The cap surrounding 
the plaque is capable of breaking off in the form of debris, thereby leading to cascades of coagulation and clotting (Fuster, 2005).

Atherosclerosis is categorized into six stages (HVIF, 2010), outlined below:

- Stage I, is a normal healthy artery with no damage or blockages.

- Stage II is characterized by the presence of fatty streaks that appear vertically thick in the vessel wall. However, there are no apparent symptoms of atherosclerosis o or any obstructions.

- As the fatty streaks accumulate, the vessel enters Stage III and an atheroma begins to develop, thereby interfering with normal blood flow.

- Stage IV is characterized by plaque maturation and hardening in which case over $50 \%$ of the vessel diameter is available for blood flow. This results in high blood pressure and heart rate for the suffering individual.

- During Stage V, the plaque may be subject to cracking in which clots may adhere. This can contribute to a progressed blockage, thereby leading to a significantly reduced blood flow to the heart such that prolonged angina may develop.

- Stage VI is the most advanced stage at which clots may potentially obstruct the entire vessel lumen diameter.

\subsection{Current Treatment Methods for Atherosclerosis}

\subsubsection{Pharmaceutical}

The main conventional treatment for atherosclerosis includes synthetic substances that fall into a class of drugs known as statins, which function to lower cholesterol levels through the inhibition of an enzyme (HMG-CoA reductase) that is responsible for 
cholesterol production in the liver. Although effective for atherosclerotic treatment, statins have been shown to lead to death or non-fatal myocardial infarction (Athyros, 2009). Patients who discontinue the use of statins are set up for more adverse coronary complications (Athyros, 2009), especially during any subsequent surgery (Schouten, 2007). Since patients must not consume oral medication after surgery and there are no intravenous forms of statins, the discontinuation of statins during the surgery may lead to postoperative troponin release, myocardial infarction, or cardiovascular death (Athyros, 2009).

Another method of treatment that has gained attention is EDTA chelation therapy, which is claimed to be effective for atherosclerotic plaque degradation (Ernst, 2000; Ernst, 1997; Lewin, 1997). EDTA chelation therapy comprises a strong market to the extent that out-of-pocket costs range from $\$ 400$ million to $\$ 3$ billion annually in the U.S. (Knudston, 2002; Lamas, 2000).

\subsubsection{Cardiovascular Stents}

Apart from pharmaceutical treatment, cardiovascular stents are being used in order to widen arterial lumen and thus allow blood flow to be unhindered. Stents are typically placed into the coronary artery by way of a catheter and guide wire and then deployed during angioplasty. The various types of stents that exist today are the result of an evolutionary transformation from traditional bare metal stents, to polymer stents, to the highly studied bioabsorbable stents that are gaining attention for their reduced risk of restenosis (Camenzind, 2007; Pfisterer, 2006; Tsimikas, 2006), which is the re-narrowing of an artery after it has been unblocked. 
According to Rajagopal, et al, two possible mechanisms have been hypothesized for the invocation of the restenosis phenomenon: arterial modeling and neointimal hyperplasia (Rajagopal, 2003). There are two proposed types of arterial modeling that exist: positive and negative. Positive remodeling involves enlargement of the coronary artery in response to plaque formation in order to limit luminal occlusion (Glagov, 1987). Negative remodeling involves further luminal occlusion in response to plaque buildup, thus contributing to restenosis (Rajagopal, 2003). Neointimal hyperplasia involves a cellular cascade that ultimately results in proliferation of smooth muscle cells upon plaque rupture by way of balloon inflation from angioplasty (Pakala, 1997; Dorn II, 1997).

It has been shown that bare metal stents have led to significantly increased risk for restenosis (Tsimikas, 2006; Pakala, 1997; Dorn II, 1997), thereby requiring the use of dual antiplatelet therapy for prevention of restenosis. Such therapy can lead to long-term bleeding, and the efficacy of it is still unproven (Doyle, 2009). Hence, polymer stents were developed, but have been shown to lead to late thrombosis and are associated with diminished arterial healing, which is associated with delayed re-endothelialization and the continued presence of fibrin (Pfisterer, 2006; Joner, 2006; John, 2008). Drug-eluting polymer stents were then developed to combat restenosis, but have been shown to be associated with inflammatory cell infiltration and possibly even arterial drug sequestration (Virmani, 2004; Carter, 2004; Finn, 2005), which may lead to arterial toxicity (Hoye, 2006; Kuchulakanti, 2006; Takano, 2006). Hence, increases in drug concentration may be counterproductive for restenosis treatment. It has been shown that 
luminal caliber significantly decreases after 6-8 months of drug-eluting polymer stent implantation and is due to the continued inflammatory response in the arterial wall (Byrne, 2009), which may be a result of residual polymer in the artery (Joner, 2006; Virmani, 2004; Finn, 2007).

In order to avoid issues with metallic and polymer stents, bioabsorbable stents are being studied. One such popular stent on the market is the EXCEL Sirolimus eluting stent, which is made of poly-lactic acid and degrades into $\mathrm{CO}_{2}$ and $\mathrm{H}_{2} \mathrm{O}$ by-products (Doyle, 2009). EXCEL is associated with 5.4\% restenosis and elicits no myocardial infarction, thrombosis, or death, thereby proving its initial safety and efficacy (Doyle, 2009).

Since pharmaceutical treatments for atherosclerosis are very expensive and can lead to complications that may be fatal in nature, there is an imperative need to research and develop alternative treatment methods that are safe, effective, and inexpensive. One such alternative that is gaining much attention is the concept of cell encapsulation, which is the central aim of this research effort. Advantages of encapsulation include the presence of a biocompatible immunoisolation barrier for cell encapsulation, ensuring that the cells do not come into contact with blood (DeVos, 1997). 


\subsection{LITERATURE REVIEW}

2.1 Cholesterol-Degrading Bacteria

Various strains of bacteria can degrade cholesterol through enzymatic pathways (ATCC, 2010). Shown in Table 1 is a tabulated list of such bacteria as identified by the American Type Culture Collection (ATCC).

Table 1. Bacteria information and availability (ATCC, 2010).

\begin{tabular}{|c|c|c|c|}
\hline ATCC No. & $\begin{array}{c}\text { Biosafety } \\
\text { Level }\end{array}$ & $\begin{array}{c}\text { ATCC Medium } \\
\#\end{array}$ & Temperature of Growth $\left({ }^{\circ} \mathrm{C}\right)$ \\
\hline 43121 & 1 & 416 & 34 \\
\hline 4277 & 1 & 196 & 26 \\
\hline 14811 & 1 & 196 & 26 \\
\hline 17825 & 1 & 3 & 26 \\
\hline $\mathbf{2 5 5 4 4}$ & $\mathbf{1}$ & $\mathbf{3}$ & $\mathbf{2 6}$ \\
\hline 31216 & 1 & 44 & 26 \\
\hline$* 31384$ & 1 & 1374 & 30 \\
\hline$* 31385$ & 1 & 1374 & 30 \\
\hline$* 31455$ & 1 & 1374 & 30 \\
\hline$* 31456$ & 1 & 1374 & 30 \\
\hline$* 31457$ & 1 & 1374 & 30 \\
\hline$* 31458$ & 1 & 1374 & 30 \\
\hline$* 31459$ & 1 & 1374 & 30 \\
\hline$* 31460$ & 1 & 1374 & 30 \\
\hline$* * 35215$ & 1 & 1317 & 37 \\
\hline 51222 & 1 & 1872 & 37 \\
\hline BAA-148 & 1 & 1872 & \\
\hline
\end{tabular}

The ATCC numbers with one asterisk correspond to those bacteria that grow on cholesterol media; the number with two asterisks corresponds to the bacterium that degrades cholesterol. The bacterium of interest (in bold) in this study was ATCC 25544, also known as Rhodococcus erythropolis. This species has the ability to produce biosurfactant compounds that are directly dependent upon the growth medium. A 
glycolipid compound known as trehalose lipid (shown in Fig. 1) is produced by $R$. erythropolis when grown on a hydrocarbon medium (Franzetti, 2010).

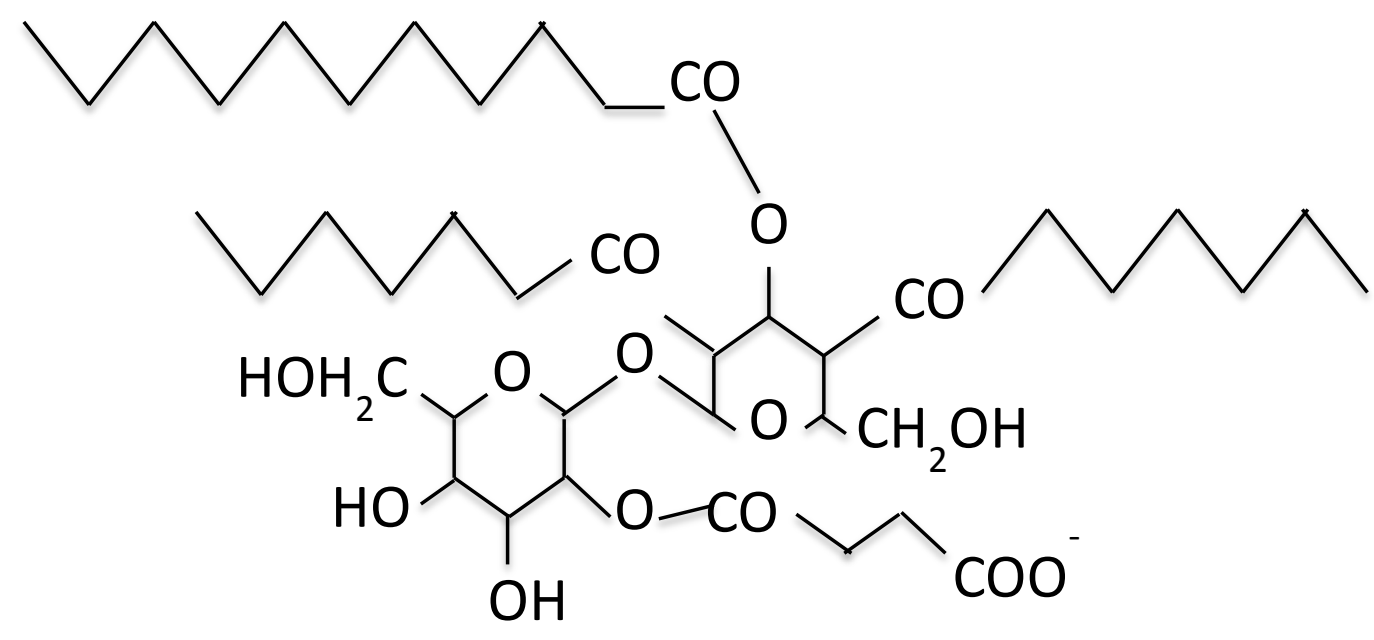

Figure 1. Chemical structure of Rhodococcus sp. trehalose lipid.

Glycolipids are sugar molecules (mono or disaccharides) attached to fatty acids.

The sugar moiety is polar, whereas the lipid moiety is non-polar, thus rendering it amphipathic. Glycolipids produced by R. erythropolis decrease the surface tension and interfacial tensions of culture broth to $25-40 \mathrm{mN} / \mathrm{m}$ and $1-5 \mathrm{mN} / \mathrm{m}$, respectively ( $\mathrm{Li}$, 1984; Rapp, 1979; Kretschmer, 1982). Several hypotheses have been formulated to explain this phenomenon: (i) the biosurfactant may aid in survival, (ii) the biosurfactant may aid in transport of nutrient, (iii) the biosurfactant may lead to reduced hydrophobicity of the culture broth (Franzetti, 2010).

This particular strain produces the enzyme cholesterol oxidase that specifically degrades cholesterol (Eqn. 1) and has a molecular mass of approximately $55 \mathrm{kDa}$ (Sojo, 
1997). Cholesterol oxidase, 3ß-Hydroxysteroid:oxygen oxidoreductase, is an enzyme that catalyzes the oxidation of cholesterol into cholest-4-en-3-one (Kreit, 2009).

$$
\text { Cholesterol }+\mathrm{O}_{2} \stackrel{\text { Cholesterol oxidase }}{\longrightarrow} \mathrm{H}_{2} \mathrm{O}_{2}+4-\text { Cholesten }-3-\text { one }
$$

Although $\mathrm{H}_{2} \mathrm{O}_{2}$ is a known cytotoxic chemical, it is naturally decomposed by peroxisomes of the human body and can be cleared by the enzyme catalase (Eqn. 2).

$$
2 \mathrm{H}_{2} \mathrm{O}_{2} \stackrel{\text { Catalase }}{\longrightarrow} 2 \mathrm{H}_{2} \mathrm{O}+\mathrm{O}_{2}
$$

Cholesterol oxidase is derived from several microbial sources, including Arthrobacter (Wilmanska, 1988), Corynebacterium (Shirokane, 1977), R. erythropolis (Richmond, 1973; Atrat, 1992), Nocardia rhodochrous and Rhodococcus rhodochrous (Buckland, 1976; Aihara, 1986; Cheetham, 1980; Cheetham, 1982; Cheetham, 1979; Minuth, 1995), Mycobacterium (Schatz, 1949; Smith, 1995), Pseudomonas (Rhee, 1991), Schizopyllum commune (Fukuyama, 1979), Brevibacterium sterolicum (Uwajima, 1973; Ohta, 1991), Streptoverticillium cholesterolicum (Inouye, 1982), Streptomyces violascens (Ishizaki, 1989; Lartillot, 1990; Kamei, 1978), and Rhodococcus sp. (Watanabe, 1986; Kreit, 1992; Watanabe, 1989). The enzyme's activity is optimal at a pH of 7.0 and $37^{\circ} \mathrm{C}$. Other physical properties vary from species to species. Sojo, et al report that the ATCC 25544 strain produces both intracellular (cell-bound) and extracellular cholesterol oxidase, but more intracellular cholesterol oxidase is produced than extracellular cholesterol oxidase (Sojo, 1997).

Applications of cholesterol oxidase have been mainly geared towards cholesterol quantification through use as an analytical probe. The utility of the enzyme is vast in application and has been studied with regards to cholesterol quantification of the 
following: total and esterified serum (Kreit, 2009; Shirokane, 1977; Allain, 1974; Brooks, 1983; Murata, 1992; Lapinleimu, 1994; Gray, 1995); LDL (Sugiuchi, 1998) and HDL (Cobbaert, 1998); cholesterol on the erythrocyte cell membranes (Lange, 1984); gall stones (Wei, 1989); human bile (Aufenanger, 1989; Bocos, 1992); fluorescence (Gray, 1995 ) and chemiluminescence (Mike, 1992; Sasamoto, 1995) detection methods. Cholesterol oxidase has also been integrated into a rapid bioreactor to measure serum triglyceride and total cholesterol (Makino, 1987).

Due to the diversity of the enzyme's applications, many efforts have been expended on optimizing cholesterol oxidase production, which has been deemed as an expensive process due to low productivity. Hence, efforts of cloning and genetic manipulation are of high interest to optimize production.

\subsubsection{Bacteria Growth Curve Theory}

Shown in Fig. 2 is a standard bacteria growth curve. There are four main phases, namely lag, log, stationary, and death/decline phases. The lag phase occurs immediately after the bacteria culture is created. During this phase, the bacteria cells are adapting to the new environment. It is important to note that the cells are still active. It is during this phase that the intracellular enzyme is produced (Shuler, 2002). The log phase is the time during which the cells begin to actively replicate and grow at an exponential rate. Because nutrition is limited, there are a finite number of cells that can grow. That is, the cells reach saturation at which point cell growth begins to cease. The point at which the cell growth rate is equal to the cell death rate is when the population begins to stabilize and enters what is known as the stationary phase. It is during this stationary phase that 
extracellular enzyme is produced (Shuler, 2002). The final phase for the cells is the death/decline phase, which is when the cell death rate exceeds the cell growth rate.

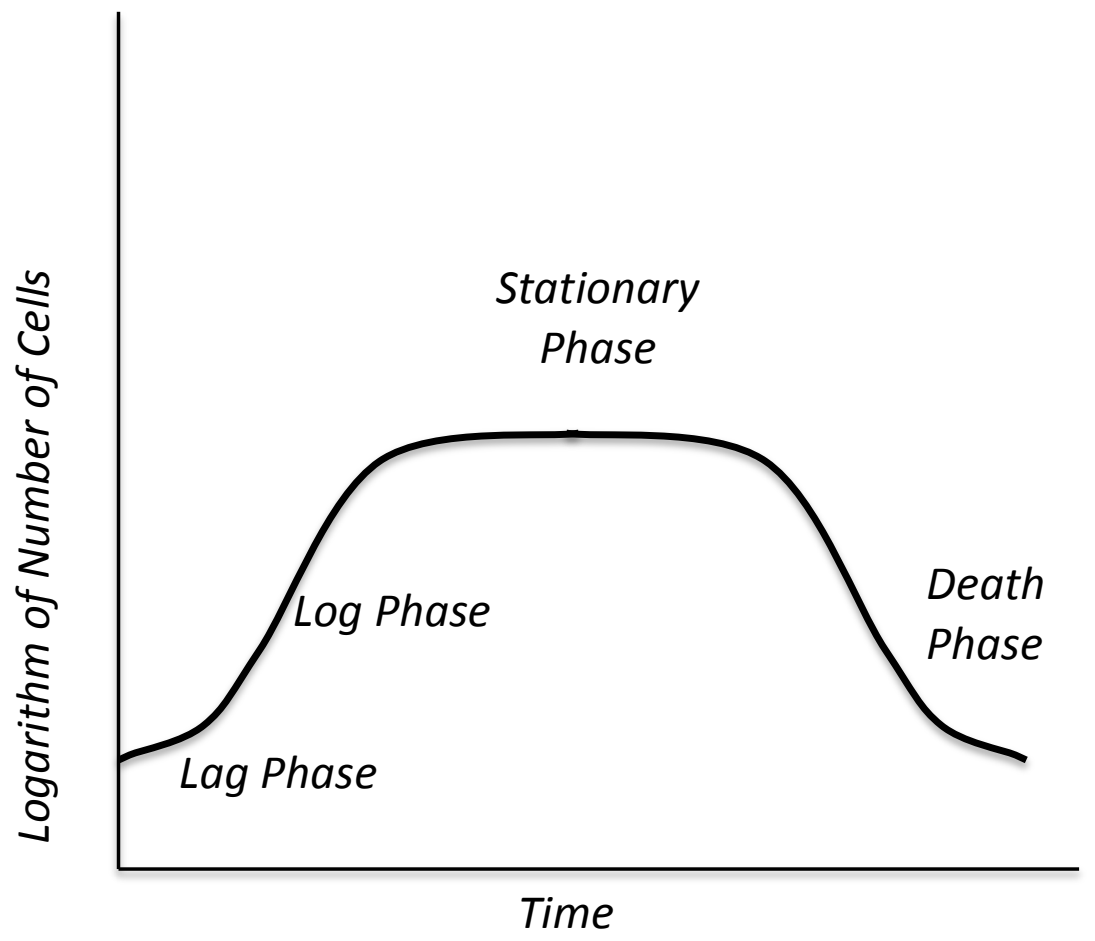

Figure 2. Bacterial growth curve.

2.2 Biocompatibility of Alginate

Alginate is a polymer that is composed of $\alpha$-L-guluronic acid (G) and $\beta$-Dmannuronic acid (M) blocks (Nunamaker, 2007). Depending on the ratio of these blocks, properties of the alginate material can be altered accordingly. A higher percentage of G results in alginate that is stronger, while a higher percentage of $\mathrm{M}$ results in a more flexible gel (Amsden, 1999). The range of flexibility changes according to the following order: $\mathrm{MG}>\mathrm{MM}>\mathrm{GG}$ (Smidsrod, 1973). Part of the reason why higher $\mathrm{G}$ alginates are stronger is due to the greater number of cross-links that form as a result of the higher 
affinity of $\mathrm{Ca}^{2+}$ for the $\mathrm{G}$ sites (Kong, 2004). High $\mathrm{G}$ alginates are known to exhibit high permeability to antibodies (Klein, 1983; Stewart, 1993), which may potentially weaken its biocompatibility. This increased biological response may be quelled through the use of alginate that consists of 40-45\% G and is high purity (Fritschy, 1994; De Vos, 1997; De Vos, 1993; De Vos, 1994; De Vos, 1997).

\subsection{Microcapsule Technology}

\subsubsection{Atomization}

Alginate microcapsules are used extensively because of the controllable range of membrane permeability and the ease of solvent free microcapsule synthesis steps conducted at the physiological $\mathrm{pH}$ of 7.4. To immobilize enzyme bio-compound within alginate microcapsules, the compound at a specific concentration is suspended in medium viscosity sodium alginate and atomized into $10 \%(\mathrm{w} / \mathrm{v}) \mathrm{CaCl}_{2}$ cross-linking solution (Stewart, 1993). The atomizer design (Fig. 3) is comprised of two concentric channels such that coaxial airflow shears the liquid droplets in a reproducible manner. Droplet size can be controlled by adjusting the coaxial airflow rate $\left(\mathrm{F}_{\mathrm{A}}\right)$, the compound/Naalginate suspension flow rate $\left(\mathrm{F}_{\mathrm{L}}\right)$, and the radial dimensions of the atomizer. 
Na-Alginate + Bio-compound $\left(\mathrm{F}_{\mathrm{L}}\right)$

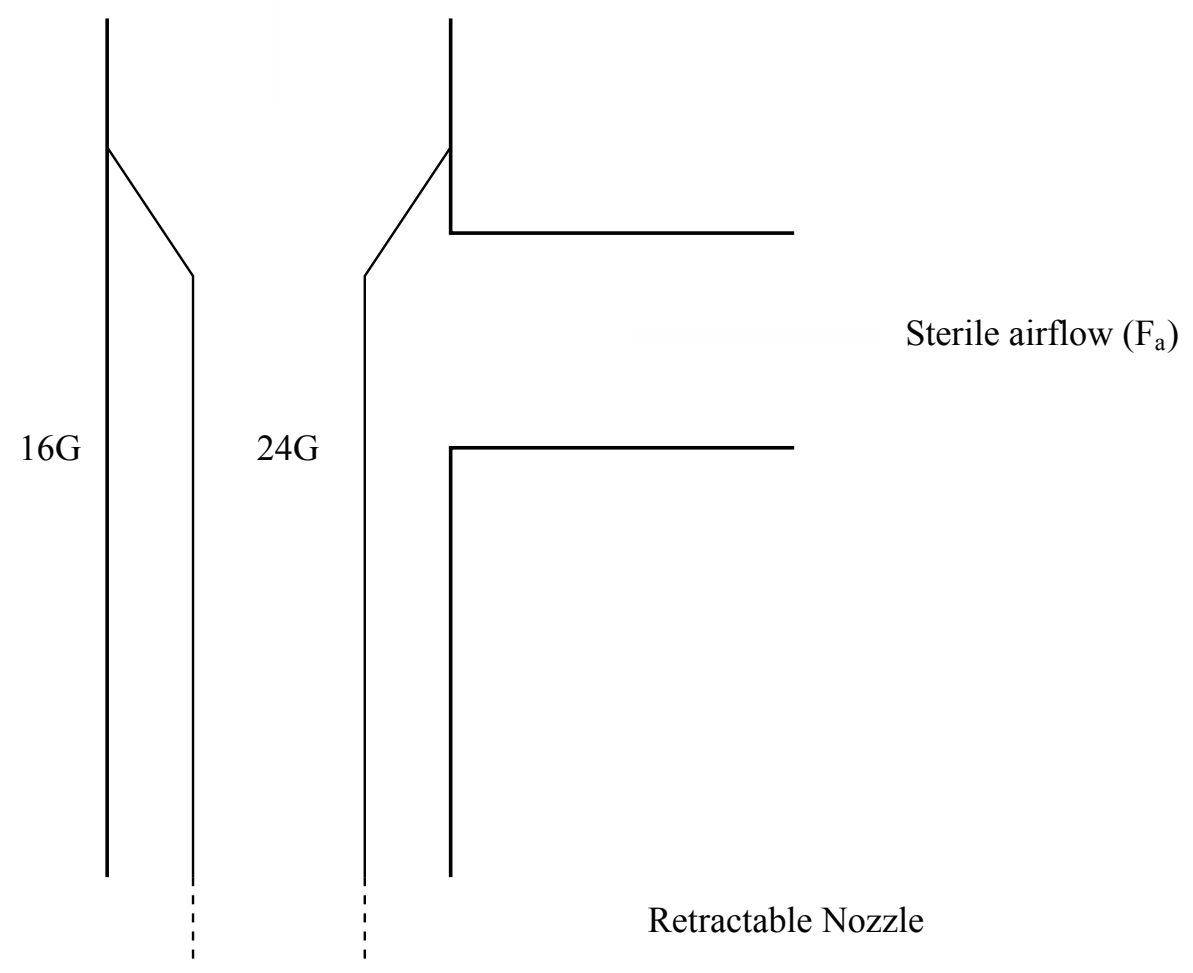

Figure 3. Design of atomization needle (drawing not to scale).

\subsubsection{Inkjet Bioprinting}

Inkjet printing involves ejecting liquid droplets from a printhead (Fig. 4) by way of various modes of impulses, including acoustic, thermal, or piezoelectric (Martin, 2008; Le, 1998; Brunahl, 2002), which cause the pressure plate to oscillate back and forth, thereby releasing ink droplets. The main advantages of inkjet printing include the miniaturization capability for droplet generation on the order of $10 \mu \mathrm{m}$ (Dong, 2006) and method reproducibility. The major disadvantages, however, are that this is a highly meticulous and time-consuming process, with regards to jetting biological fluids nonNewtonian and highly viscous in nature (Dohnal, 2010). 


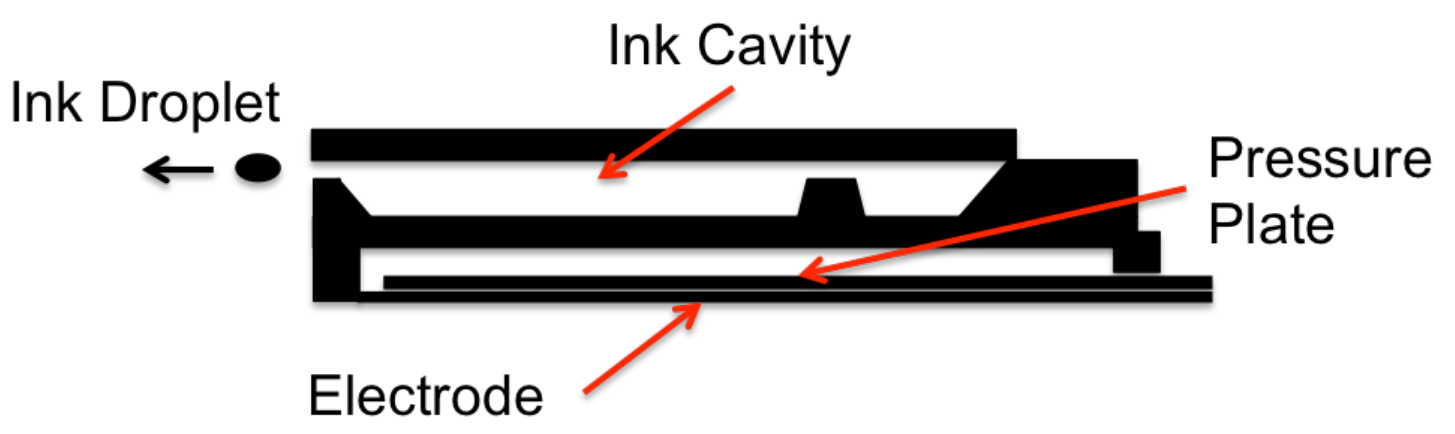

Figure 4. Cross-sectional view of inkjet printhead (drawing not to scale).

\subsection{Extraction Theory}

Extraction theory is based off of how a solute is distributed within a 2-phase system at equilibrium (Fournier, 2007). Suppose that $\mathrm{N}_{1}$ moles of solute are (initially) mixed in $\mathrm{N}_{2}$ moles of aqueous liquid (phase II) and $\mathrm{N}_{3}$ moles of organic solvent (phase I), which has high selectivity for the solute. Described in Eqn. 3 is the distribution of these three components amongst the two immiscible phases at equilibrium.

$$
\gamma_{i}^{I} x_{i}^{I} f_{i}^{I}(T, P)=\gamma_{i}^{I I} x_{i}^{I I} f_{i}^{I I}(T, P)
$$

where $\gamma_{i}^{I}$ and $\gamma_{i}^{I I}$ are the activity coefficients of component $i$ in phases I and II, respectively, $x_{i}^{I}$ and $x_{i}^{I I}$ are the mole fractions of component $i$ in phases I and II, respectively, and $f_{i}^{I}(T, P)$ and $f_{i}^{I I}(T, P)$ are the pure component fugacities of component $i$ in phases I and II, respectively, as a function of temperature and pressure. Since component $i$ does not change state in either phase at the same temperature and pressure, the pure component fugacities of component $i$ are the same in either phase. Hence, Eqn. 3 becomes:

$$
\gamma_{i}^{I} x_{i}^{I}=\gamma_{i}^{I I} x_{i}^{I I}
$$


where $\gamma_{i}^{I}$ and $\gamma_{i}^{I I}$ are the activity coefficients of component $i$ in phases I and II, respectively, and $x_{i}^{I}$ and $x_{i}^{I I}$ are the mole fractions of component $i$ in phases I and II, respectively. Eqn. 4 can then be rearranged in order to obtain the partition coefficient $\mathrm{K}$ (Eqn. 5), which is the ratio of mole fractions of component $i$ in either phase.

$$
K=\frac{x_{i}^{I}}{x_{i}^{I I}}=\frac{\gamma_{i}^{I}}{\gamma_{i}^{I I}}
$$

where $K$ is the partition coefficient, $\gamma_{i}^{I}$ and $\gamma_{i}^{I I}$ are the activity coefficients of component $i$ in phases I and II, respectively, and $x_{i}^{I}$ and $x_{i}^{I I}$ are the mole fractions of component $i$ in phases I and II, respectively.

Shown in Fig.5 is the extraction scheme used in this research study.

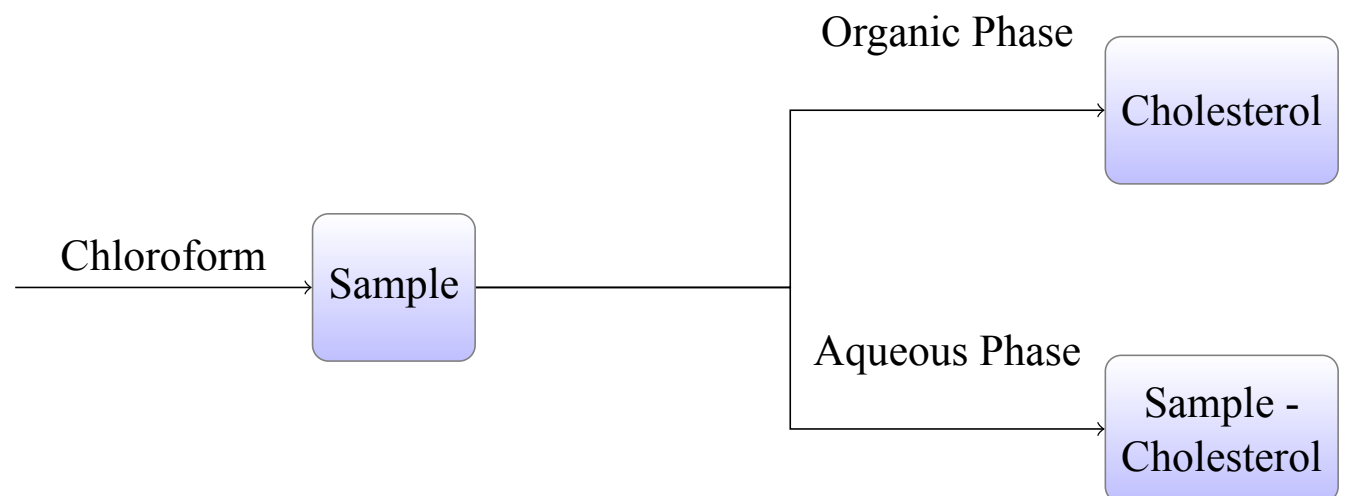

Figure 5. Cholesterol extraction scheme

The partition coefficient, $\mathrm{K}$, can be calculated as given in Eqn. 6 .

$$
K=\frac{x_{\text {OUT }}^{I}}{x_{\text {OUT }}^{I I}}
$$

where $K$ is the partition coefficient, $x_{O U T}^{I}$ is the final mole fraction of solute in the organic phase, and $x_{O U T}^{I I}$ is the final mole fraction of solute remaining in the aqueous phase. 


\subsection{Prior Studies with Cholesterol-Degrading Bacteria}

Many strains of cholesterol-degrading bacteria strains have been identified and studied in the literature. For this study, a literature survey was conducted on bacteria capable of producing cholesterol oxidase enzyme. Shown in Table 2 is a summary of the literature survey of prior cholesterol degradation experiments. Data of interest included those that pertained to microbial degradation of cholesterol as opposed to extraction of microbial-derived enzyme followed by cholesterol degradation.

Johnson, et al (Johnson, 1990) studied cholesterol degradation by R. equi in BHI growth medium containing an initial cholesterol concentration of $125 \mu \mathrm{g} / \mathrm{mL}$. They reported that up to $80 \%$ of cholesterol was degraded over a 7-day period by 10 of 27 cultures. The same authors also studied cholesterol degradation in egg yolk and milk cream by $R$. equi. 33706 . It was reported that $40 \%$ of egg yolk cholesterol was degraded in $60 \mathrm{~min}$, and $2.36 \%$ of milk cream cholesterol was removed in $60 \mathrm{~min}$.

Bianchi, et al (Bianchi, 1996) used bacteria strains ATCC 25544, ATCC 4277, and ATCC DSM20131 to compare cholesterol degradation rates for the cases of free and encapsulated bacteria in chitin. Cell concentrations were taken from the exponential growth phase. It was seen that after 3 days, free bacteria had degraded nearly all cholesterol, and the encapsulated bacteria degraded $97 \%$ of all cholesterol. Tok, et al (Tok, 2010) used various strains of Lactobacillus delbrueckii subsp. bulgaricus (ATCC 11842) for cholesterol degradation for the cases of free and encapsulated bacteria in Caalginate. 
Table 2. Summary of literature survey to-date of prior cholesterol degradation studies using bacteria.

\begin{tabular}{|c|c|c|c|c|c|c|}
\hline Study & Organism & Solvent/Medium & Substrate & Membrane & Degradation Results & Reference \\
\hline $\begin{array}{l}\text { Johnson, } \\
\text { et al }\end{array}$ & R. equi & $\begin{array}{l}\text { n-propanol, } \\
\text { BHI }\end{array}$ & Cholesterol & Free & $80 \%$ in 7 days & $\begin{array}{c}\text { Johnson, } \\
1990\end{array}$ \\
\hline $\begin{array}{l}\text { Johnson, } \\
\text { et al }\end{array}$ & R. equi 33706 & $\begin{array}{l}\text { n-propanol, } \\
\text { BHI }\end{array}$ & Egg yolk & Free & $40 \%$ in $60 \mathrm{~min}$ & $\begin{array}{c}\text { Johnson, } \\
1990\end{array}$ \\
\hline $\begin{array}{l}\text { Johnson, } \\
\text { et al }\end{array}$ & R. equi 33706 & $\begin{array}{l}\text { n-propanol, } \\
\text { BHI }\end{array}$ & Milk cream & Free & $2.36 \%$ in $60 \mathrm{~min}$ & $\begin{array}{c}\text { Johnson, } \\
1990 \\
\end{array}$ \\
\hline $\begin{array}{l}\text { Bianchi, } \\
\text { et al }\end{array}$ & $\begin{array}{c}\text { ATCC 25544, } \\
4277, \text { DSM20131 }\end{array}$ & $\begin{array}{c}\text { DMF, } \\
\text { Agar slant }\end{array}$ & Cholesterol & $\begin{array}{l}\text { Free, } \\
\text { Chitin } \\
\end{array}$ & $\begin{array}{c}\text { Nearly all in } 3 \text { days, } \\
97 \% \text { in } 3 \text { days }\end{array}$ & $\begin{array}{c}\text { Bianchi, } \\
1996 \\
\end{array}$ \\
\hline $\begin{array}{l}\text { Tok, } \\
\text { et al }\end{array}$ & ATCC 11842 & $\begin{array}{l}\text { Ethanol, } \\
\text { MRS Broth }\end{array}$ & Cholesterol & $\begin{array}{c}\text { Free, } \\
\text { Ca-alginate }\end{array}$ & $\begin{array}{c}31 \% \\
31 \% \text { in } 48 \mathrm{~h}\end{array}$ & $\begin{array}{l}\text { Tok, } \\
2010\end{array}$ \\
\hline $\begin{array}{l}\text { Goetschel, } \\
\quad \text { et al }\end{array}$ & ATCC 25544 & $\begin{array}{c}\text { Aqueous (2,2'- } \\
\text { dipyridal }+ \\
\text { phosphate buffer }) \\
\end{array}$ & Cholesterol & $\begin{array}{l}\text { Free, } \\
\text { Liposomes }\end{array}$ & $\begin{array}{l}33 \% \text { in } 24 \mathrm{~h}, \\
98 \% \text { in } 16 \mathrm{~h}\end{array}$ & $\begin{array}{l}\text { Goetschel, } \\
1992\end{array}$ \\
\hline $\begin{array}{l}\text { Garofalo, } \\
\quad \text { et al }\end{array}$ & $P$. pictorum & Serum & Cholesterol & $\begin{array}{c}\text { Free, } \\
\text { Open pore } \\
\text { agar, } \\
\text { Alginate, } \\
\text { Poly-1- } \\
\text { lysine }\end{array}$ & $\begin{array}{l}25 \% \text { in } 12 \text { days, } \\
50 \% \text { in } 12 \text { days }\end{array}$ & $\begin{array}{l}\text { Garofalo, } \\
1989\end{array}$ \\
\hline $\begin{array}{l}\text { Gilliland, } \\
\quad \text { et al }\end{array}$ & L. acidophilus & $\begin{array}{l}\text { Serum, MRS Broth, } \\
\text { oxgall }\end{array}$ & $\begin{array}{c}\text { Serum } \\
\text { Cholesterol }\end{array}$ & N/A & $\begin{array}{c}\text { 8-29.8 } \mu \mathrm{g} / \mathrm{mL} \text { (uptake } \\
\text { anaerobically), } \\
\text { No uptake during } \\
\text { aerobic growth }\end{array}$ & $\begin{array}{l}\text { Gilliland, } \\
1985\end{array}$ \\
\hline
\end{tabular}


Table 2. (Continued)

\begin{tabular}{|c|c|c|c|c|c|c|}
\hline Study & Organism & Solvent/Medium & Substrate & Membrane & Degradation Results & Reference \\
\hline $\begin{array}{l}\text { Rasic, } \\
\text { et al }\end{array}$ & $\begin{array}{l}\text { Str. } \\
\text { Thermophilus, } \\
\text { L. acidophilus, } \\
\text { L. delbrueckii, } \\
\text { Bif. bifidum }\end{array}$ & $\begin{array}{c}\text { Serum, } \\
\text { MRS Broth }\end{array}$ & $\begin{array}{c}\text { Serum } \\
\text { Cholesterol }\end{array}$ & $\mathrm{N} / \mathrm{A}$ & $59-276 \mu \mathrm{g} / \mathrm{mL}$ (uptake) & $\begin{array}{c}\text { Rasic, } \\
1992\end{array}$ \\
\hline $\begin{array}{l}\text { Noh, } \\
\text { et al }\end{array}$ & L. acidophilus & $\begin{array}{l}\text { MRS Broth }+ \\
\text { Tween } 80\end{array}$ & $\begin{array}{l}\text { Water-soluble } \\
\text { cholesterol, } \\
\text { Cholesterol- } \\
\text { phospatidylcho } \\
\text { line micelles }\end{array}$ & N/A & $\begin{array}{c}\text { 7-117 } \mu \mathrm{g} / \mathrm{mL} \text { (uptake), } \\
8-55 \mu \mathrm{g} / \mathrm{mL} \text { (uptake) }\end{array}$ & $\begin{array}{l}\text { Noh, } \\
1997\end{array}$ \\
\hline $\begin{array}{l}\text { Tahri, } \\
\text { et al }\end{array}$ & $\begin{array}{c}\text { BB536, ATCC } \\
15697 / 15700 / 1 \\
5698 / 25527 / 25 \\
525 / 25910 / 259 \\
12 / 25911\end{array}$ & $\begin{array}{l}\text { TPY Medium + } \\
\text { taurocholic acid }\end{array}$ & $\begin{array}{c}\text { Serum } \\
\text { Cholesterol }\end{array}$ & N/A & $6-50 \%$ removal & $\begin{array}{c}\text { Tahri, } \\
1996\end{array}$ \\
\hline $\begin{array}{l}\text { Tahri, } \\
\text { et al }\end{array}$ & $\begin{array}{c}\text { BB536, } \\
\text { ATCC15700/ } \\
25527 \\
\end{array}$ & $\begin{array}{l}\text { TPY Medium + } \\
\text { oxgall }\end{array}$ & $\begin{array}{c}\text { Serum } \\
\text { Cholesterol }\end{array}$ & N/A & $\begin{array}{c}0-3 \% \text { removal (resting } \\
\text { cells), } \\
22-42 \% \text { (growing cells) }\end{array}$ & $\begin{array}{c}\text { Tahri, } \\
1995\end{array}$ \\
\hline Lin, et al & L. acidophilus & $\begin{array}{l}\text { MRS Medium + } \\
\text { bile salts }\end{array}$ & $\begin{array}{c}\text { Serum } \\
\text { Cholesterol }\end{array}$ & N/A & $\begin{array}{c}20-57 \% \text { removal (oxgall), } \\
43-71 \% \text { (cholic acid), } \\
11-52 \% \text { (taurocholic acid) }\end{array}$ & $\begin{array}{l}\text { Lin, } \\
2000\end{array}$ \\
\hline Strauss & $\begin{array}{l}\text { N/A (Enzyme } \\
\text { mix) }\end{array}$ & Serum & Collagen & N/A & N/A & $\begin{array}{c}\text { Medical } \\
\text { Breakthroughs, } \\
2011 \\
\end{array}$ \\
\hline
\end{tabular}


It was found that a maximum of $31 \%$ of total cholesterol was removed. Immobilized bacteria were shown to have the greatest rates of cholesterol removal within 48 hours of incubation.

ATCC 25544 was used for cholesterol degradation experiments for aqueous dispersion of cholesterol and cholesterol embedded in liposomes (Goetschel, 1992). 33\% of cholesterol that was dispersed in aqueous medium had undergone conversion after 24 hours of incubation. In the case of cholesterol liposomes, $98 \%$ was converted after 16 hours. Garofalo, et al studied the use of P. pictorum encapsulated in open pore agar beads and alginate-poly-l-lysine capsules for cholesterol degradation (Garofalo, 1989). As indicated by their results, about $50 \%$ of cholesterol was degraded by immobilized bacteria as opposed to $25 \%$ by free bacteria.

Gilliland, et al (Gilliland, 1985) studied serum cholesterol removal of various strains of $L$. acidophilus, including GP1B, GP4A, RP43, RP32, C1-5, C2-5, GP2B, P47, and S-1. It was shown that strains C1-5, C2-5, GP2B, and P47 had low cholesterol removal with the lowest removal of about $5 \mu \mathrm{g} / \mathrm{mL}$.

Rasic, et al (Rasic, 1992) studied the serum cholesterol assimilation of $L$. delbrueckii subsp. bulgaricus (LB1, LB2, LB3), Str. thermophilus (T1, T2), Bif. bifidum (BYU, BPO), yoghurt culture (Jog.), and L. acidophilus (AP, AM, AD). LB1 was shown to have the highest assimilation of $276 \mu \mathrm{g} / \mathrm{mL}$ over a time period of 20 hours.

Tahri, et al (Tahri, 1996) showed that strains BB536, ATCC 15697, 15700, $15698,25527,25525,25910,25912$, and 25911 were able to deplete $40-61 \%$ of serum cholesterol over a 24-hour time period. In another study by Tahri, et al (Tahri, 1995), 
bacterial strains BB536, ATCC 15700 and 25527 were used to study serum cholesterol assimilation in the presence of bile salts. It was shown that ATCC 15700 had the highest assimilation of $60 \%$. It was stated by the authors that the bile salts led to significant assimilation.

Meei-Yn Lin, et al (Lin, 2000) studied serum cholesterol degradation using several strains of Lactobacillus acidophilus (ATCC 4356, B, E, Farr, LA-1, and N-1) in the presence of different bile salts (oxgall, cholic acid, and taurocholic acid). The combination of strain and bile salt that resulted in the highest degradation ability of about $71 \%$ over a 24-hour duration was that of ATCC 4356 and cholic acid.

Noh, et al (Noh, 1997) showed that L. acidophilus ATCC 43121 supplemented with $92 \mu \mathrm{g} / \mathrm{mL}$ water-soluble cholesterol and oxgall had assimilated $44 \mu \mathrm{g} / \mathrm{mL}$ during growth. When Tween 80 was added, the assimilation was $117 \mu \mathrm{g} / \mathrm{mL}$. Cholesterolphospatidylcholine micelles (III-E, III-S, Dioleoyl, Distearoyl) were also studied, and it was shown that the Dioleoyl type had the highest assimilation of $47 \mu \mathrm{g} / \mathrm{mL}$. When Tween 80 was added to the micelles, the assimilation was $55 \mu \mathrm{g} / \mathrm{mL}$.

The most recent and unique study that is still under development by Strauss (Medical Breakthroughs, 2011) is that of a "Liquid Drano," which consists of an enzyme mix that degrades mostly collagen present within atherosclerotic plaque.

\subsection{Cholesterol Degradation Rate}

Kinetics of cholesterol degradation of free and immobilized bacteria will be compared. Cholesterol degradation rates will be expressed in the form of the rate equation used to correlate reaction rate with concentration of the reactant species in a 
chemical reaction (Ebbing, 2010). In previous research performed by Salva, et al, it was found that cholesterol oxidase from Brevibacterium sp. exhibited a first order reaction rate (Salva, 1999). Assume the reaction shown in Eqn. 7. The cholesterol degradation rate, $r$, is given by Eqn. 8:

$$
\begin{aligned}
& A \rightarrow B+C \\
& r=k[A]^{n}
\end{aligned}
$$

where $k$ is the rate constant of reaction, [A] is the cholesterol concentration and $n$ is the reaction order. 


\subsection{RESEARCH OBJECTIVES}

The objectives of this research effort were three-fold:

3.1 The first objective was to optimize the growth medium for non-immobilized $R$. erythropolis (ATCC 25544) in order to minimize the production of the trehalose biosurfactant.

3.2 The second objective was to devise extraction methods to enable biosurfactant and cholesterol quantification for free and immobilized $R$. erythropolis.

3.3 The third objective was to assess the effect of capsule miniaturization on cholesterol degradation rates supported by statistical significance testing.

Much research has been conducted on the use of microencapsulation technology and bacterium for cholesterol degradation, as documented in the Literature Review section. To date, no cholesterol degradation studies have been performed on Rhodococcus erythropolis (ATCC 25544) encapsulated in Ca-alginate beads. Additionally, no characterization has been performed on the miniaturization of the capsules immobilizing the bacteria. Most studies in the literature have dealt with extraction of cholesterol oxidase produced by bacteria followed by cholesterol degradation. Furthermore, the effects of glycolipid biosurfactant synthesis on the encapsulated bacterial growth and activity have not been documented in the literature. Since ATCC 25544 has been shown to degrade cholesterol at a high rate (Bianchi, 1996), it has been chosen as the strain for this research effort. 


\subsection{MATERIALS AND METHODS}

Described in this chapter are the methodologies undertaken in this research effort.

Shown in Fig. 6 is the roadmap of this research study from start to finish.

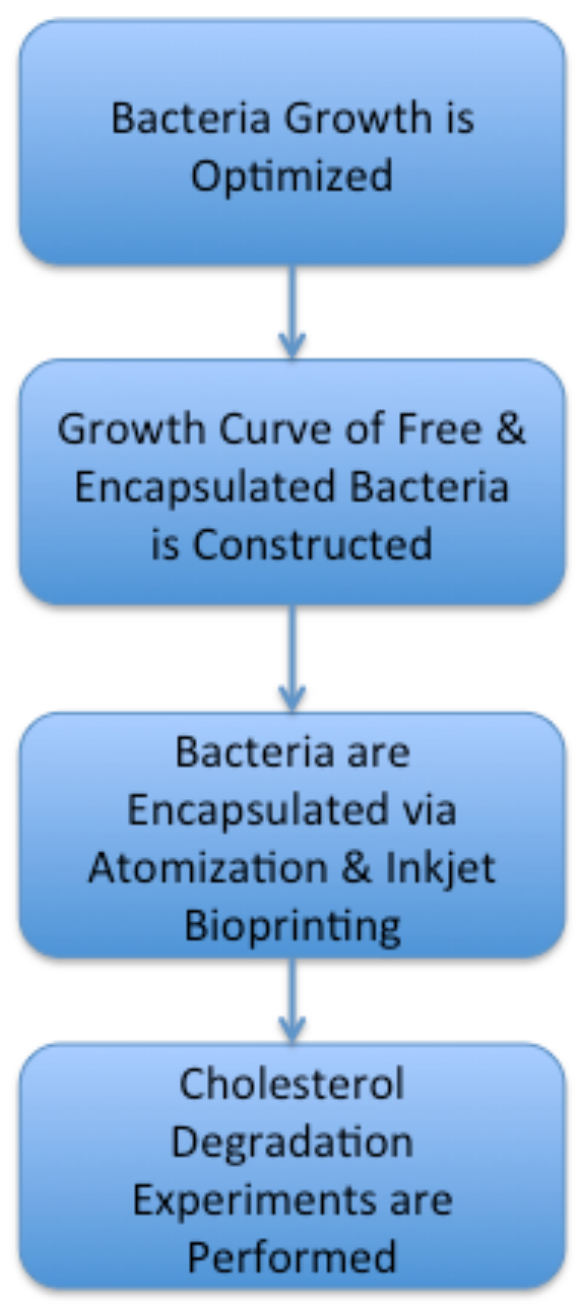

Figure 6. Roadmap of research study.

4.1 Materials

\subsubsection{Bacterial Cell Culture}

Rhodococcus erythropolis (ATCC 25544) and LB growth medium were obtained from the American Type Culture Collection (ATCC). Cholesterol powder of 95\% purity 
was obtained from Sigma Aldrich (C7529-25G). Chemicals used for cell immobilization were obtained from Sigma Aldrich.

An incubator (Heraeus) with $\mathrm{CO}_{2}$ gas was used for all bacterial cultures at $37^{\circ} \mathrm{C}$.

All materials (excluding the bacterium) used in this study were sterilized using an autoclave (TOMY SS-320) in order to prevent contamination of live bacterial cell cultures. Prior to experimentation, liquids were further sterilized using a sterile Millipore luer-lock, fitted filter attached to a 30-mL syringe.

Bacterial cell count measurements were carried out on CELL-VUß CBC disposable hemacytometers (Millenium Sciences, Inc.) under a Nikon Eclipse Ti-S microscope with an attached Andor Technologies camera.

\subsubsection{Preparation of LB Broth Medium}

LB Broth was prepared according to ATCC's instructions. The contents of one packet were emptied into a clean autoclaved $1000-\mathrm{mL}$ capped glass bottle to which 500 $\mathrm{mL}$ sterile DI water was added. The bottle was loosely capped and autoclaved. Once autoclaved, the bottle was allowed to cool to room temperature with the cap was tightly fastened, and stored in a refrigerator at $4^{\circ} \mathrm{C}$.

\subsubsection{Preparation of 1X PBS}

1X PBS was prepared by mixing $8 \mathrm{~g} \mathrm{NaCl}, 0.2 \mathrm{~g} \mathrm{KCl}, 1.44 \mathrm{~g} \mathrm{Na}_{2} \mathrm{HPO}_{4}, 0.24 \mathrm{~g}$ $\mathrm{KH}_{2} \mathrm{PO}_{4}$ with $800 \mathrm{~mL}$ DI water in a sterile clean $1000-\mathrm{mL}$ capped glass bottle. The $\mathrm{pH}$ was adjusted to 7.4 by adding enough $\mathrm{NaOH}$ as necessary. The acidity was monitored

continuously with a $\mathrm{pH}$ electrode while adding $\mathrm{NaOH}$. Once the $\mathrm{pH}$ was adjusted to 7.4, the total volume of the solution was made to $1000 \mathrm{~mL}$ by adding enough $\mathrm{DI}$ water as 
necessary. The bottle was then autoclaved. Once autoclaved, the bottle was allowed to cool to room temperature with the cap was tightly fastened, and stored in a refrigerator at $4^{\circ} \mathrm{C}$.

\subsubsection{Preparation of 3\% (w/v) Sodium Citrate}

A $3 \%(\mathrm{w} / \mathrm{v})$ sodium citrate was prepared by mixing $3 \mathrm{~g}$ sodium citrate dihydrate with $100 \mathrm{~mL}$ DI water in a sterile clean $200-\mathrm{mL}$ glass beaker. Once fully mixed, the solution was filter sterilized into a sterile Falcon ${ }^{\circledR}$ tube, which was capped tightly and stored in the refrigerator at $4^{\circ} \mathrm{C}$.

\subsubsection{Quantification Assays}

Assay quantification and optical density measurements were carried out using an Agilent 8453 UV-Vis Spectrophotometer. Plastic cuvettes (FisherBrand, methacrylate, 1.5-mL, 13-mm path length) were used for all measurements carried out in the visible range. Quartz micro cuvettes (Agilent Ultra Micro 50, Part No. 5062-2496) were used for all measurements of samples containing organic solvents.

The chemicals used for the glycolipid assay were obtained from SJSU and consisted of anthrone (Metheson Coleman and Bell), 12.1M hydrochloric acid $(\mathrm{HCl})$, concentrated sulfuric acid $\left(\mathrm{H}_{2} \mathrm{SO}_{4}\right)$, chloroform $\left(\mathrm{CHCl}_{3}\right)$, methanol $\left(\mathrm{CH}_{3} \mathrm{OH}\right)$, and acetone. Cholesterol assays were performed using a cholesterol quantitation kit from Abcam (Abcam ab65359). The contents of the Abcam assay kit consisted of all necessary reagents, namely cholesterol standard, cholesterol assay buffer, enzyme mix, cholesterol esterase, and cholesterol probe. 


\subsubsection{Software}

The camera software used for size measurements was NIS Elements BR 3. Data analysis for the design of experiment (DOE) and standard formulae were validated using Minitab 16. A MicroFab JetServer was used for inkjet bioprinting of capsules. Microsoft Excel 2011 was used to plot all assay data, calibration curves, and concentration profiles.

\subsection{Bacterial Growth Medium Optimization}

\subsubsection{Challenge with Bacterial Growth Measurements}

Bacterial growth measurements were conducted for free and encapsulated bacteria in a growth medium composition of LB Broth and BSA as described in Section 4.3. The corresponding growth curves are shown in Fig. 7. The growth curve of free bacteria is shown in blue, and the growth curve of encapsulated bacteria is shown in red.

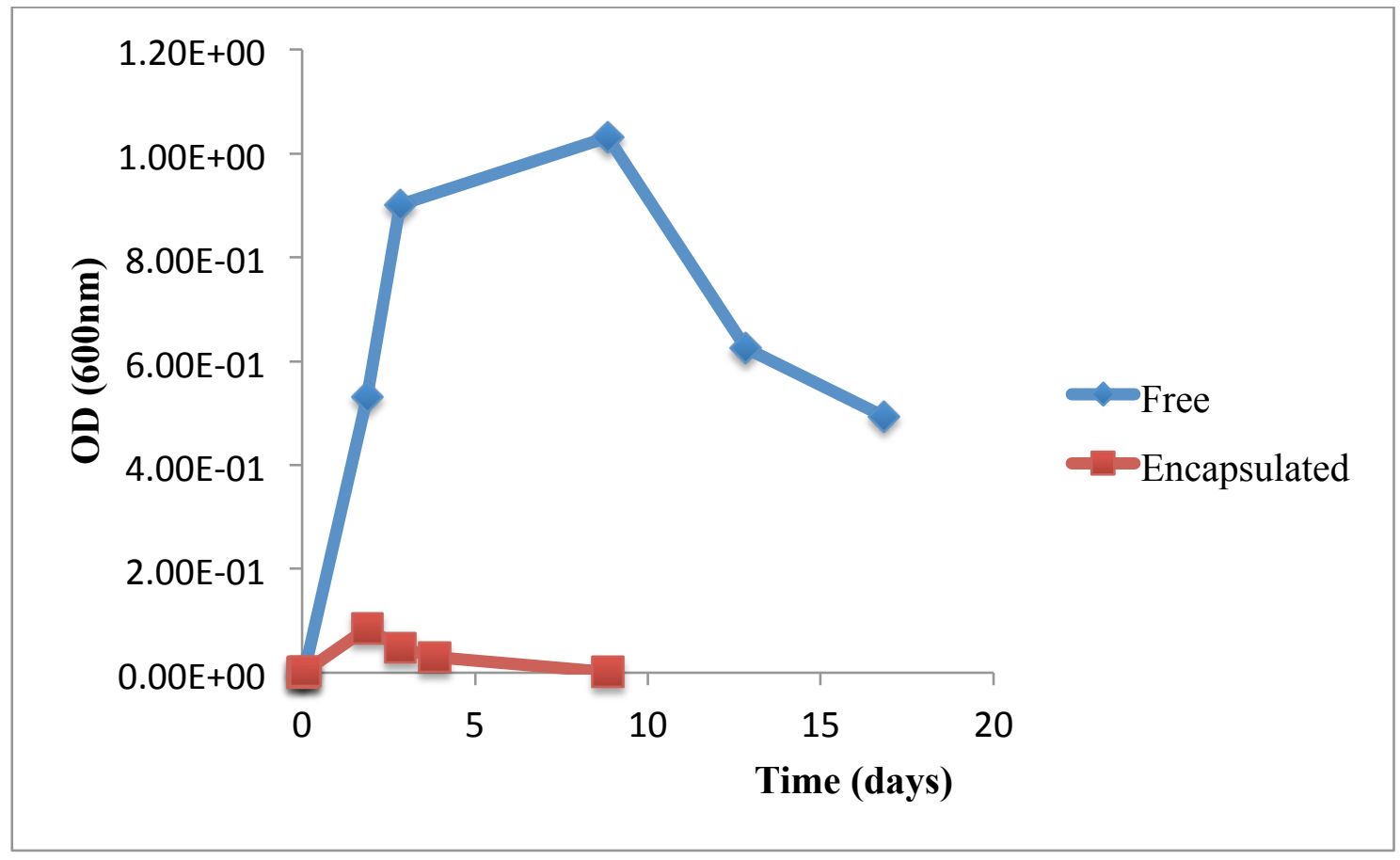

Figure 7. Growth curve of free (shown in blue) and encapsulated bacteria (shown in red) in regular growth medium (LB and BSA). 
After $200 \mathrm{~h}$ of incubation, measurements of bacterial growth in the encapsulated case were impossible to perform due to the presence of a glycolipid biosurfactant that breached the capsule membrane as detected visually under the microscope. Refer to Fig. 31 in Section 5.4.

\subsubsection{Design of Experiments (DOE) using Taguchi Screening Designs}

In this research, the technique of Design of Experiments (DOE), specifically Taguchi designs, was used to optimize the growth medium composition in order to minimize the production of bio-surfactant (response 1) and monitor growth (response 2). Taguchi designs are modified orthogonal arrays for robust screening and optimization of operating parameters (Roy, 2001). The type of optimization used was Nominal the Best with a target amount of biosurfactant produced of $0 \mathrm{mg}$. The formulae needed to conduct the optimization based on the Sensitivity $(\mathrm{Sm})$ Signal to noise ratios $(\mathrm{S} / \mathrm{N})$, Difference (D) and Rank (R) for the Nominal the Best Optimization types are given by Eqns. 9-12 (Roy, 2001).

$$
\mathrm{D}=\frac{\sum_{i, j}[\mathrm{~S} / \mathrm{N}(\mathrm{dB})]}{\mathrm{L}}
$$

where $\mathrm{D}$ is the difference, $i$ is the element corresponding to the level, $j$ is the element corresponding to the factor, $\mathrm{S} / \mathrm{N}(\mathrm{dB})$ is the signal-to-noise ratio in $\mathrm{dB}$, and $\mathrm{L}$ is the total number of levels.

$$
\mathrm{R}=\operatorname{Maximum}\left(n_{i}\right)-\operatorname{Minimum}\left(n_{i}\right)
$$

where $\mathrm{R}$ is the rank and $n_{k}$ is the value of response for the $k$-th response value. 


$$
\mathrm{S} / \mathrm{N}(\mathrm{dB})=10 \log _{10}\left[\frac{\bar{n}^{2}}{\frac{\sum_{k}\left(n_{k}-\bar{n}\right)^{2}}{n_{k}-1}}-\frac{1}{\mathrm{~N}}\right]
$$

where $\mathrm{S} / \mathrm{N}(\mathrm{dB})$ is the signal-to-noise ratio in $\mathrm{dB}, \bar{n}$ is the mean of response data, $n_{k}$ is the value of response for the $k$-th response value, and $\mathrm{N}$ is the total number of replications.

$$
\operatorname{Sm}(d B)=10 \log _{10}\left[\frac{\left(\sum_{k} n_{k}\right)^{2}}{\mathrm{~N}}\right]
$$

where $\mathrm{Sm}(\mathrm{dB})$ is the sensitivity in $\mathrm{dB}, n_{k}$ is the value of response for the $k$-th response value, and $\mathrm{N}$ is the total number of replications.

The optimal operating level by parameter is determined by ranking the importance of each factor based on averaged $(\mathrm{Sm})$ and $(\mathrm{S} / \mathrm{N})$ as conducted in the case of an ANOVA for traditional orthogonal array analysis. The ranking scale is an attribute scale ranging from one to a maximum possible value equal to the number of factors in the experimental matrix. As the difference (D) increases, the ranking (R) increases.

An $\mathrm{L}_{16}$ Taguchi screening design matrix was conducted (Roy, 2001) according to the layout in Table 3 with 5 factors [LB Broth (in \% vol), BSA (in \% vol), PBS (in \% vol), temperature (in ${ }^{\circ} \mathrm{C}$ ), and cholesterol concentration (in $\mathrm{mg} / \mathrm{mL}$ )] and 4 levels for a 48-hr growth monitoring study period. The experiments in Table 3 were conducted in duplicate. Optimization types by response are shown in Table 4.

Following manual calculations and response plot generation for the $\mathrm{Sm}$ and $\mathrm{S} / \mathrm{N}$ quantities, the results were validated graphically using Minitab 16. The expanded experimental matrix is shown in Table 5. The concentration at which cholesterol was centered was the high-risk blood cholesterol level of $2 \mathrm{mg} / \mathrm{mL}$ (Tahri, 1995). 
Table 3. $L_{16}$ Taguchi design $(N=2)$.

\begin{tabular}{|c|l|l|}
\hline No & \multicolumn{1}{|c|}{ Variables } & \multicolumn{1}{c|}{ Levels } \\
\hline 1 & BSA $(\%$ vol $)$ & $0,6.6,13.2,20.0$ \\
\hline 2 & LB $(\%$ vol $)$ & $0,13.2,26,40$ \\
\hline 3 & 1 X PBS $(\%$ vol $)$ & $0,13.2,26,40$ \\
\hline 4 & CHOL $(\mathrm{mg} / \mathrm{ml})$ & $0,13.2,26,40$ \\
\hline 5 & TEMP $\left({ }^{\circ} \mathrm{C}\right)$ & $4,23,30,37$ \\
\hline
\end{tabular}

Table 4. Optimizations type by response.

\begin{tabular}{|c|c|}
\hline Responses & Type of Optimization \\
\hline Bacterial growth & $\begin{array}{c}\text { Nominal the best } \\
\text { (Target }=\text { unknown })\end{array}$ \\
\hline Amount of bio-surfactant produced & Nominal the best (Target $=0)$ \\
\hline
\end{tabular}

Table 5. $L_{16}$ (5 variables, 4 levels) Taguchi matrix for biosurfactant minimization.

\begin{tabular}{|c|c|c|c|c|c|c|}
\hline No. & $\begin{array}{c}\text { BSA } \\
(\% \text { vol })\end{array}$ & $\begin{array}{c}\text { LB } \\
(\% \text { vol })\end{array}$ & $\begin{array}{c}\text { PBS } \\
(\% \text { vol })\end{array}$ & $\begin{array}{c}\text { Cholesterol } \\
(\mathrm{mg} / \mathrm{mL})\end{array}$ & $\begin{array}{c}\text { Temperature } \\
\left({ }^{\circ} \mathrm{C}\right)\end{array}$ & $\begin{array}{c}\text { Bacteria } \\
(\% \text { vol })\end{array}$ \\
\hline 1 & 0.0 & 0.0 & 0.0 & 0 & 4 & 5.00 \\
\hline 2 & 0.0 & 13.2 & 13.2 & 3 & 23 & 5.00 \\
\hline 3 & 0.0 & 26.0 & 26.0 & 6 & 30 & 5.00 \\
\hline 4 & 0.0 & 40.0 & 40.0 & 9 & 37 & 5.00 \\
\hline 5 & 6.6 & 0.0 & 13.2 & 6 & 37 & 5.00 \\
\hline 6 & 6.6 & 13.2 & 0.0 & 9 & 30 & 5.00 \\
\hline 7 & 6.6 & 26.0 & 40.0 & 0 & 23 & 5.00 \\
\hline 8 & 6.6 & 40.0 & 26.0 & 3 & 4 & 5.00 \\
\hline 9 & 13.2 & 0.0 & 26.0 & 9 & 23 & 5.00 \\
\hline 10 & 13.2 & 13.2 & 40.0 & 6 & 4 & 5.00 \\
\hline 11 & 13.2 & 26.0 & 0.0 & 3 & 37 & 5.00 \\
\hline 12 & 13.2 & 40.0 & 13.2 & 0 & 30 & 5.00 \\
\hline 13 & 20.0 & 0.0 & 40.0 & 3 & 30 & 5.00 \\
\hline 14 & 20.0 & 13.2 & 26.0 & 0 & 37 & 5.00 \\
\hline 15 & 20.0 & 26.0 & 13.2 & 9 & 4 & 5.00 \\
\hline 16 & 20.0 & 40.0 & 0.0 & 6 & 23 & 5.00 \\
\hline
\end{tabular}




\subsubsection{Experimental Protocol}

An experimental flow diagram of bacteria growth measurements for microencapsulated bacteria is shown below in Fig. 8. In short, equal volumes of chloroform:methanol $(2: 1, \mathrm{v} / \mathrm{v})$ were added to the culture vial, and the vial was shaken vigorously. The contents were filtered through a 100-micron nylon mesh cell strainer in order to separate the microcapsules from the culture broth. The microcapsules were rinsed with $3 \mathrm{~mL}$ acetone followed by $3 \mathrm{~mL}$ DI water. The acetone and DI water were retained. The microcapsules and culture broth had undergone specific protocols, outlined below, in order to obtain growth measurements and glycolipid quantification, respectively. 


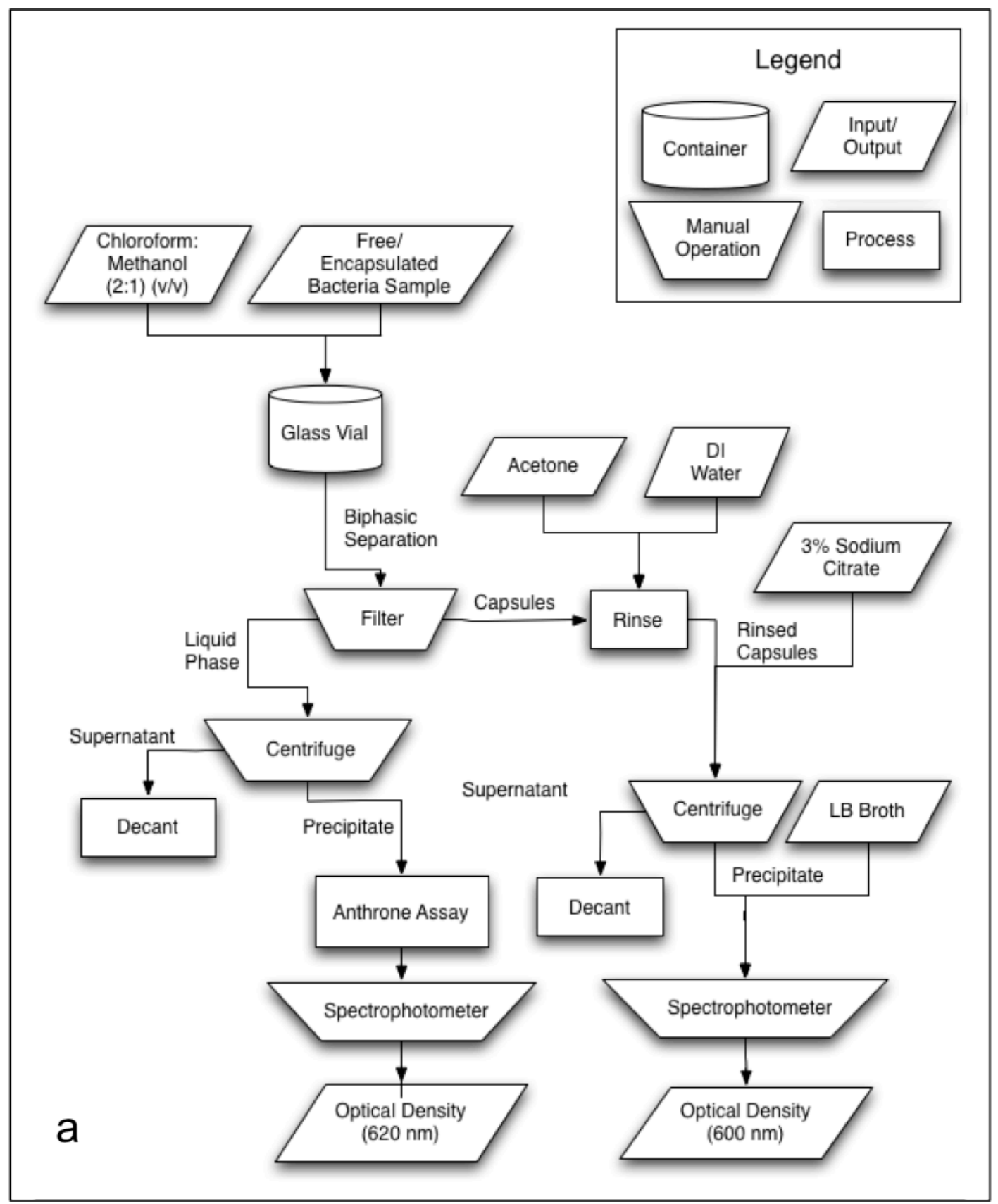

Figure 8a. Experimental flow diagram for biosurfactant quantification and bacteria growth measurements. 


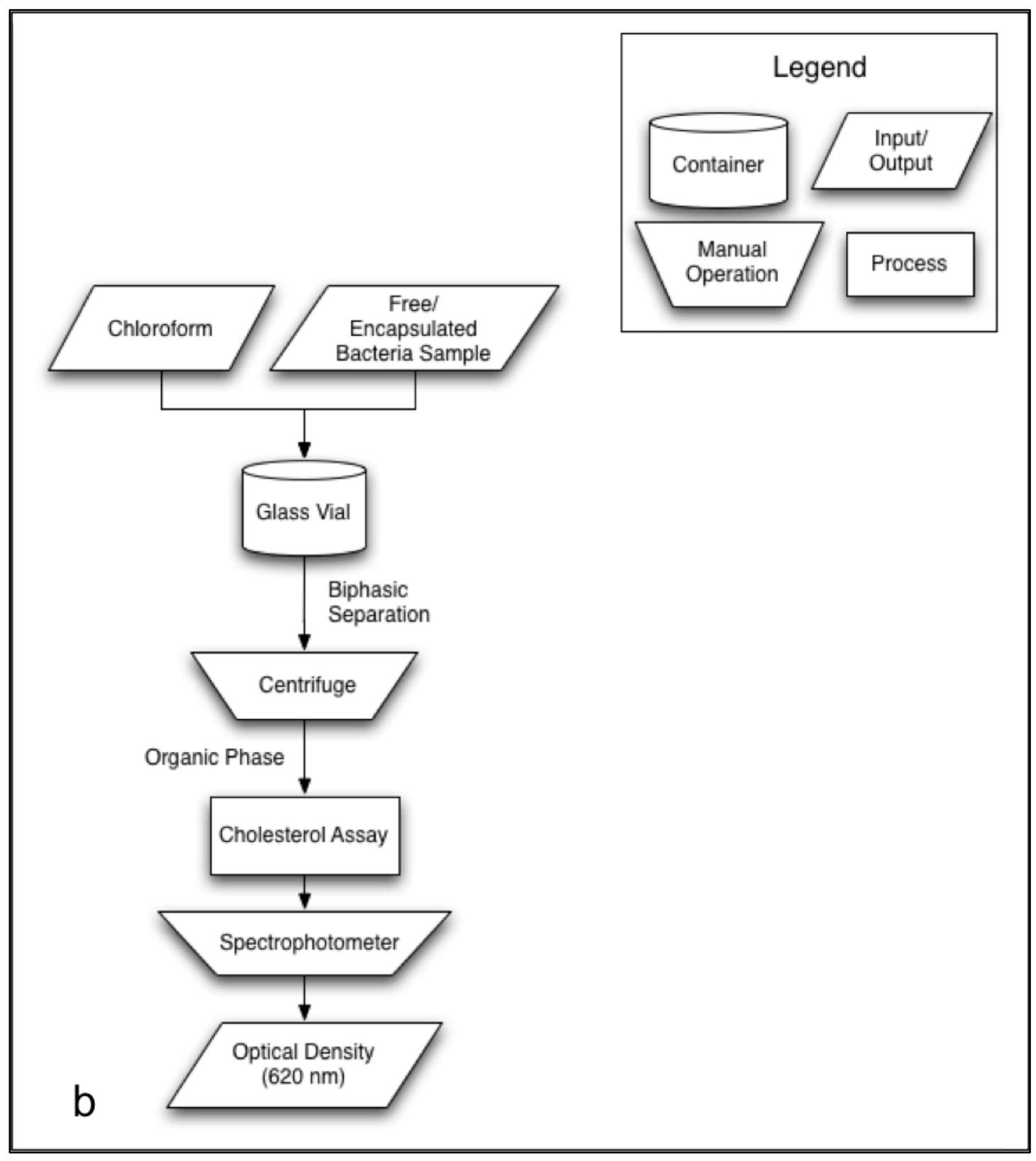

Figure $8 b$. Experimental flow diagram for cholesterol quantification.

\subsubsection{Protocol for Growth Measurement}

The microcapsules were removed from the filter and placed into a $20 \mathrm{~mL}$ glass scintillation vial. $4 \mathrm{~mL}$ of $3 \%(\mathrm{w} / \mathrm{v})$ sodium citrate solution were added to the vial. The vial was then capped and vortexed in order to dissolve the capsules. The contents in the 
vial were transferred into $1.5-\mathrm{mL}$ Eppendorf tubes and then centrifuged at 8,000 rpm for 5 min to separate the bacteria from the liquid. After centrifugation was complete, the supernatant in each tube was removed, thus leaving behind the bacteria pellet. Each pellet was transferred into a fresh clean tube with $1.5 \mathrm{~mL}$ of fresh LB Broth and vortexed until the pellets were fully dissolved. After $2 \mathrm{X}$ dilution, the bacterial solution was placed in a plastic cuvette for spectrophotometric measurement of \%transmittance at a wavelength of $600 \mathrm{~nm}$ using fresh LB Broth as a control.

\subsubsection{Glycolipid Extraction and Quantification}

Ristau, et al's (Ristau, 1983) method of glycolipid extraction was used. A chloroform:methanol $(2: 1, \mathrm{v} / \mathrm{v})$ was added in equal volume to the bacterial culture, shaken vigorously, and allowed to sit in order for the layers to separate. This resulted in a biphasic separation in which case the glycolipid was sandwiched in between the organic phase (bottom) and aqueous phase (top) as shown in Fig. 9. In Fig. 9, the aqueous phase was stained with blue dextran for visualization purposes. 


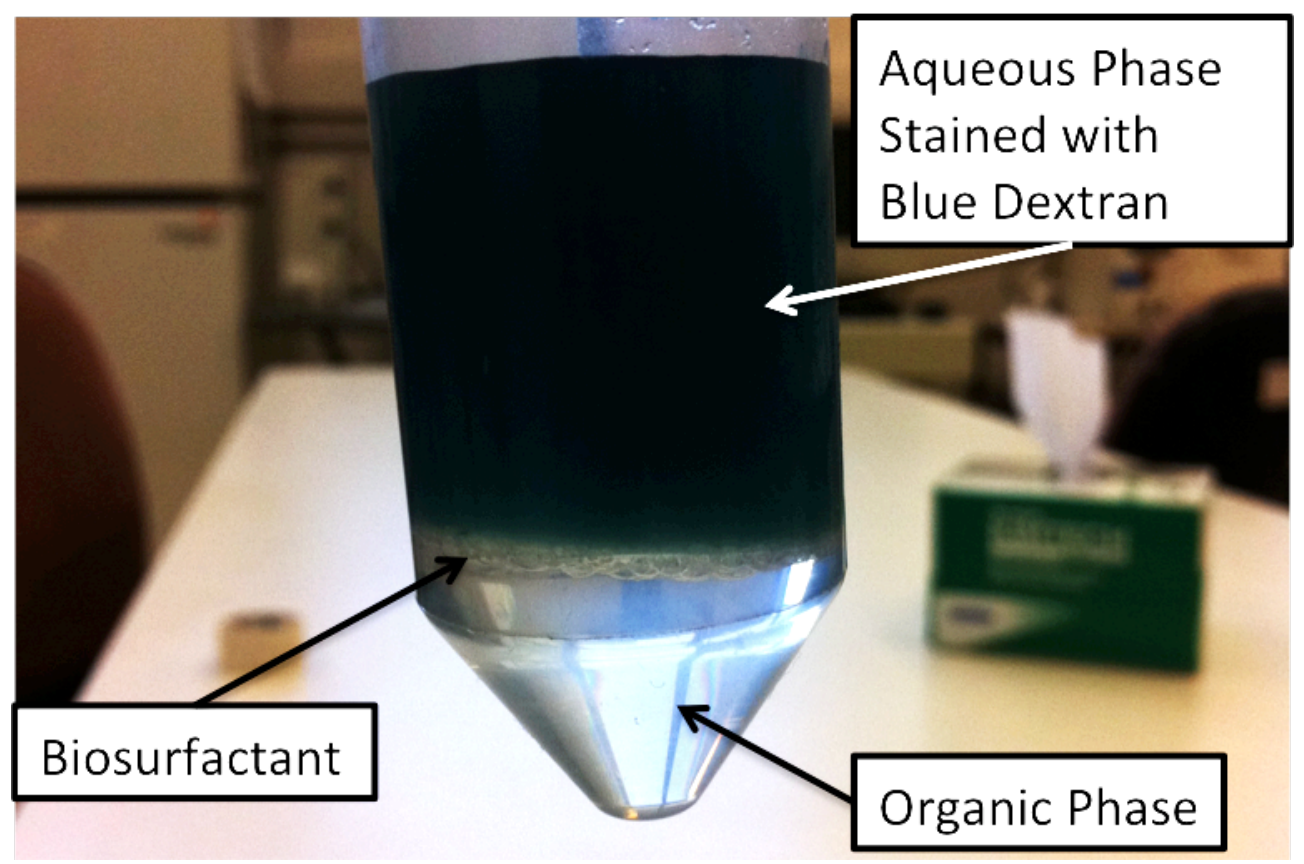

Figure 9. Biphasic separation of glycolipid biosurfactant.

The organic phase consisted of chloroform and cholesterol while the aqueous phase consisted of the bacteria, culture broth, and methanol (Ristau, 1983). The organic phase was decanted and discarded into a waste container. $1 \mathrm{~mL}$ of distilled water was added to the remaining glycolipid precipitate and vortexed until dissolved. $0.5 \mathrm{~mL}$ of each glycolipid precipitate was transferred into separate $40-\mathrm{mL}$ glass scintillation vials and subsequently mixed with $0.5 \mathrm{~mL}$ DI water. Each sample was then quantified using the Anthrone assay method.

The culture broth was transferred into $1.5 \mathrm{~mL}$ Eppendorf tubes and centrifuged at $8,000 \mathrm{rpm}$ for $3 \mathrm{~min}$ in order to separate the glycolipid from the liquid. After centrifugation, the aqueous and organic phases were removed, thus leaving behind the glycolipid precipitate. All glycolipid precipitates were transferred into a clean tube with 
$1 \mathrm{~mL}$ DI water. These samples were then subject to the Anthrone assay for quantification of glycolipid as outlined in Section 4.2.1.2.1.

The Anthrone assay (Ristau, 1983) was used to quantify glycolipids by measuring the carbohydrate content present in the sugar moieties. The assay mechanism (Nigam, 2007) is shown in Fig. 10. Hydrochloric acid $(\mathrm{HCl})$ serves to dehydrate the carbohydrate into a compound known as furfural, which condenses with Anthrone to form a green color, the intensity of which is proportional to the amount of carbohydrate in the sample. The intensity of the color is measured through the peak height of the absorbance at a wavelength of $620 \mathrm{~nm}$. The assay was calibrated against glucose standard using the following volumetric measurements outlined in Table 6.

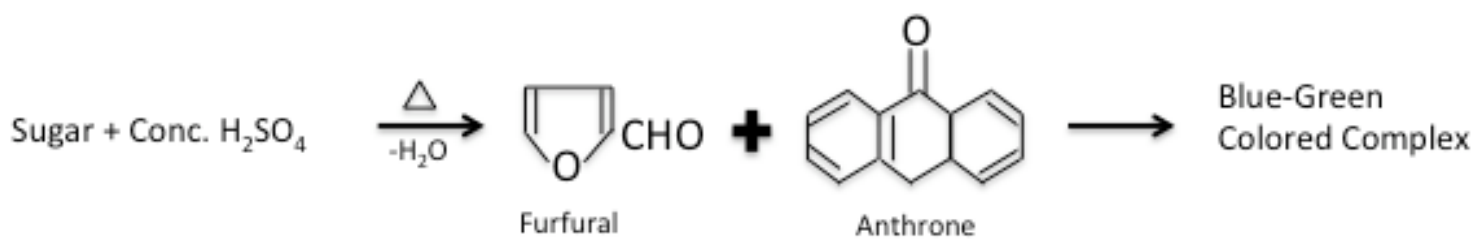

Figure 10. Chemical Principle of Anthrone Assay.

Table 6. Volumetric measurements for set-up of calibration curve for anthrone assay.

\begin{tabular}{|c|c|c|c|}
\hline Vial\# & $\begin{array}{c}\text { Concentration } \\
(\mathrm{mg} / \mathrm{mL})\end{array}$ & $\begin{array}{c}\mathrm{V}_{\text {Stock Solution }} \\
(\mathrm{mL})\end{array}$ & $\begin{array}{c}\mathrm{V}_{\text {DI Water }} \\
(\mathrm{mL})\end{array}$ \\
\hline 1 & 0 & 0.0 & 1.0 \\
\hline 2 & 20 & 0.2 & 0.8 \\
\hline 3 & 40 & 0.4 & 0.6 \\
\hline 4 & 60 & 0.6 & 0.4 \\
\hline 5 & 80 & 0.8 & 0.2 \\
\hline 6 & 100 & 1.0 & 0.0 \\
\hline
\end{tabular}

$1.0 \mathrm{~mL}$ of each concentration was transferred into separate $40-\mathrm{mL}$ glass scintillation vials in triplicate and placed in a laminar flow hood. $2 \mathrm{~mL}$ of concentrated 
$\mathrm{HCl}$ were added to each vial, which was placed in a boiling water bath for three hours. 4 $\mathrm{mL}$ of $0.2 \%(\mathrm{w} / \mathrm{v})$ anthrone solution dissolved in cold $\mathrm{H}_{2} \mathrm{SO}_{4}$ were added to each vial slowly and carefully. The vials were then placed into a boiling water bath at $100^{\circ} \mathrm{C}$ for 15 min. Once complete, the vials were removed from the water bath and kept in the laminar flow hood to cool down and allow the resulting vapor to vent. Once cooled down to room temperature $\left(23^{\circ} \mathrm{C}\right)$, a $1.5 \mathrm{~mL}$ volume of the contents was transferred into a plastic cuvette for optical density spectrophotometric measurements at a wavelength of $620 \mathrm{~nm}$ using DI water as a control. The peak heights of the absorbance spectra at 620 nm were plotted against the sample concentrations to yield a calibration curve.

\subsection{Growth Curve of Free and Encapsulated Bacteria}

\subsubsection{Free Bacteria}

Growth measurements were setup with the optimized medium. Samples were taken every 24 hours and subsequently diluted 10X prior to absorbance peak height and \%transmittance measurements using fresh LB Broth as a control. Next, $0.10 \mathrm{~mL}$ of each sample were pipetted into a disposable hemacytometer (Fig. 11), allowed to sit for $3 \mathrm{~min}$, and taken to a Nikon Eclipse Ti-S microscope for a cell count (Fig. 12). Cell count measurements were taken at five locations, which are circled in red in Fig. 11, and then averaged to obtain a cell count. 


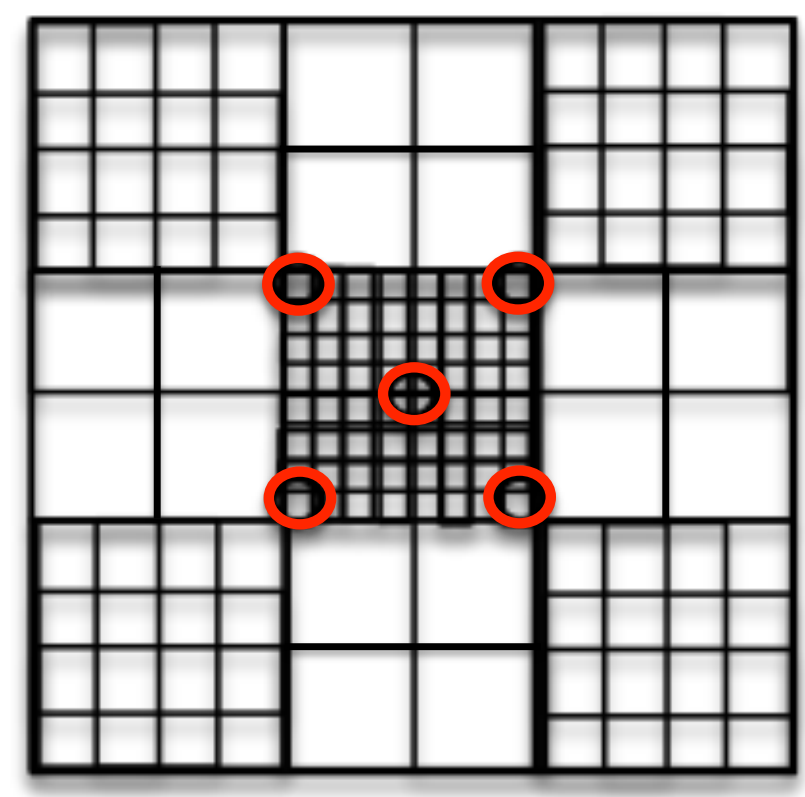

Figure 11. Cell counting chambers of cbc hemacytometer (drawing not to scale). chambers circled at regions where used for cell counting.

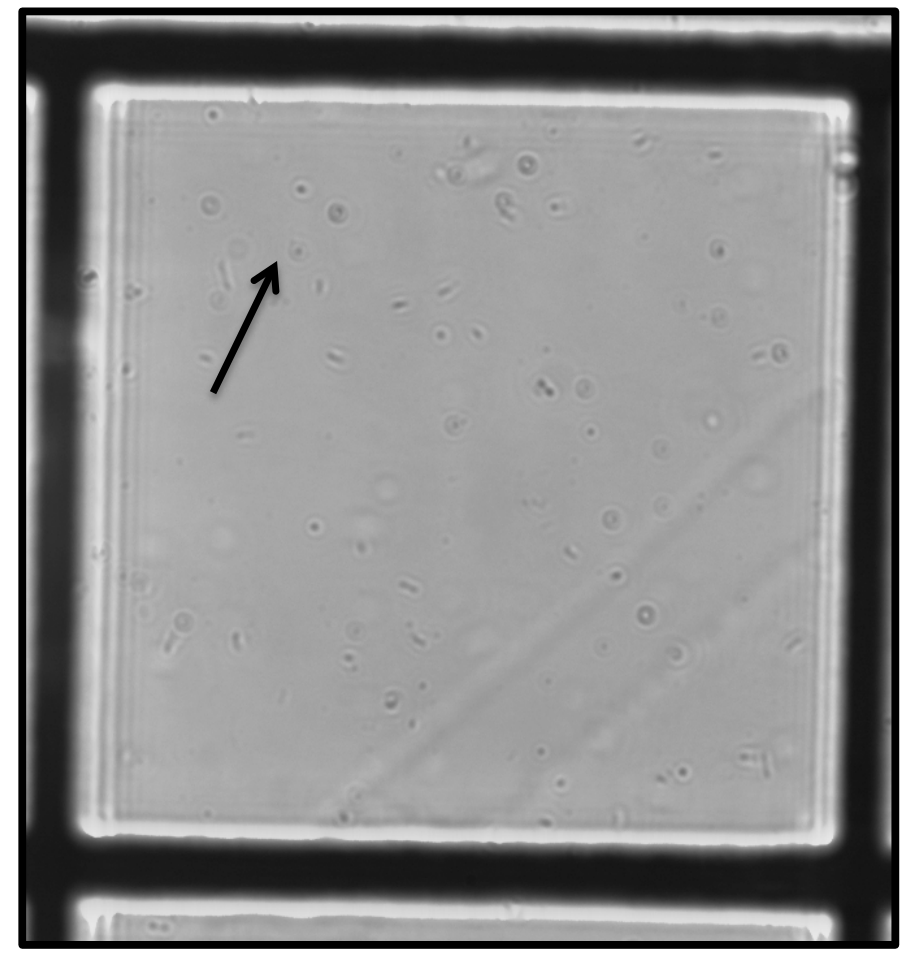

Figure 12. Cell counting chamber of a cbc hemacytometer with live bacteria cells. 
The cell count measurements were then divided by the individual volumes of the selected chambers to obtain a cell concentration value in number of cells per $\mathrm{mL}$ of culture. The cell concentration was multiplied by the total volume of sample to obtain the total cell number, which was plotted against the peak heights of the absorbance to construct a calibration curve.

\subsubsection{Encapsulated Bacteria}

Encapsulated bacteria were created using the atomization technique. As described in Section 4.4, 20 autoclaved 40-mL glass scintillation vials were set up in triplicate with $5 \mathrm{~mL}$ of optimized medium. Growth measurements were carried out in the same manner as in Section 4.2.2.1. Cell counts were measured, and the growth curve was constructed in the same manner as in Section 4.2.4.2.1.

\subsubsection{Bacterial Growth Curve}

Total bacteria cell number for free and atomized bacteria was plotted against time (in days) in order to construct the bacteria growth curve.

\subsubsection{Free Bacteria}

A $1 \mathrm{~mL}$ of stock bacterial culture was added to $75 \mathrm{~mL}$ LB broth and $1 \mathrm{~mL}$ BSA in a clean autoclaved $125-\mathrm{mL}$ Erlenmeyer flask. The flask was then loosely capped and placed in an incubator at $37^{\circ} \mathrm{C}$. Samples were taken every $24 \mathrm{~h}$ starting from the initial inoculation. Each sample was diluted 10x in fresh LB broth and vigorously mixed for 20 s using a vortex. Once mixed, the contents were transferred to a disposable plastic cuvette. Peak height absorbance and $\%$ transmittance measurements were taken at a wavelength of $600 \mathrm{~nm}$ using fresh LB Broth as a control. 


\subsubsection{Encapsulated Bacteria}

The same growth medium from Section 4.2.1 was used for encapsulated bacteria. Encapsulated bacteria were placed in autoclaved 40-mL glass scintillation vials in order to be set up for destructive sampling. Growth medium was added to each vial in a ratio of (75:1, v/v) LB Broth to BSA.

The capsules were filtered using a $100-\mu \mathrm{m}$ nylon filter and placed into a $20 \mathrm{~mL}$ glass scintillation vial. $4 \mathrm{~mL}$ of $3 \%(\mathrm{w} / \mathrm{v})$ sodium citrate solution were added to the vial. The vial was then capped and vortexed in order to dissolve the capsules. The contents in the vial were transferred into 1.5-mL Eppendorf tubes and then centrifuged at 8,000 rpm for $5 \mathrm{~min}$ to separate the bacteria from the liquid. After centrifugation was complete, the supernatant in each tube was removed, thus leaving behind the bacteria pellet. Each pellet was transferred into a fresh clean tube with $1.5 \mathrm{~mL}$ of fresh LB Broth. The tubes were vortexed until the pellets were fully dissolved. After 10X dilution, the bacterial solution was placed in a plastic cuvette for spectrophotometric measurement at a wavelength of $600 \mathrm{~nm}$ using fresh LB Broth as a control.

\subsection{Encapsulation of Bacteria via Atomization and Inkjet Bioprinting}

\subsubsection{Atomization}

Bacteria were immobilized by atomization according to the procedure described in (Garofalo, 1989). 3\% (w/v) alginate was prepared by mixing $3 \mathrm{~g}$ of medium viscosity alginic acid with $100 \mathrm{~mL}$ sterile $0.9 \% \mathrm{NaCl}$ in a capped $150-\mathrm{mL}$ Erlenmeyer glass flask on a stirring plate for $24 \mathrm{~h}$. Once fully mixed, the flask was autoclaved and allowed to cool to room temperature. Next, $1 \mathrm{~mL}$ of bacteria culture was placed into a $1.5-\mathrm{mL}$ 
Eppendorf centrifuge tube and centrifuged at $8,000 \mathrm{rpm}$ for $5 \mathrm{~min}$. The supernatant from the tube was discarded, and the resulting bacteria pellet was rinsed with DI water by vortexing and subsequently centrifuging. This process was repeated three times. The pellet was then transferred into the freshly prepared autoclaved alginate and then mixed for $30 \mathrm{~min}$.

The bacteria-alginate solution was withdrawn into a sterile 10 -mL syringe, which was then connected to the atomization needle attached to a $\mathrm{N}_{2}$ source. The syringeneedle assembly was placed into the syringe pump slot and fixated by actuating the lever. The atomization needle tip was oriented toward a $50-\mathrm{mL}$ beaker containing $20 \mathrm{~mL}$ sterilized $1.5 \% \mathrm{CaCl}_{2}$ and situated on a stirring plate (Fig. 13). An extrusion rate of 0.50 $\mathrm{mL} / \mathrm{min}$ was selected on the front panel of the syringe pump. The $\mathrm{N}_{2}$ source was switched on, and the rate of airflow through the atomization needle was set to 12 $\mathrm{mL} / \mathrm{min}$. 


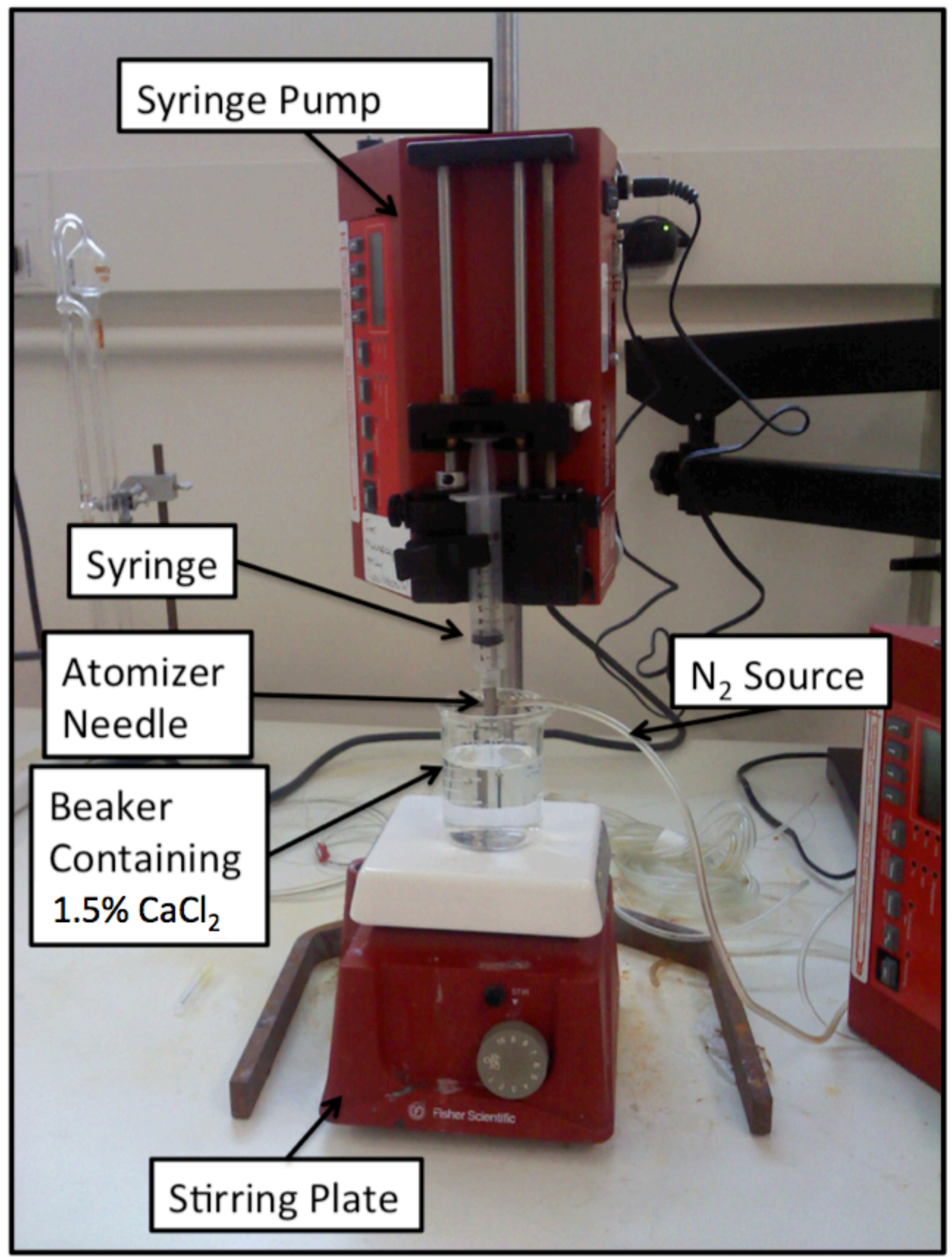

Figure 13. Experimental setup for alginate bead fabrication. 


\subsubsection{Inkjet Bioprinting}

Bacteria were immobilized by inkjet printing according to the procedure described in (Mobed-Miremadi, 2011). Shown in Fig. 14 is a picture of the physical setup of the inkjet printing scheme. Microcapsules were fabricated using the Microfab's Jetlab

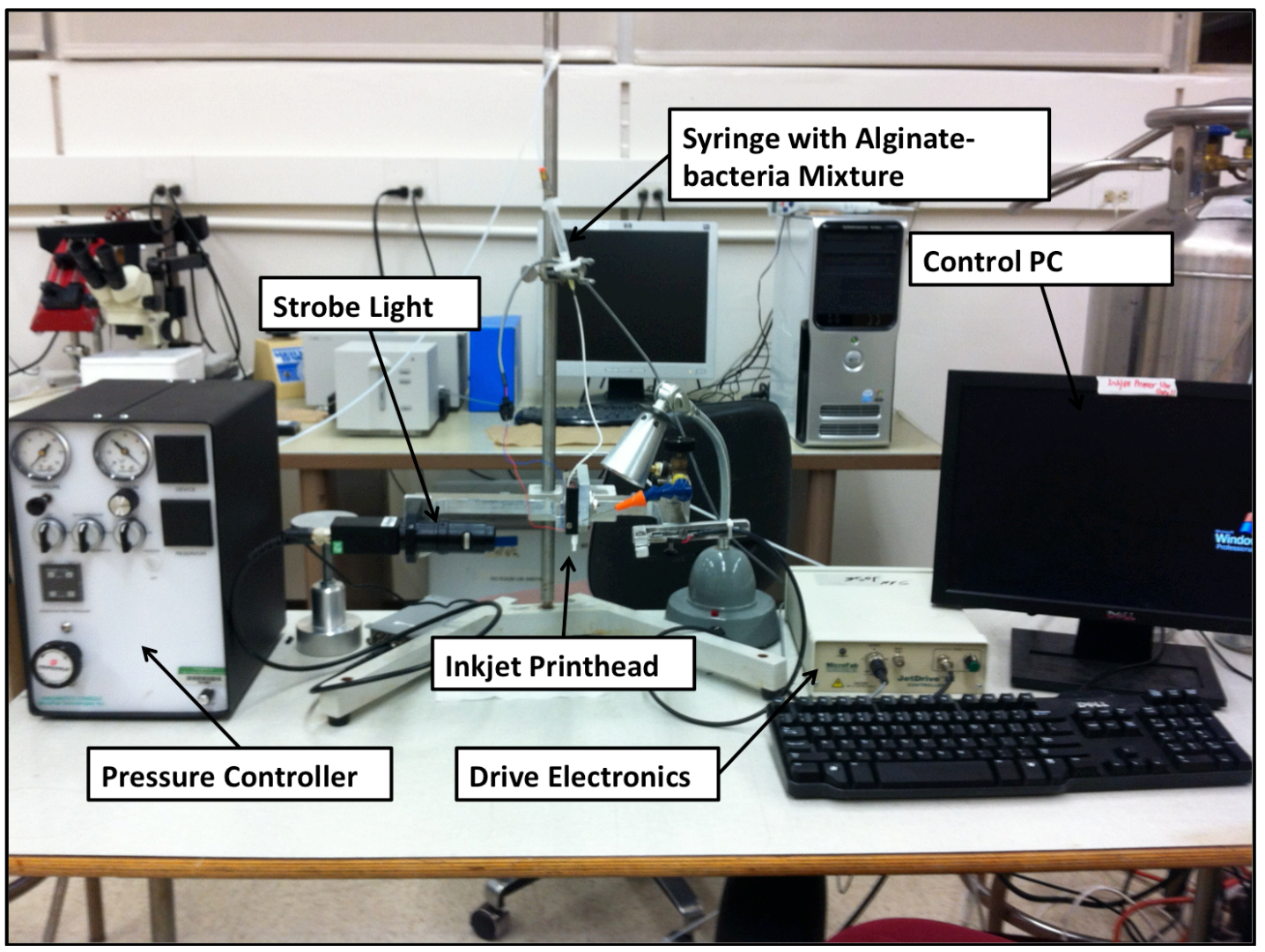

Figure 14. Set-up of inkjet printing scheme.

System based on the modification of a previously established method, specifically with the addition of a physical adsorption step previously established methodology (MobedMiremadi, 2011). The apparatus consisted of a CCD camera (30 fps), a control unit, a printhead, a triggering unit, a fluid delivery unit, and a PC equipped with proprietary software (MicroFab JetServer) to tune the bio-ink formulation to the jetting parameters. 
The printhead had an aperture of $60 \mu \mathrm{m}$ and was rated for $\mu=40 \mathrm{cP}$ and $\gamma=72 \mathrm{dyn} / \mathrm{cm}$. After inputting the jetting variable settings, droplet generation began with the triggering box sending electrical signals to the inkjet control unit and to the CCD camera control PC, simultaneously. The inkjet engine fired the $0.5 \%(\mathrm{w} / \mathrm{v})$ filter-sterilized low viscosity sodium alginate solution $[\mu=5 \mathrm{cP}, \gamma=43 \mathrm{dyn} / \mathrm{cm}]$ mixed with bacteria $(1 \mathrm{ml}$ centrifuged bacteria/ml of alginate), into a $15 \%(\mathrm{w} / \mathrm{v}) \mathrm{CaCl}_{2}$ receiving solution. The beads were allowed to cross-link for $30 \mathrm{~min}$. Following the cross-linking step, 1\% (w/v) low viscosity chitosan was added into the receiving solution to make the final chitosan concentration $0.5 \%(\mathrm{w} / \mathrm{v})$. This physical adsorption step was carried out for $30 \mathrm{~min}$ at room temperature using stirring was necessary to confer mechanical strength to the suspension during the subsequent concentration and centrifugation steps. The capsules were then centrifuged at $8,000 \mathrm{rpm}$ for $5 \mathrm{~min}$ and washed with a $0.9 \%(\mathrm{w} / \mathrm{v}) \mathrm{NaCl}$ solution 3 times.

The source of $\mathrm{N}_{2}$ gas was turned on, and the airflow was set to $20 \mathrm{psi}$. The printhead underwent rinses with isopropyl alcohol, DI water, and $0.9 \% \mathrm{NaCl}$, each performed three times and in series in that order. The printhead was rinsed by first filling the syringe with the appropriate liquid and then setting the $1^{\text {st }} \mathrm{knob}$ on the inkjet printer to "ON" and "PURGE." Any clogs that were present in the printhead were mitigated by connecting the tubing output from the syringe directly onto the print head and manually purging it with $0.9 \% \mathrm{NaCl}$. Once rinsing and any clogs were completed, $5-\mathrm{mL}$ bacteriaalginate mixture was put into the syringe. Input parameters shown in Fig. 15 were entered in the MicroFab JetServer ${ }^{\mathrm{TM}}$ software. 


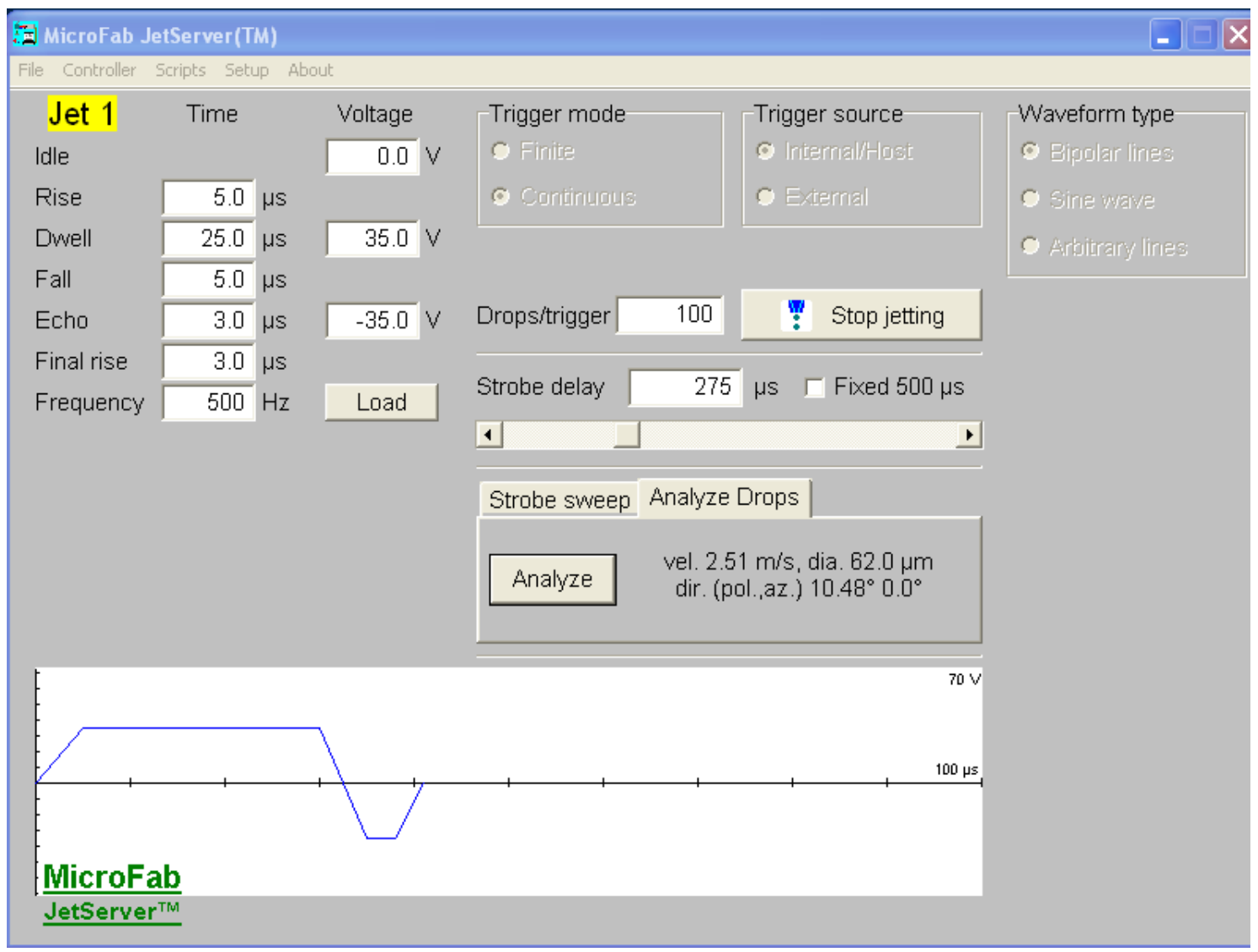

Figure 15. Input parameters for inkjet bioprinting system using microfab jetserver TM.

The "PURGE" setting was enabled and the $1^{\text {st }}$ knob was set to "ON." The

vacuum pump was then switched on and set to 25 psi. The backpressure was adjusted as necessary until the meniscus on the print head tip appeared to be flat. The external lamp was dimmed, and the strobe light was set to $200 \mu \mathrm{s}$. "START JETTING" on the software was then selected, and the voltage was adjusted as necessary until capsules were visible as shown in Fig. 16. Capsules were jetted for $2 \mathrm{~h}$ into a petri dish filled with $7 \mathrm{~mL}$ sterilized $15 \% \mathrm{CaCl}_{2}$. After $2 \mathrm{~h}$ of jetting, the capsules were allowed to sit in the $15 \%$ $\mathrm{CaCl}_{2}$ solution for $30 \mathrm{~min}$ in order to undergo cross-linking. After cross-linking, the capsules were placed into a sterile Falcon ${ }^{\circledR}$ tube containing $10 \mathrm{~mL}$ of $1 \%(\mathrm{w} / \mathrm{v})$ chitosan 
solution and allowed to sit for $30 \mathrm{~min}$ in order to be coated. After coating was complete, the contents of the tube were transferred into 1.5-mL Eppendorf centrifuge tubes, capped, and centrifuged at 8,000 rpm for $3 \mathrm{~min}$. Once centrifugation was complete, the supernatant solution from each tube was discarded, and the capsules were consolidated into a single 1.5-mL Eppendorf centrifuge tube to which $1-\mathrm{mL} 0.9 \% \mathrm{NaCl}$ was added.

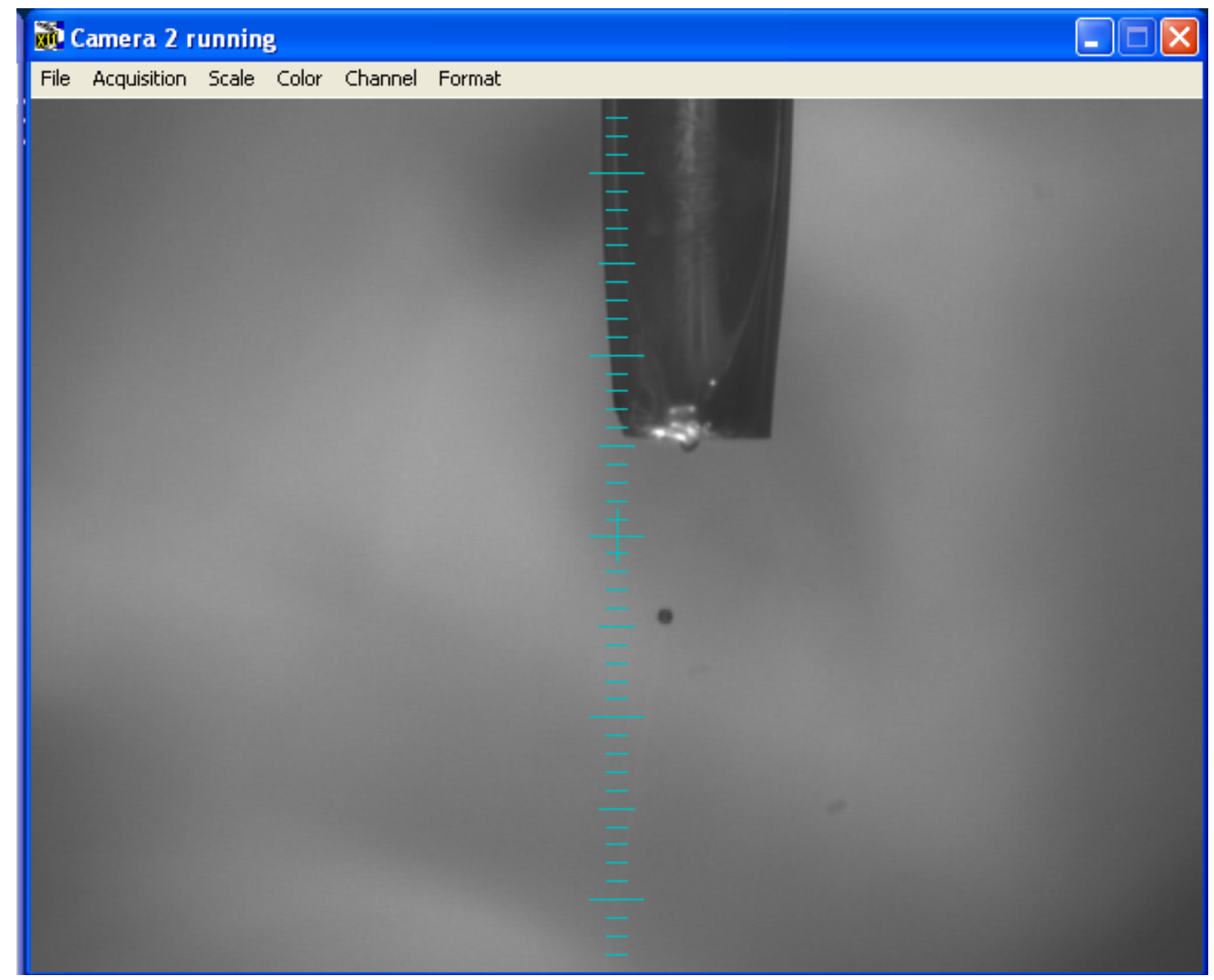

Figure 16. Close-up view of inkjet printhead ejecting encapsulated bacteria.

\subsubsection{Encapsulation Efficiency}

An encapsulation efficiency experiment was conducted in order to understand how many of the initial cells mixed in the alginate were retained in the capsules after 
crosslinking. In order to do so, $1 \mathrm{~mL}$ of a known concentration of bacteria infused in alginate was atomized into microcapsules using the procedure from Section 4.2.2. The capsules were then placed in an autoclaved 20-mL glass scintillation vial. $4 \mathrm{~mL}$ of $3 \%$ $(\mathrm{w} / \mathrm{v})$ sodium citrate was added to dissolve the capsules. The vial was then capped tightly and vortexed until the capsules were fully dissolved. The contents of the vial were then added into 1.5-mL Eppendorf centrifuge tubes, which were then centrifuged at 8,000 rpm for $5 \mathrm{~min}$. The supernatant was then discarded, and the resulting bacteria pellets were collected into a single fresh falcon tube in which they were re-suspended in fresh LB Broth, then vortexed until fully dissolved. The absorbance of the bacteria was measured by way of spectrophotometry at a wavelength of $600 \mathrm{~nm}$ using fresh LB Broth as a control. The peak absorbance value was recorded and, the total cell number was calculated by way of the calibration curve in Section 5.1.1. Eqn. 13 was used to determine encapsulation efficiency:

$$
\% \text { Efficiency }=\frac{\text { Final Cell Count after Dissolving Capsules }}{\text { Initial Cell Count Mixed into Alginate }} \times 100 \%
$$

\subsection{Cholesterol Degradation Experiments}

Cholesterol degradation experiments were conducted in three different scenarios:

1. Free bacteria in optimized medium,

2. Encapsulated bacteria via atomization, and

3. Encapsulated bacteria via inkjet bioprinting. 
The purpose of these experiments was to study the effects of miniaturization on cholesterol degradation. The effects of cell number on cholesterol degradation were also studied.

\subsubsection{Experimental Set-up}

The cell counts from the lag, log, and peak growth were chosen from the bacteria growth curve in Section 5.1. To obtain the cell counts at those regions, $1.5 \mathrm{~mL}$ aliquots of fresh bacteria culture were first diluted in fresh LB Broth. Peak absorbance values were measured at $600 \mathrm{~nm}$ using fresh LB Broth as a control. The cell count was calculated and verified using the calibration curve. The cells were then placed in $1.5 \mathrm{~mL}$ Eppendorf tubes and centrifuged at 8,000 rpm for $4 \mathrm{~min}$. Once complete, the supernatant liquids were discarded, and $1.5 \mathrm{~mL}$ sterile DI water were added to each tube, which was then capped and vortexed for $20 \mathrm{sec}$ to re-suspend the cells. The tubes were then centrifuged again at $8,000 \mathrm{rpm}$. The process of washing the cells with DI water was repeated for a total of three washes in order to ensure no remnants from the previous growth medium were present.

For the case of cholesterol degradation by free bacteria, the cells were suspended in $2 \mathrm{~mL}$ fresh LB by vortexing for $1 \mathrm{~min}$. The cells were then transferred to autoclaved 40-mL scintillation glass vials and set up in triplicate as outlined in Table 7.

Table 7. Set-up parameters of cholesterol degradation experiment $(N=3)$.

\begin{tabular}{|l|c|c|c|}
\hline $\begin{array}{c}\text { Phase on Growth Curve from which } \\
\text { Cell Count was Selected }\end{array}$ & \multicolumn{3}{|c|}{ Incubation Time (days) } \\
\hline $\operatorname{Lag}\left(\mathrm{N}_{\text {low }}=4.53 \times 10^{8}\right)$ & 2 & 5 & 8 \\
\hline $\log \left(\mathrm{N}_{\text {med }}=6.90 \times 10^{8}\right)$ & 2 & 5 & 8 \\
\hline Stationary $\left(\mathrm{N}_{\text {high }}=1.76 \times 10^{9}\right)$ & 2 & 5 & 8 \\
\hline
\end{tabular}


The specified cell counts in Table 7 were harvested and mixed into multiple fresh autoclaved alginate mixtures, one per vial, which were then subjected to encapsulation. Bacteria were encapsulated via atomization in the same manner as described in Section 4.2.2. For inkjet bacteria, the low cell count was used. All samples for atomized and inkjet bacteria were set up in triplicate.

\subsubsection{Cholesterol Layer Identification}

The phase in which cholesterol was to be extracted was determined through Salkowski's reaction (Romley, 1903). The principle of Salkowski's reaction is that the double bond in cholesterol reacts with concentrated sulfuric acid to give bicholestadien disulphonate, which is pink to dark magenta in color. Shown in Fig. 18 is a series of glass test tubes filled with different mixtures of solutions and the phase in which cholesterol was present. As described in Salkowski's reaction, reaction of cholesterol with $\mathrm{H}_{2} \mathrm{SO}_{4}$ caused the cholesterol to appear pink to dark magenta in color. When $\mathrm{H}_{2} \mathrm{SO}_{4}$ was added to cholesterol dissolved in chloroform, the chloroform layer appeared magenta, indicating that cholesterol was present in that layer. When chloroform and $\mathrm{H}_{2} \mathrm{SO}_{4}$ were added to whole culture broth, encapsulated bacteria, and cholesterol, the chloroform layer once again appeared magenta in color, thereby confirming that the cholesterol was consistently present within that layer. Hence, cholesterol extraction was performed from the chloroform phase. 


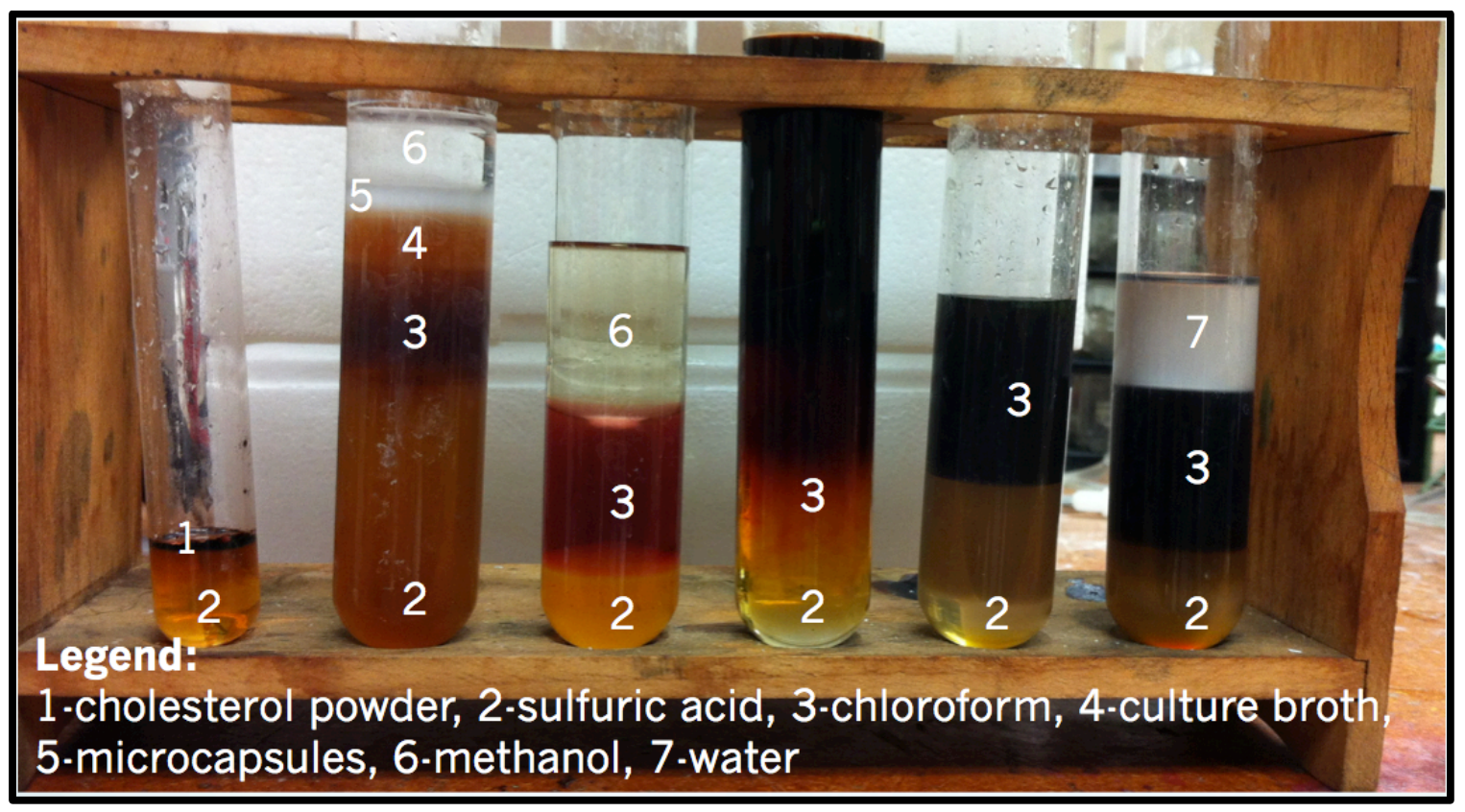

Figure 17. Cholesterol phase identification using salkowski's method (1-cholesterol powder, 2-sulfuric acid, 3-chloroform, 4-culture broth, 5-capsules, 6-methanol, 7-water).

\subsubsection{Cholesterol Quantification}

Quantification of cholesterol was carried out by way of a colorimetric assay kit from Abcam. The Abcam assay kit utilizes the mechanism of cholesterol quantification as follows. In summary, cholesterol reacts with cholesterol oxidase enzyme in the presence of $\mathrm{O}_{2}$ to produce 4-cholesten-3-one and $\mathrm{H}_{2} \mathrm{O}_{2} \cdot \mathrm{H}_{2} \mathrm{O}_{2}$ reacts with the provided cholesterol probe to produce resorufin, which is pink in color. The intensity of the pink color is proportional to the amount of cholesterol present in solution. The intensity was measured through the peak values of the absorbance at a wavelength of $570 \mathrm{~nm}$.

All contents of the assay were warmed to room temperature in a shaker until thawed. The vials containing cholesterol esterase and enzyme mix were each dissolved in $220 \mu \mathrm{L}$ of cholesterol assay buffer. A $0.25 \mu \mathrm{g} / \mu \mathrm{L}$ stock solution of cholesterol 
standard was prepared by mixing $20 \mu \mathrm{L}$ of cholesterol standard with $140 \mu \mathrm{L}$ cholesterol assay buffer and vortexing for $1 \mathrm{~min}$. A calibration curve was constructed by adding the volumes of cholesterol standard and cholesterol assay buffer outlined in Table 8 into a series of $1.5 \mathrm{~mL}$ Eppendorf centrifuge tubes, which were labeled accordingly.

Table 8. Volumetric measurements of set-up for calibration curve of abcam cholesterol assay.

\begin{tabular}{|c|c|c|c|}
\hline Tube \# & $\begin{array}{c}\text { Mass of } \\
\text { Cholesterol }(\mu \mathrm{g})\end{array}$ & \begin{tabular}{c}
$\mathrm{V}_{\text {Cholesterol Standard }}(\mu \mathrm{L})$ \\
\hline 1
\end{tabular} & $\begin{array}{c}\mathrm{V}_{\text {Cholesterol Assay Buffer }} \\
(\mu \mathrm{L})\end{array}$ \\
\hline 2 & 0 & 0 & 50 \\
\hline 3 & 1 & 4 & 46 \\
\hline 4 & 2 & 8 & 42 \\
\hline 5 & 3 & 12 & 38 \\
\hline 6 & 4 & 16 & 34 \\
\hline
\end{tabular}

The reaction mix was prepared by adding $44 \mu \mathrm{L}$ cholesterol assay buffer, $2 \mu \mathrm{L}$ cholesterol probe, $2 \mu \mathrm{L}$ enzyme mix, and $2 \mu \mathrm{L}$ cholesterol esterase into a $1.5 \mathrm{~mL}$ Eppendorf centrifuge tube and vortexing for $1 \mathrm{~min}$. Enough reaction mix was prepared such that there were $50 \mu \mathrm{L}$ per sample being assayed. $50 \mu \mathrm{L}$ of reaction mix was added to each tube and vortexed for $10 \mathrm{sec}$. After mixing, the tubes were placed in the incubator at $37^{\circ} \mathrm{C}$ for $60 \mathrm{~min}$. Once incubation was complete, the tubes were removed from the incubator and vortexed. Optical density spectrophotometric measurements were conducted in the quartz glass cuvette at $620 \mathrm{~nm}$ using $100 \mu \mathrm{L}$ cholesterol assay buffer as a control sample. The peak absorbance values were recorded. Samples were diluted with cholesterol assay buffer as necessary in order to keep the absorbance at a maximum value of 1.0 . 


\subsection{RESULTS}

5.1 Growth medium Optimization and Validation

\subsubsection{Optimization}

Shown in Fig. 18 is the Sm plot for glycolipid biosurfactant production after $48 \mathrm{~h}$ of incubation for BSA, LB, PBS, Cholesterol, and Temperature. The amounts of biosurfactant are represented by the $\mathrm{y}$-axes. The corresponding $\mathrm{S} / \mathrm{N}$ plots for biosurfactant production are shown in Fig. 19. Similarly, the Sm and S/N plots for bacterial growth, with y-axes for all Sensitivity plots representing the $\% \mathrm{~T}$ are presented in Figs. 20 and 21, respectively. The analyses for biosurfactant production and bacterial growth are presented in Tables 9 and 10. The raw data for both responses are tabulated in Appendix B.

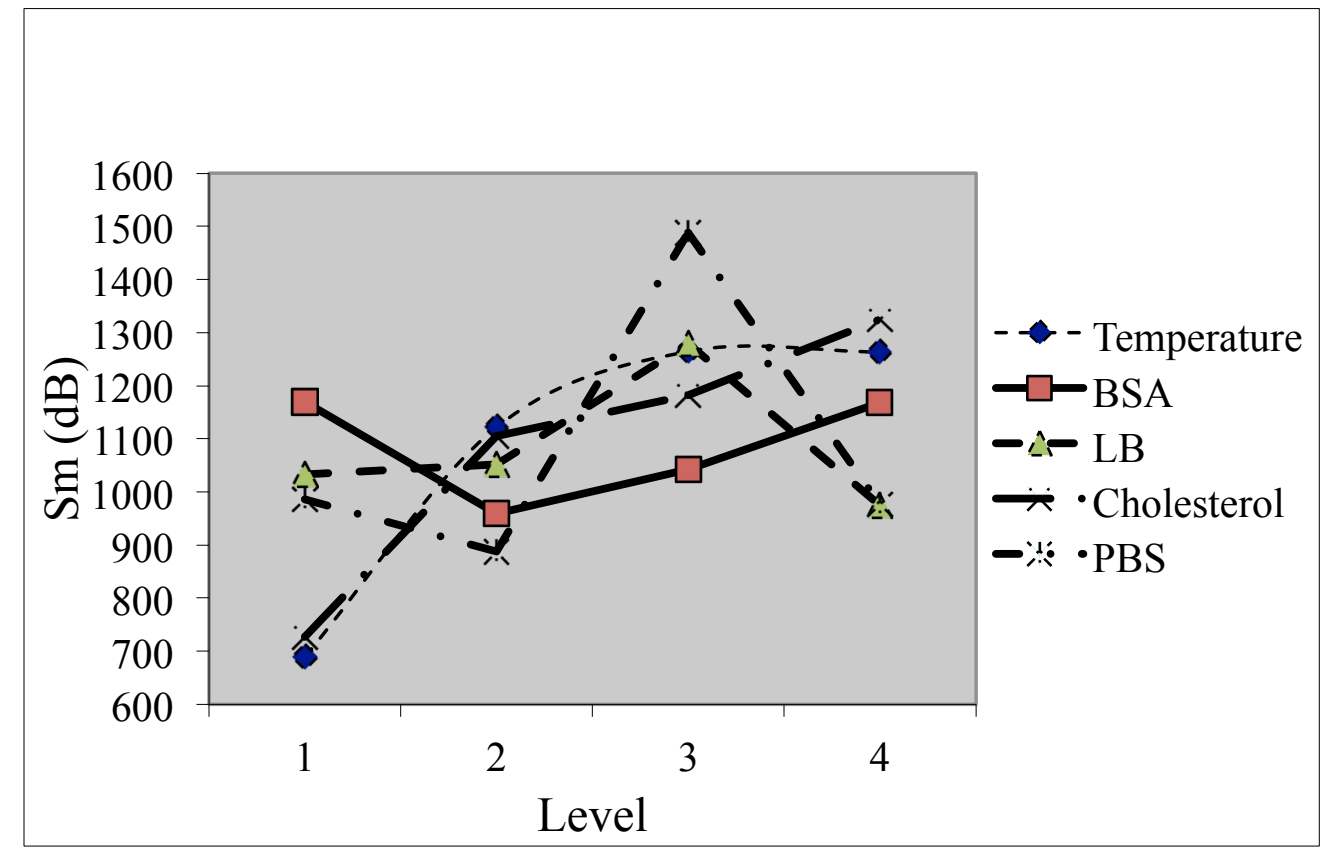

Figure 18. Sensitivity plot for BSA, LB, PBS, cholesterol, and temperature on biosurfactant production. 


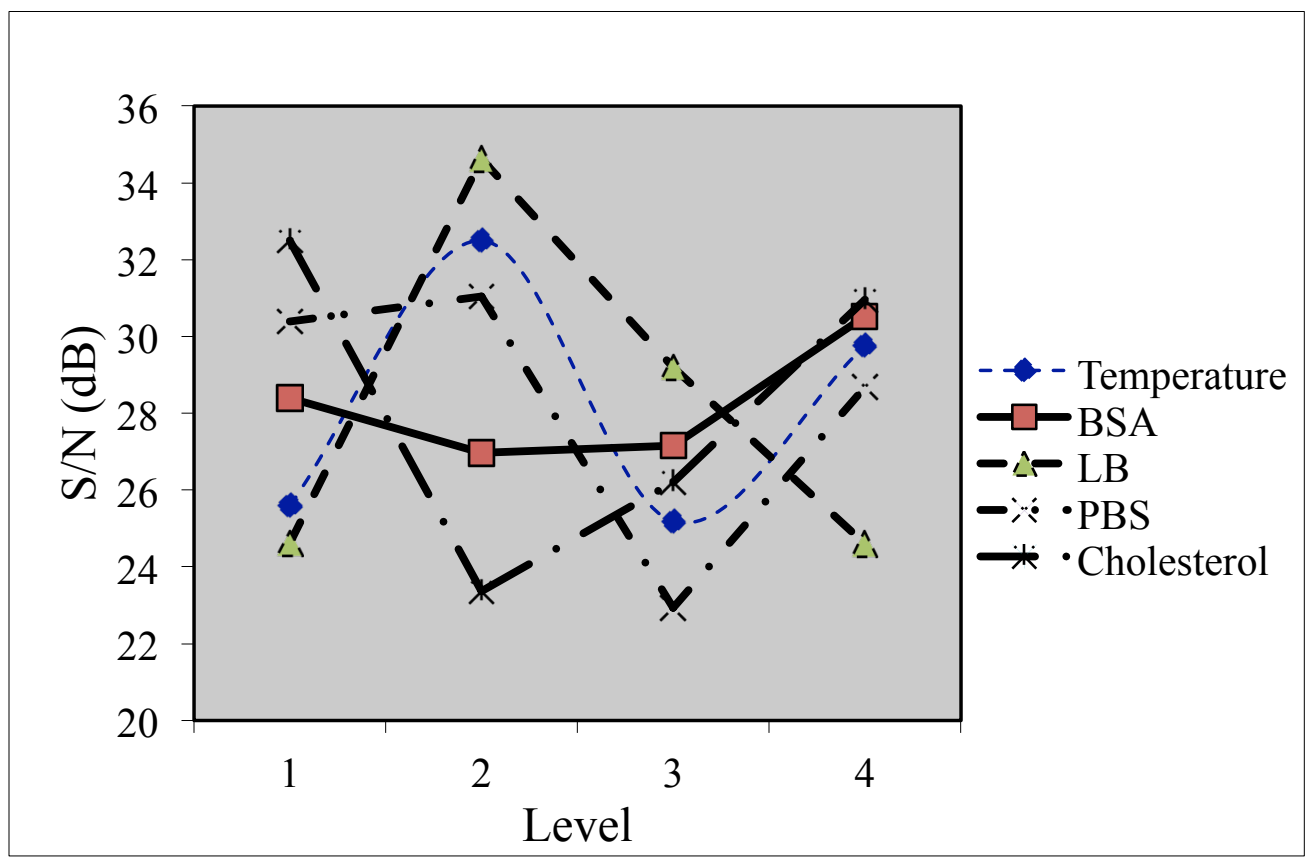

Figure 19. Signal-to-noise ratio plot for BSA, LB, PBS, cholesterol, and temperature on biosurfactant production.

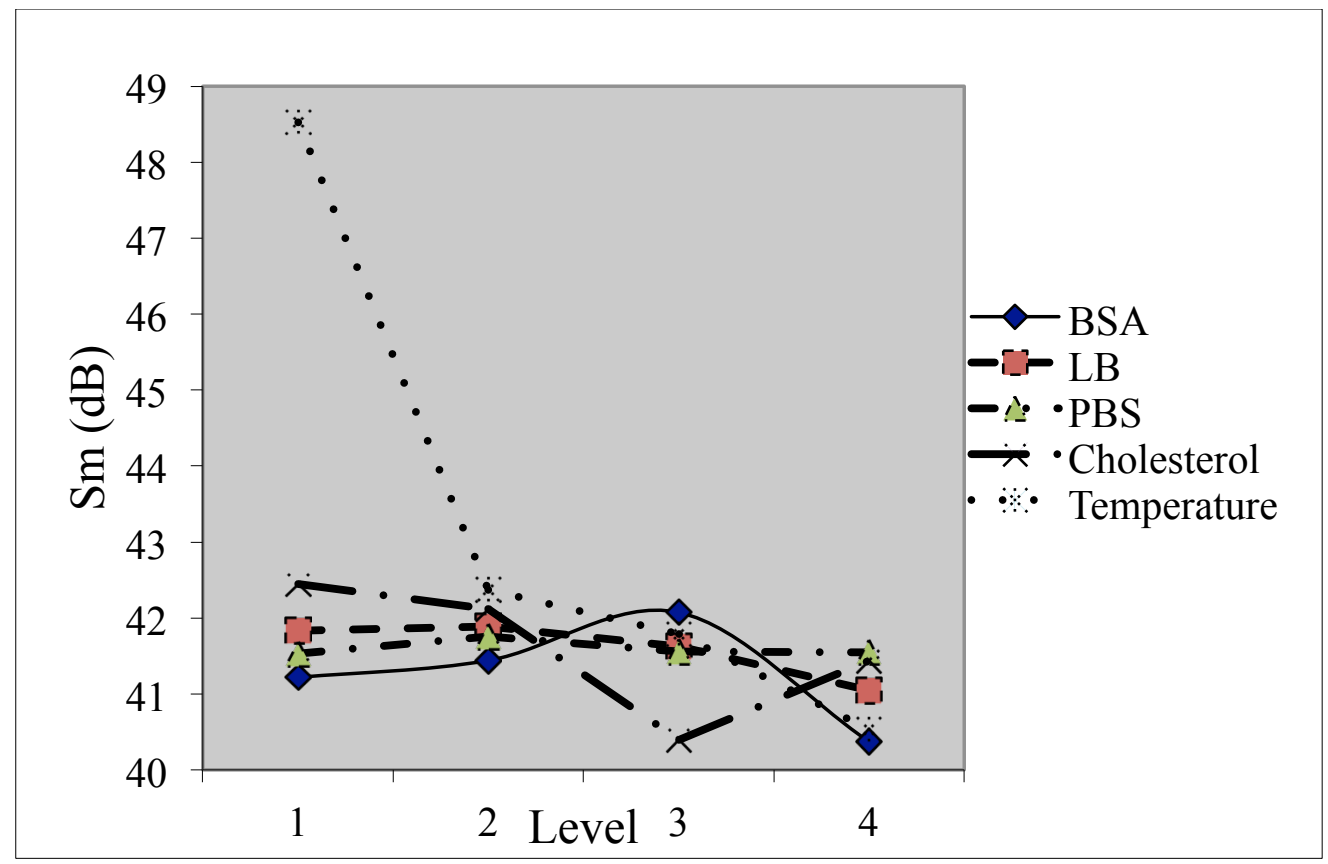

Figure 20. Sensitivity plot for BSA, LB, PBS, cholesterol, and temperature on bacteria growth. 


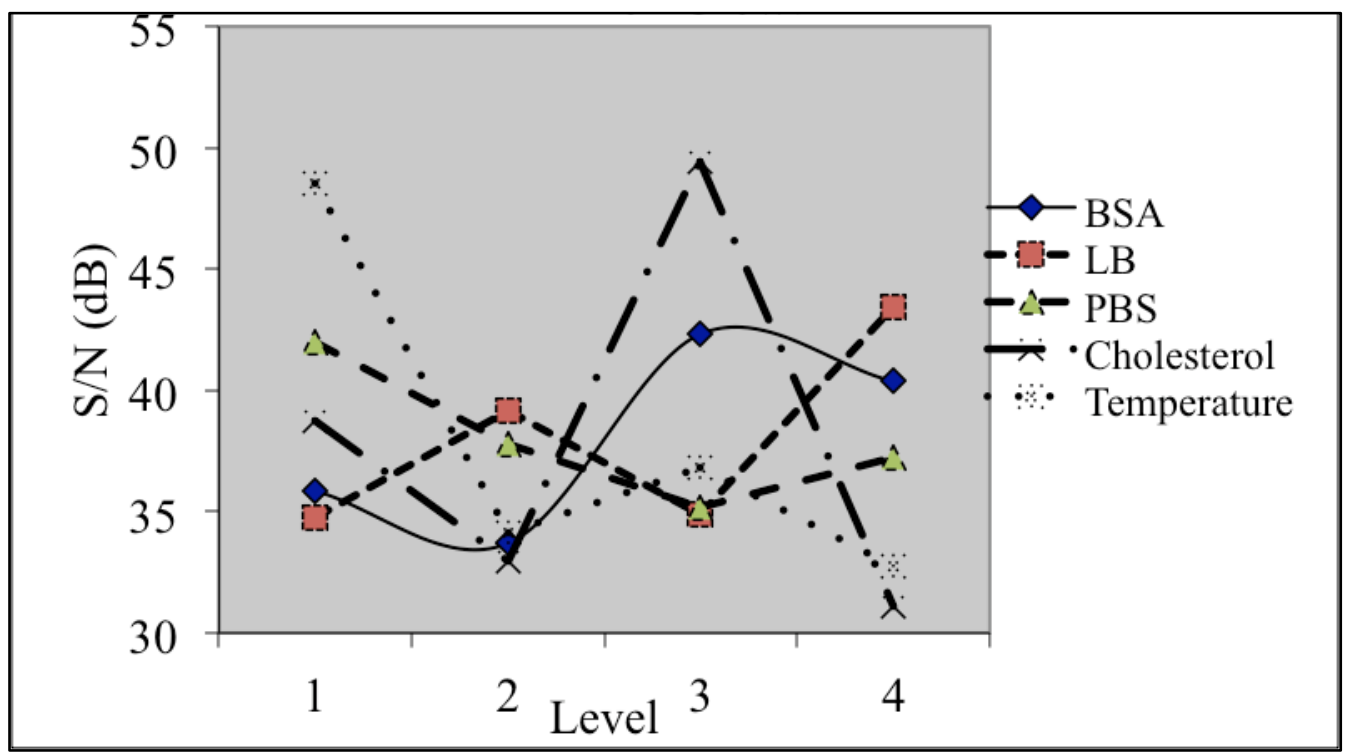

Figure 21. Signal-to-noise ratio plot for BSA, LB, PBS, cholesterol, and temperature on bacteria growth.

The regions circled in red in Fig. 22 constitute the optimum operating levels where bio-surfactant production has been minimized. The highlighted results should theoretically correspond to the last column of Table 9, hence there is a one to one correspondence between the tabulated values and the ones circled in red for BSA, LB, and PBS are $6.6 \%, 13.2 \%$, and $13.2 \%$ (by volume), respectively. The regions circled in red for CHOL and TEMP are $3 \mathrm{mg} / \mathrm{mL}$ and $37^{\circ} \mathrm{C}$, which are selected tabulated diverging from the calculated theoretical level based on system constraints: a) There could be no cholesterol degradation in the absence of cholesterol substrate, b) The temperature of $37^{\circ} \mathrm{C}$ is a physiological constraint. 
Table 9. Summary of Taguchi analysis of biosurfactant production using the nominal the best optimization type.

\begin{tabular}{|c|c|c|c|c|c|c|c|c|}
\hline Variable & Delta & Rank & $\begin{array}{c}\text { Optimal } \\
\text { Level } \\
\text { Based } \\
\text { on Sm }\end{array}$ & Delta & Rank & $\begin{array}{c}\text { Optimal } \\
\text { Level } \\
\text { Based } \\
\text { on S/N }\end{array}$ & $\begin{array}{c}\text { Theoretical } \\
\text { Optimal } \\
\text { Level of } \\
\text { Operation }\end{array}$ & $\begin{array}{c}\text { Selected } \\
\text { Level of } \\
\text { Operation }\end{array}$ \\
\hline BSA & 210 & 5 & 2 & 3.54 & 5 & 4 & 2 & 2 \\
\hline LB & 305 & 4 & 4 & 10.0 & 1 & 2 & 2 & 2 \\
\hline PBS & 600 & 1 & 2 & 8.11 & 3 & 2 & 2 & 2 \\
\hline CHOL & 597 & 2 & 1 & 9.14 & 2 & 1 & 1 & 2 \\
\hline TEMP & 575 & 3 & 1 & 7.31 & 4 & 2 & 1 & 4 \\
\hline
\end{tabular}

Table 10. Summary of Taguchi analysis of bacterial growth using the nominal the best optimization type.

\begin{tabular}{|c|c|c|c|c|c|c|c|c|}
\hline Variable & Delta & Rank & $\begin{array}{c}\text { Optimal } \\
\text { Level } \\
\text { Based } \\
\text { on Sm }\end{array}$ & Delta & Rank & $\begin{array}{c}\text { Optimal } \\
\text { Level } \\
\text { Based } \\
\text { on S/N }\end{array}$ & $\begin{array}{c}\text { Theoretical } \\
\text { Optimal } \\
\text { Level of } \\
\text { Operation }\end{array}$ & $\begin{array}{c}\text { Selected } \\
\text { Level of } \\
\text { Operation }\end{array}$ \\
\hline BSA & 1.70 & 3 & 3 & 8.63 & 4 & 3 & 3 & 2 \\
\hline LB & 0.84 & 4 & 2 & 8.69 & 3 & 4 & 4 & 2 \\
\hline PBS & 0.22 & 5 & 2 & 6.83 & 5 & 1 & 1 & 2 \\
\hline CHOL & 2.06 & 2 & 1 & 18.4 & 1 & 3 & 3 & 2 \\
\hline TEMP & 7.99 & 1 & 1 & 15.8 & 2 & 1 & 1 & 4 \\
\hline
\end{tabular}




\subsubsection{Validation using Minitab}

Shown in Figs. 22 and 23 are the main effects plot for means and signal-to-noise ratios for biosurfactant at $48 \mathrm{~h}$, respectively. As can be seen, the trends are identical to the data presented in Figs. 18 and 19. Hence, the optimization method using Excel was validated.

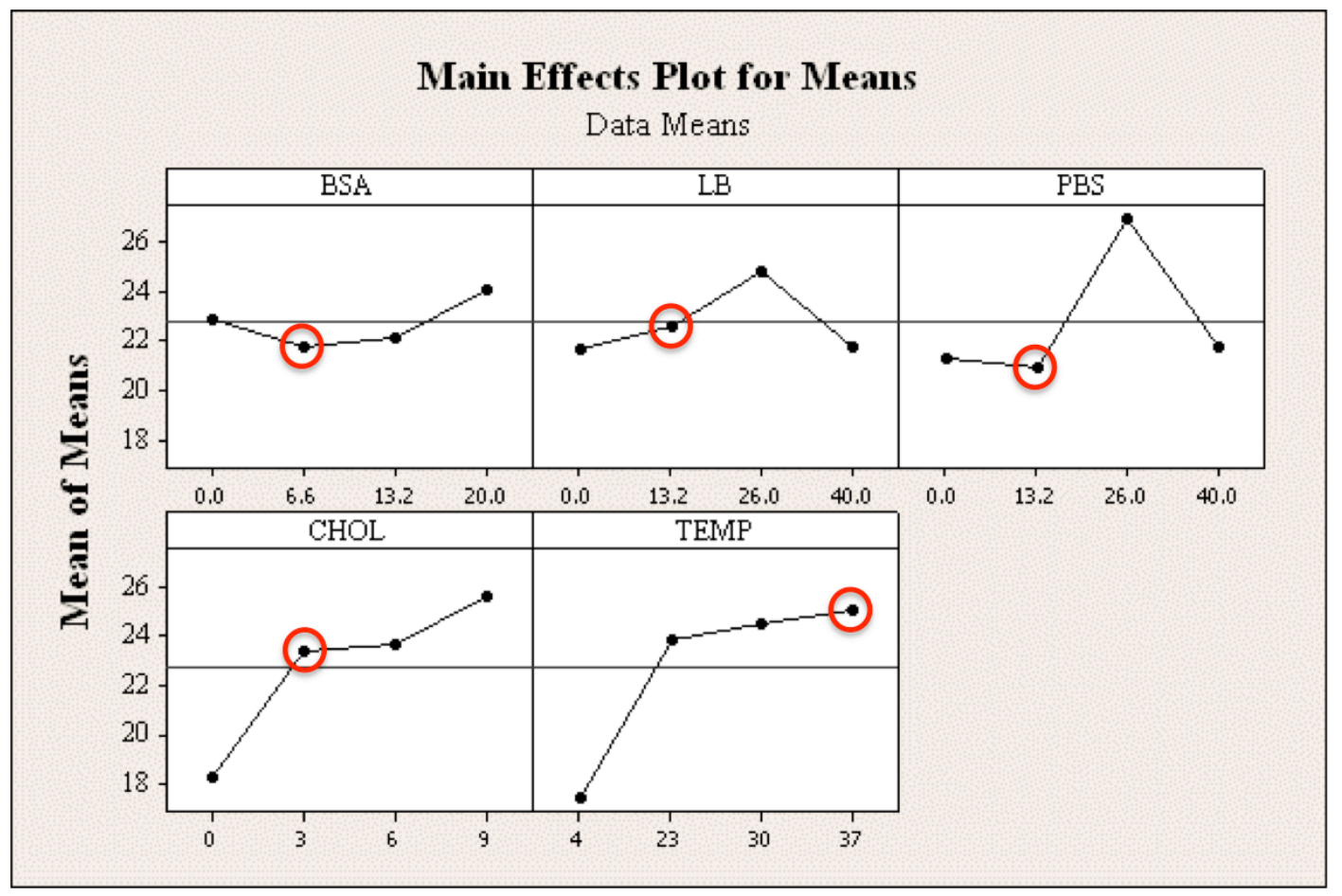

Figure 22. Main effects plot for means of glycolipid biosurfactant for $\mathrm{t}=48 \mathrm{~h}$. 


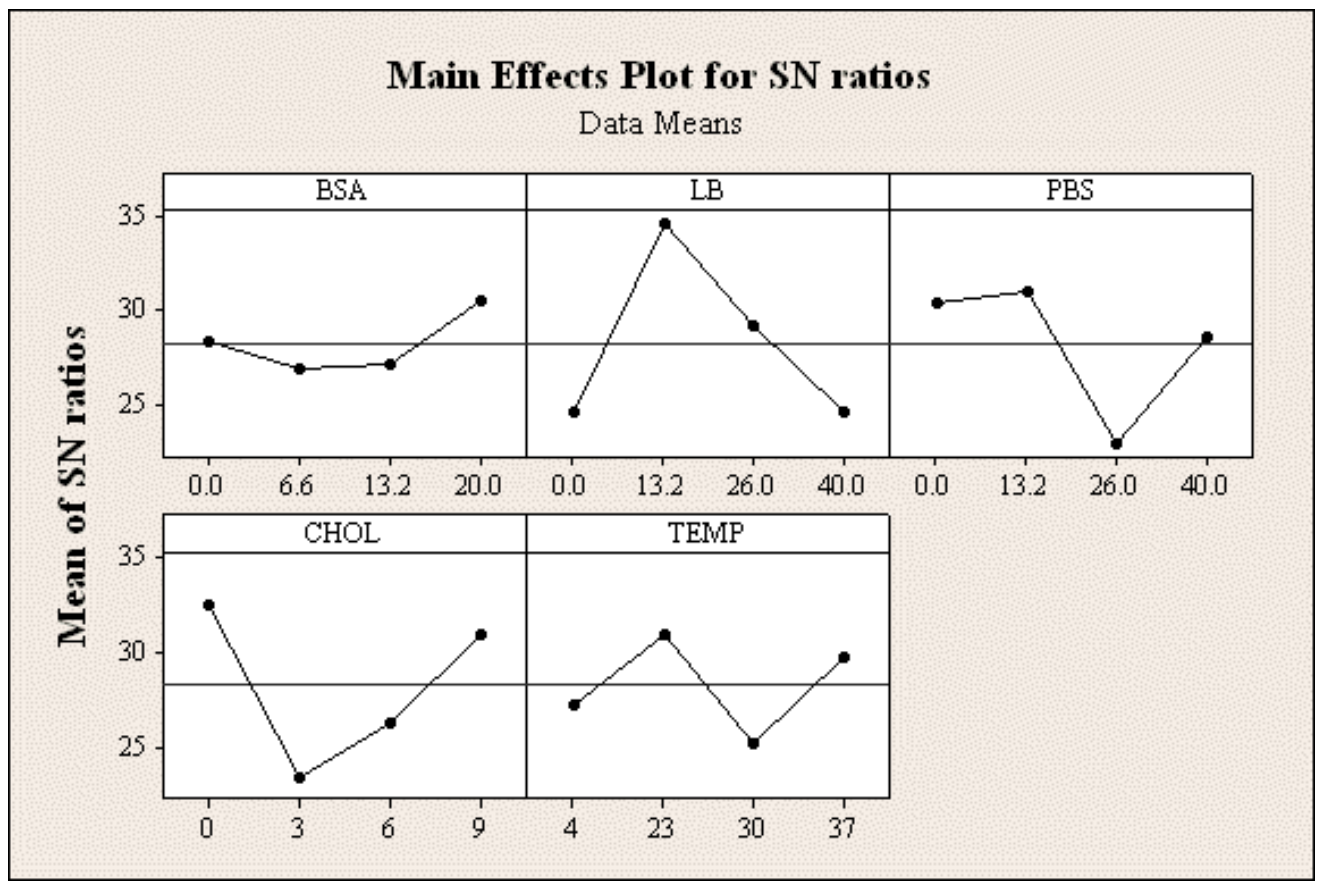

Figure 23. Main effects plot for signal-to-noise ratios of glycolipid biosurfactant for $\mathrm{t}=$ $48 \mathrm{~h}$.

\subsection{Bacteria Growth Study}

\subsubsection{Calibration Curve}

The triplicated calibration curve of bacteria cell number $(\mathrm{N})$ determined by the $\mathrm{CBC}$ hemacytometer is related to the optical density (OD) at $600 \mathrm{~nm}$ (Fig. 24) and is given by Eqn. 14:

$$
\text { Cell Number }=6 \times 10^{9} O D_{(600 \mathrm{~nm})}-8 \times 10^{7} .
$$




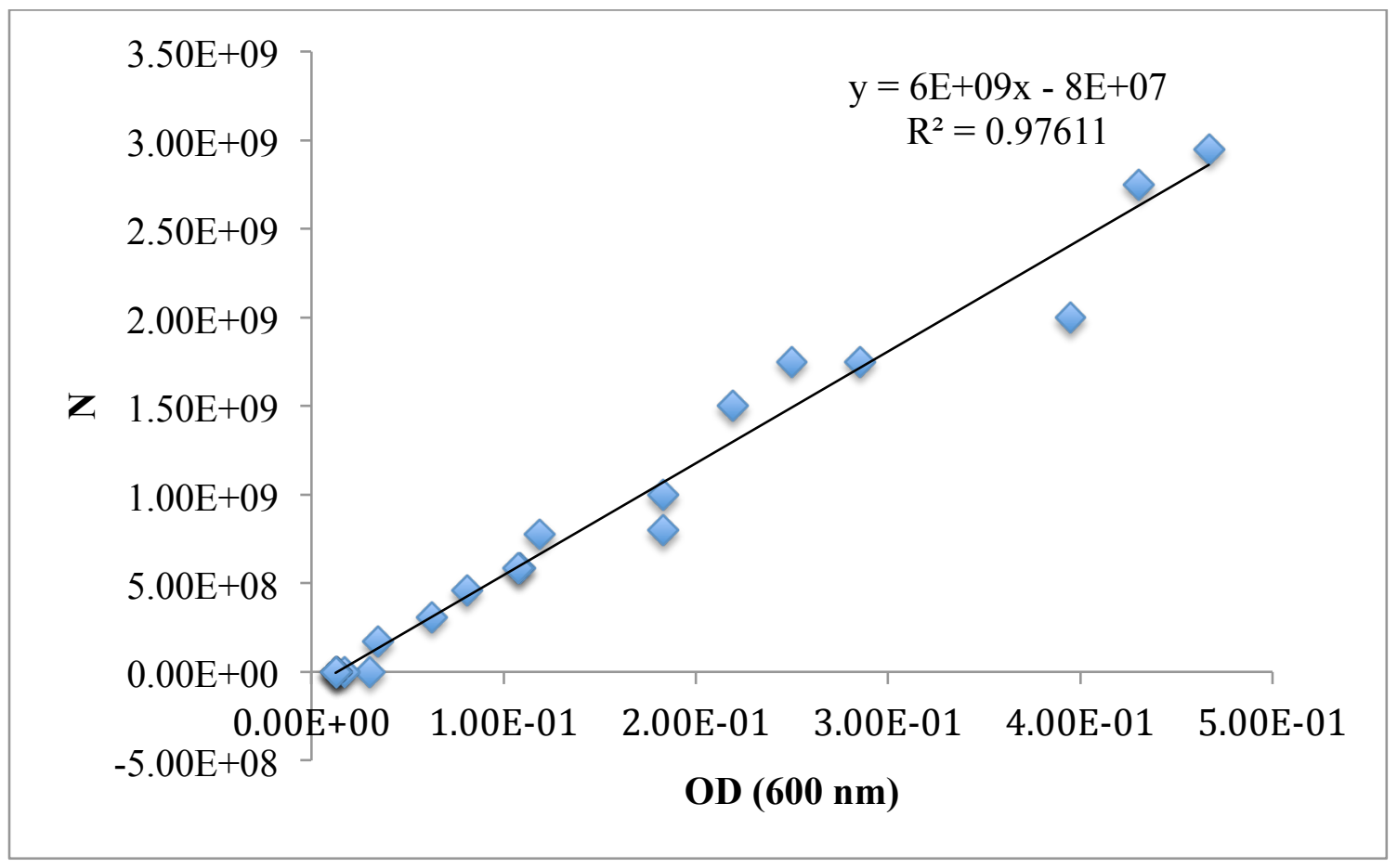

Figure 24. Calibration curve of bacterial cell count in optimized medium.

\subsubsection{Encapsulation Efficiency}

It was determined that $86.2 \%$ of the cells that mixed into the alginate mixture prior to atomization were immobilized within the capsules. The encapsulation efficiency for the inkjet bacteria is not available since the methodology has not been developed to date.

\subsubsection{Growth Curve}

\subsubsection{Growth Curves Prior to Growth Medium Optimization}

Shown in Fig. 25 is the growth curve of free bacteria (blue) and encapsulated bacteria (red) in regular growth medium, which consisted of LB Broth and BSA. Death phase begins at $45 \mathrm{~h}$ with the bulk of the encapsulated population decimated at $212 \mathrm{~h}$ as compared to the onset of the decay phase occurring at $288 \mathrm{~h}$ for the free bacteria. 


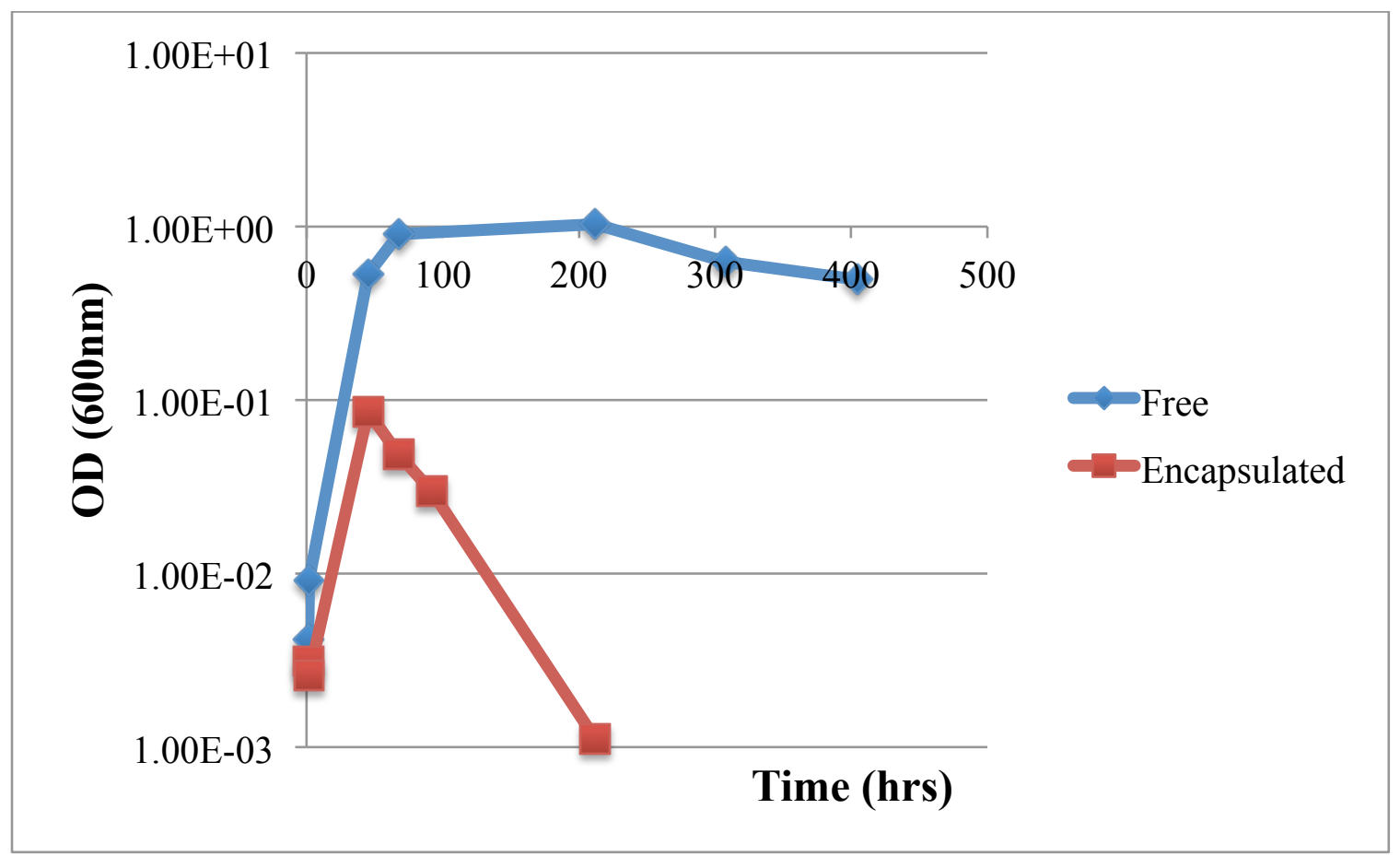

Figure 25. Growth curve of free (shown in blue) and encapsulated bacteria (shown in red) in regular growth medium (LB and BSA).

It is important to note that bacteria growth was initially conducted in a shaker at $37^{\circ} \mathrm{C}$ with the prospect that biosurfactant would emulsify. It was observed, however, that the bio-surfactant did not emulsify but in fact coalesced with the alginate membrane. In order to obtain a viable solution for immobilized bacterial growth, the DOE elaborated upon in the previous section was devised.

\subsubsection{Growth Curves Post Growth Medium Optimization}

Shown in Fig. 26 is the growth curve for free bacteria (red) and encapsulated bacteria (blue) in optimized growth medium. The regions circled in purple at $t=2,5$, and 8 correspond to the lag phase, log phase, and stationary phase, respectively. As can be seen, the lag and log phases seem to follow the typical growth behavior. However, the stationary phase seems to be short-lived. It is important to note that such atypical growth 
behavior is possible since the growth medium was altered in order to minimize the amount of biosurfactant by-product that is naturally created by the bacteria (Shuler, 2002).

From the calibration curve, total cell numbers were obtained and were plotted against time for both free and microencapsulated bacteria, thus constituting the bacteria growth curve shown in Fig. 26. As can be seen for the free bacteria, there was a lag phase of 3 days, a log phase from 5-7 days, and a peak growth observed at 8 days, which was the short-lived stationary phase. It can be seen that growth of microencapsulated bacteria was characterized by a lag compared to that of free bacteria. Such a characteristic is indicative of the diffusion barrier provided by the alginate membrane. From the curve, it was inferred that the bacteria were able to survive in the encapsulated state as a result of growth medium optimization. 


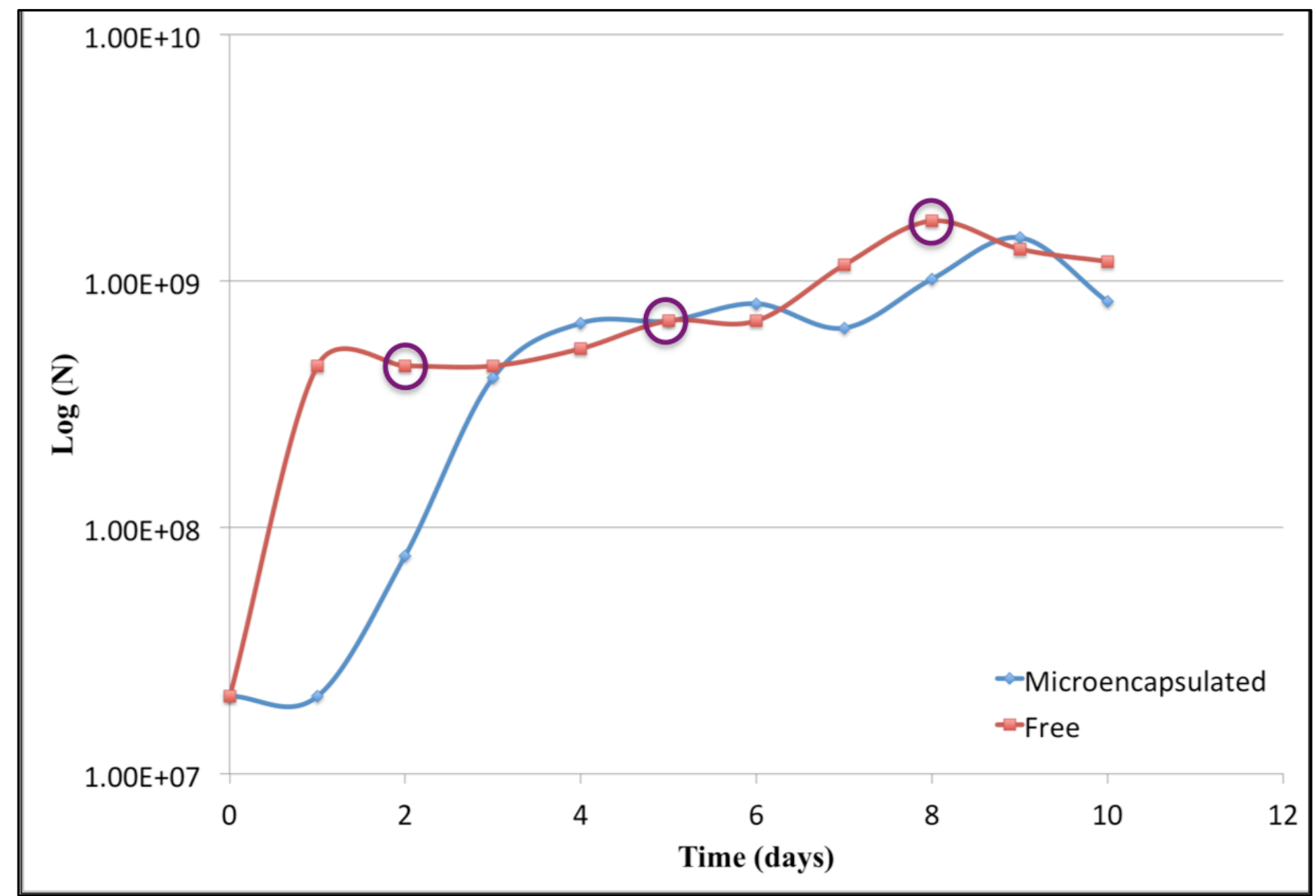

Figure 26. Growth curve of free (shown in red) and encapsulated bacteria (shown in blue) in optimized medium. 


\subsection{Glycolipid Quantification}

\subsubsection{Calibration Curve}

Shown in Fig. 27 are the colorimetric products of the anthrone assay when calibrated against the glucose standard at concentrations of $0-100 \mathrm{mg} / \mathrm{mL}$ (left to right). As the concentration of glucose increases, the color of the reaction gains a darker green tone. As shown in Fig. 28, the triplicated spectrophotometric calibration curve correlating absorbance (A) to the glucose standard concentration is linear and given by a correlation given by Eqn. 15 .

$$
A_{620}=0.0093[\text { Concentration of Glucose Standard }(\mathrm{mg} / \mathrm{mL})]
$$

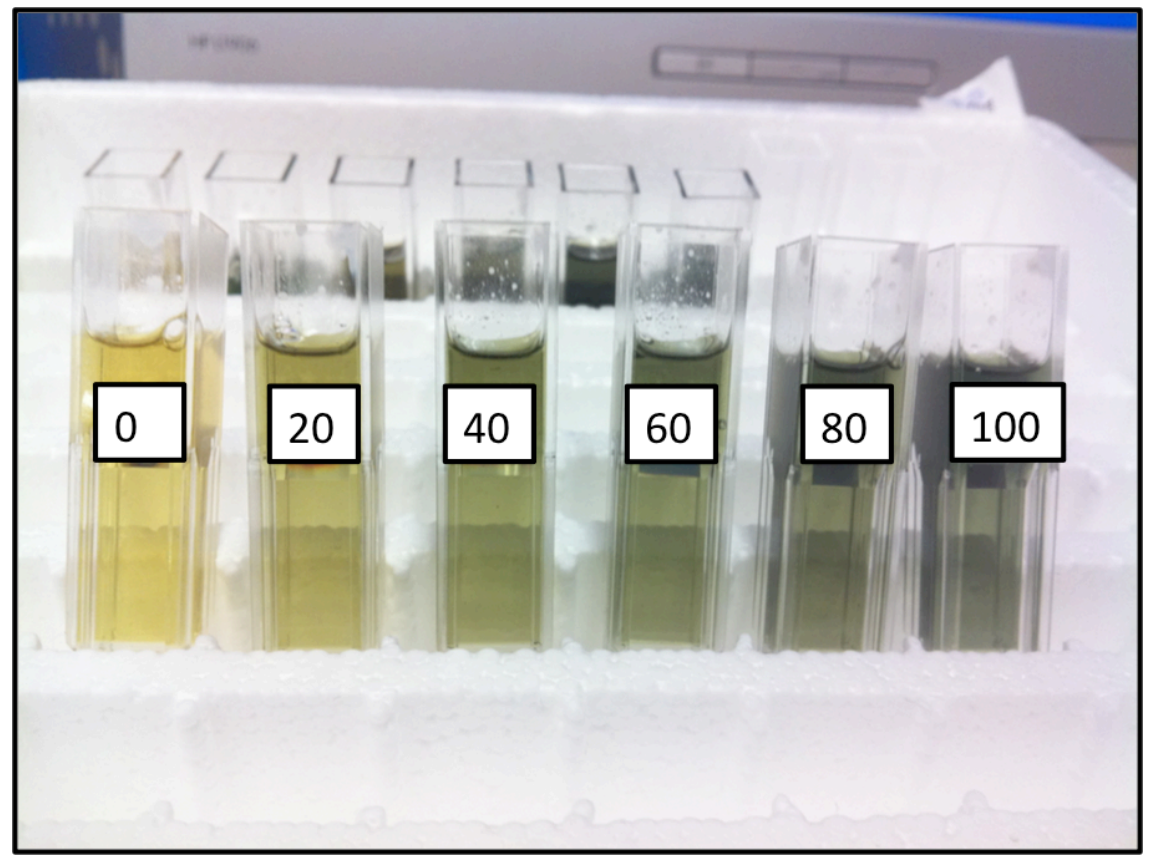

Figure 27. Calibration curve samples of anthrone assay for a glucose concentration range of $0-100 \mathrm{mg} / \mathrm{mL}$ (left to right). 


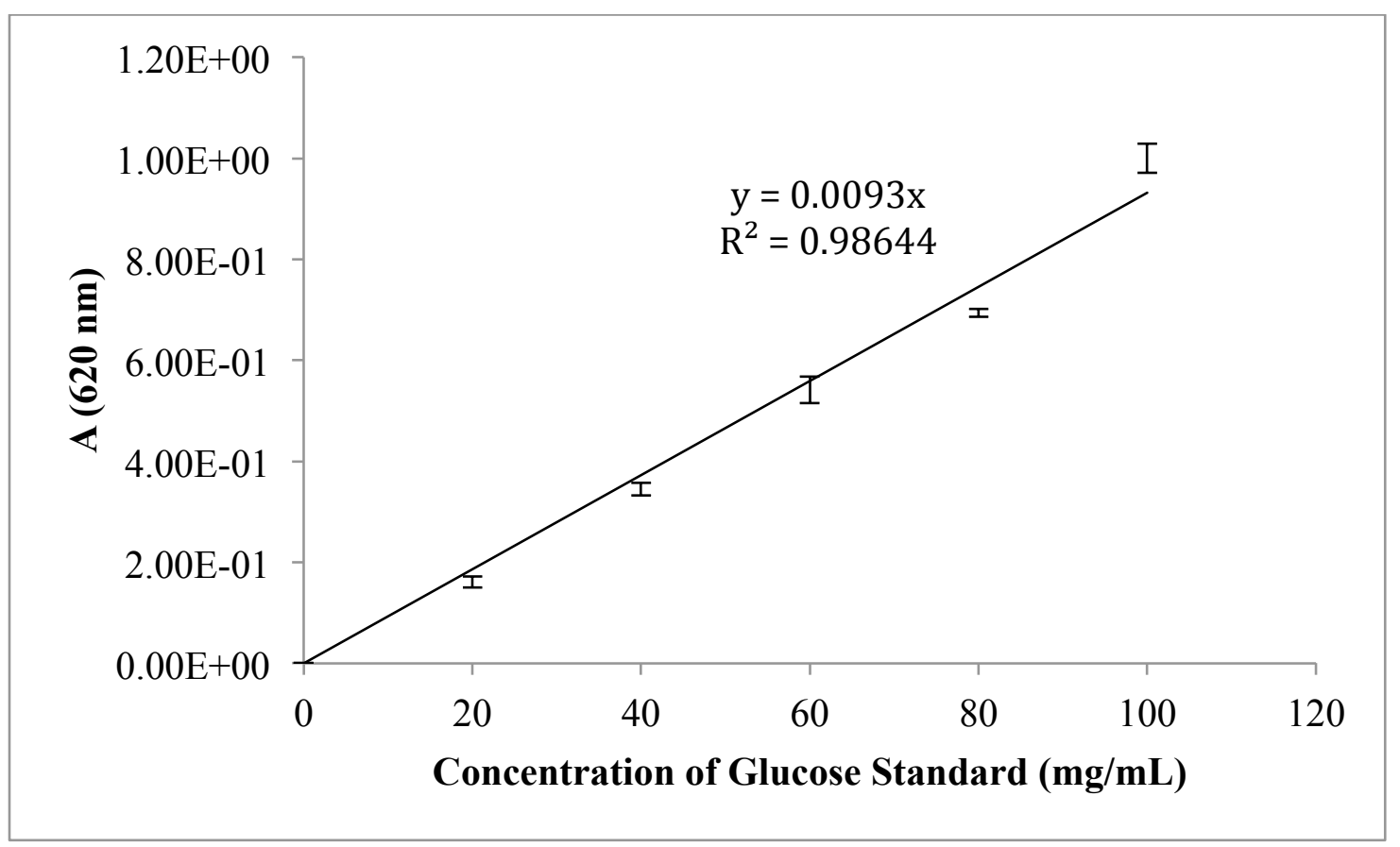

Figure 28. Calibration curve of anthrone carbohydrate assay against glucose standard. 5.3.2 Glycolipid Profile For Encapsulated Bacteria

Shown in Fig. 29 is the mass profile of glycolipid produced by atomized bacteria over time. As can be seen, the glycolipid production stabilized after 7 days, thus confirming the validity of the DOE optimization parameters. The experiment was performed in duplicate $(\mathrm{N}=2)$ starting from an initial cell count of $\mathrm{N}=2.06 \times 10^{7}$, and destructive sampling was employed. An S-Shaped trend is detected with the glycolipid mass being asymptotic at $50 \mathrm{mg}$ between days 6 and 10 days. It could be observed that $80 \%$ of the glycolipid production occurs the first 2 days. 


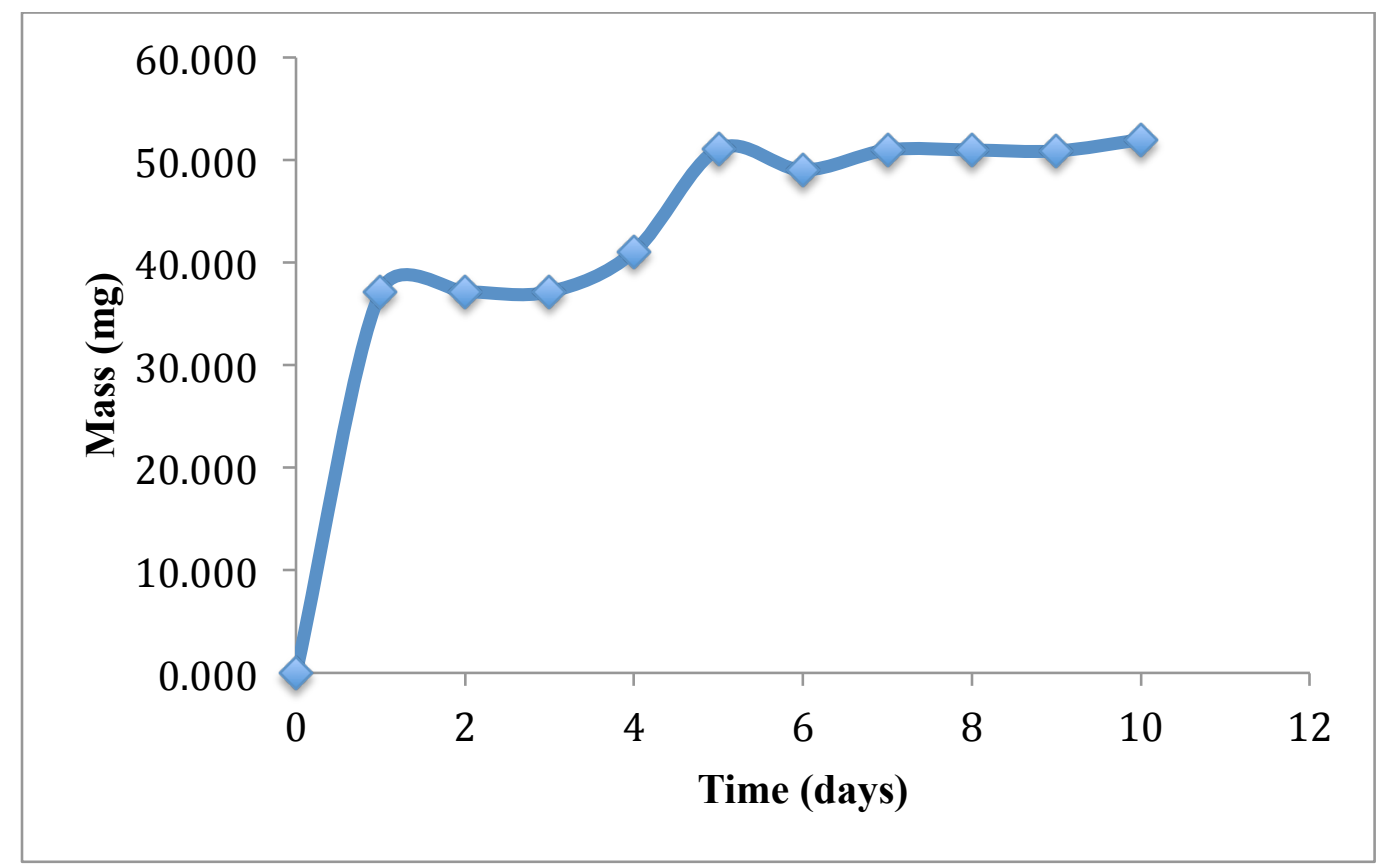

Figure 29. Mass profile of glycolipid for atomized bacteria.

\subsection{Cholesterol Degradation Studies}

As shown in Fig. 30, microcapsules fabricated by atomization had an average diameter of $850 \pm 50 \mu \mathrm{m}$ and had a thickness of $6 \mu \mathrm{m}$. A total of 30 microcapsules were examined to calculate the dimensional statistics. Shown in Fig. 31 are the encapsulated bacteria in culture broth at $4 \mathrm{X}$ magnification. As can be seen, the glycolipid biosurfactant and cholesterol powder adsorbed onto the surface of the alginate capsules. 


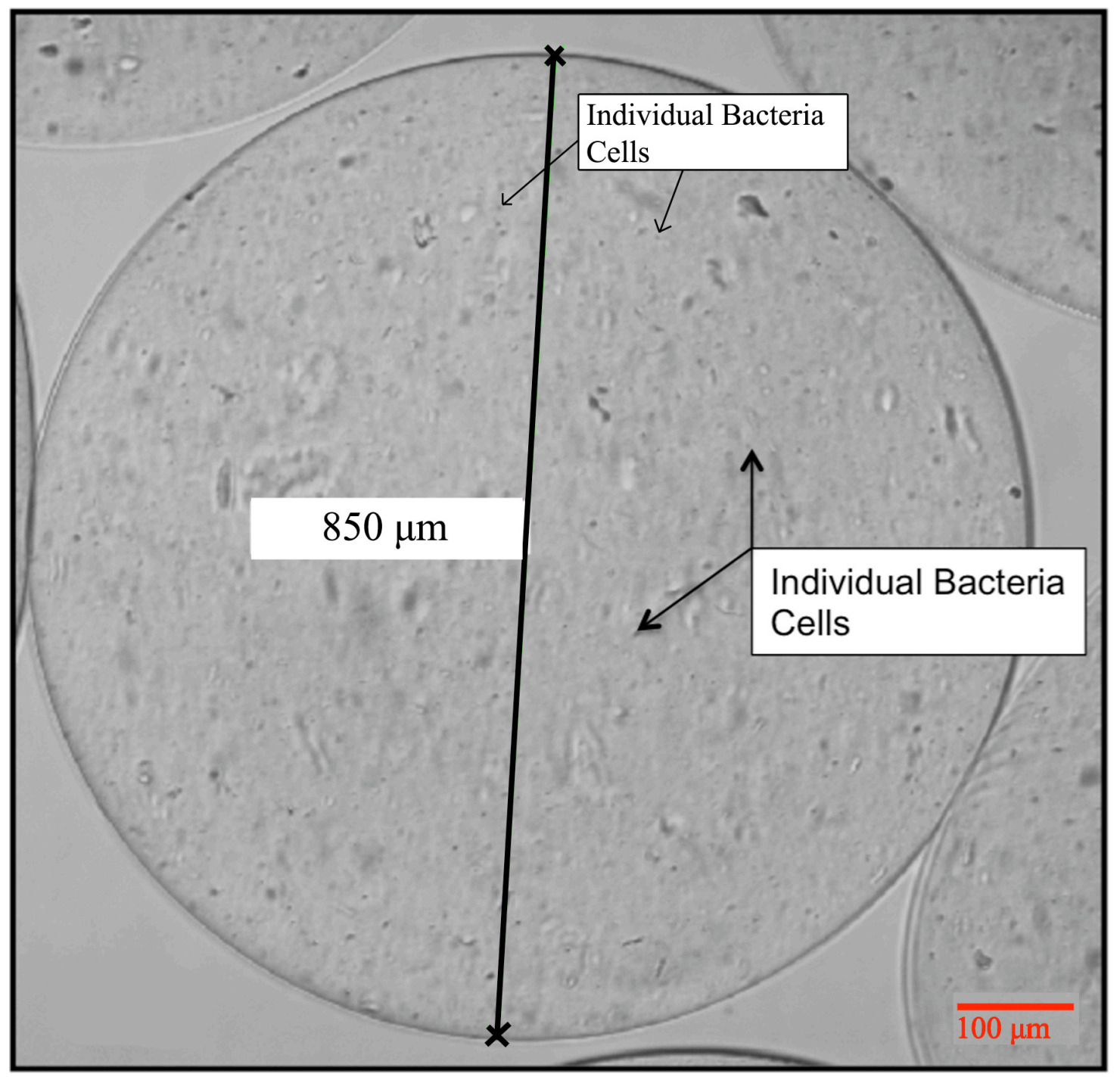

Figure 30. Atomized bacteria (at 10X) used throughout the study (before experiment). 


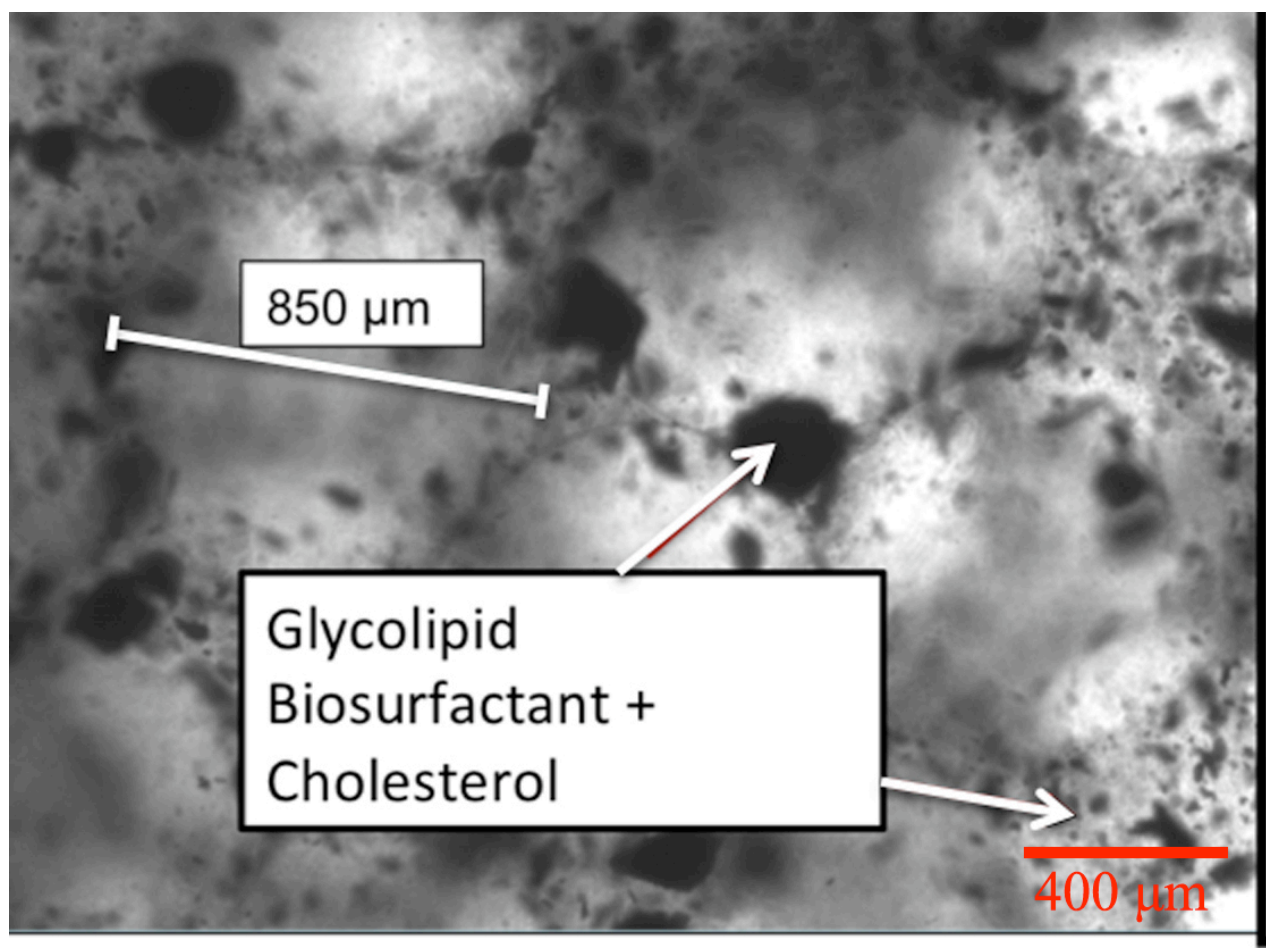

Figure 31. Atomized bacteria (at $4 \mathrm{X}$ ) in culture broth after $\mathrm{t}=8$ days of incubation (before extraction).

Shown in Fig. 32 are the same capsules at 10X magnification from Fig. 31 after treatment with $(2: 1, \mathrm{v} / \mathrm{v})$ chloroform:methanol. As can be seen, the medium is free of glycolipid biosurfactant and cholesterol, and the alginate membranes appear to be intact. Shown in Fig. 33 are the capsules at 20X magnification fabricated by inkjet printing. The capsule diameter was $32 \pm 5 \mu \mathrm{m}$ based on 30 examined capsules. In comparison to the atomized capsules (Fig. 30), a lower bacterial cell density can be observed in the inkjet capsules as presented in Fig. 35. Since the surface area-to-volume ratio increases with miniaturization, a smaller core volume is available for growth. 


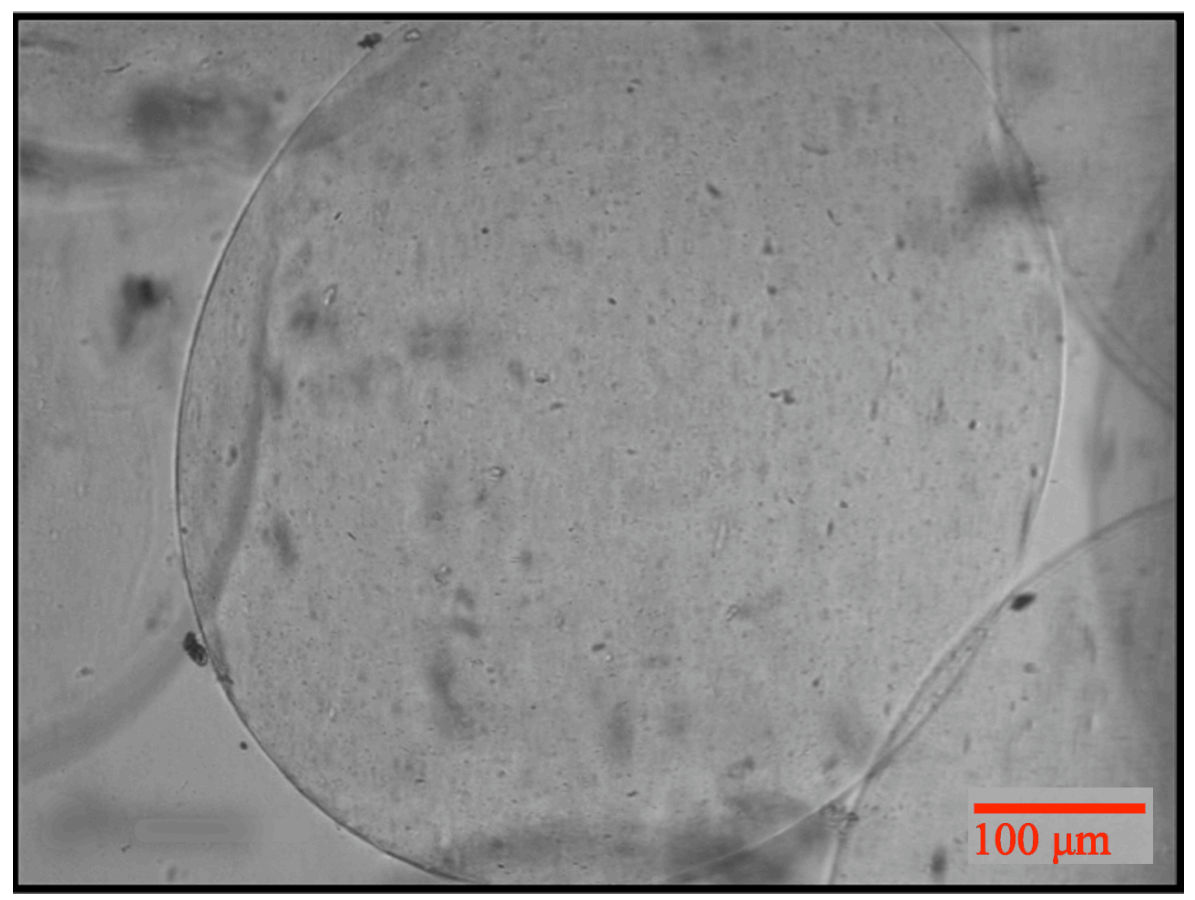

Figure 32. Atomized bacteria (at 10X) after 8 days of incubation (after extraction).

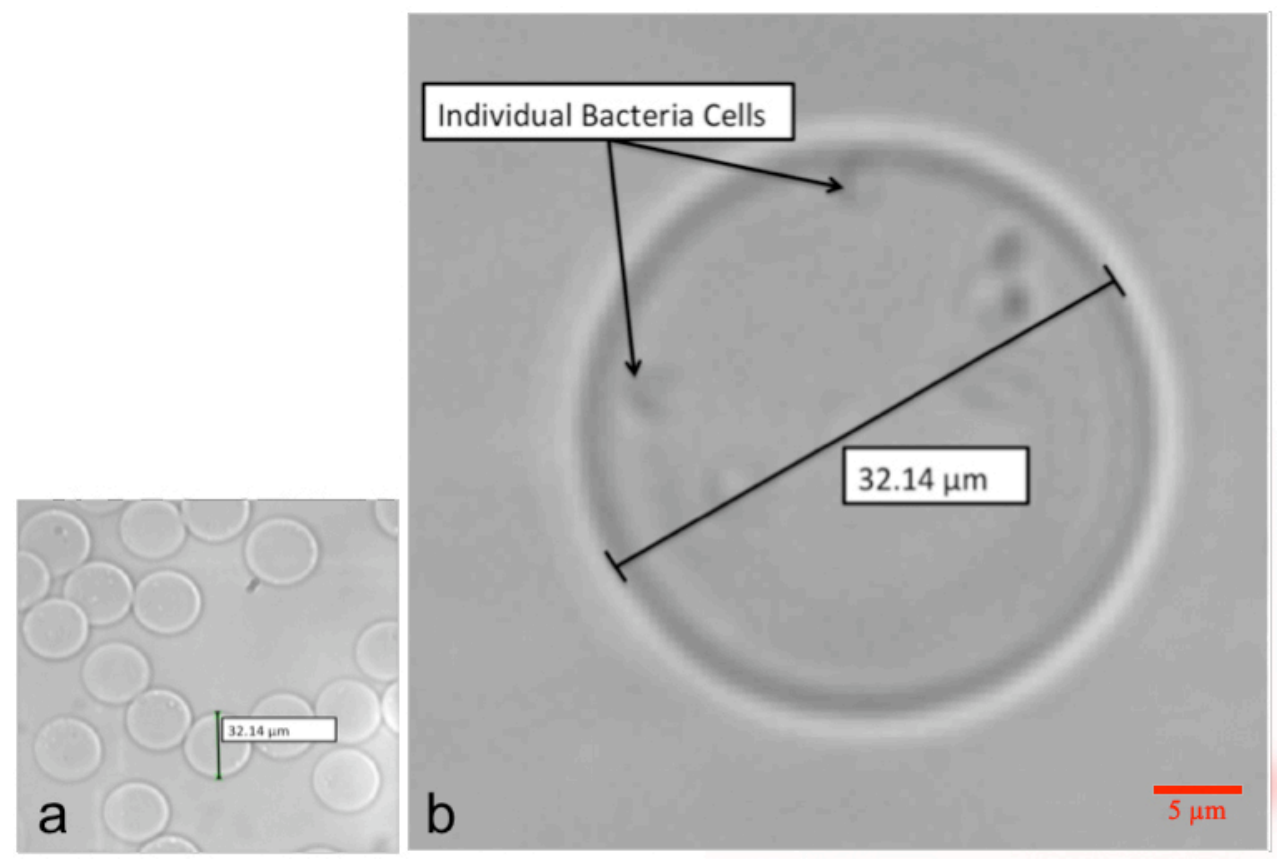

Figure 33. a) Encapsulated bacteria (at 20X) fabricated by way of inkjet printing, b) magnified bacterial cells (at 60X) within miniaturized capsule (individual cells labeled with arrows.) 


\subsubsection{Cholesterol Quantification}

Shown in Fig. 34 is the triplicated calibration curve for the Abcam Cholesterol Quantitation Kit. The correlation of absorbance (A) regressed against the mass of cholesterol $(\mu \mathrm{g})$ is linear and is characterized by the following equation (Eqn. 16):

$$
A_{570 \mathrm{~nm}}=0.2212[\text { Mass of Cholesterol }(\mu \mathrm{g})] \text {. }
$$

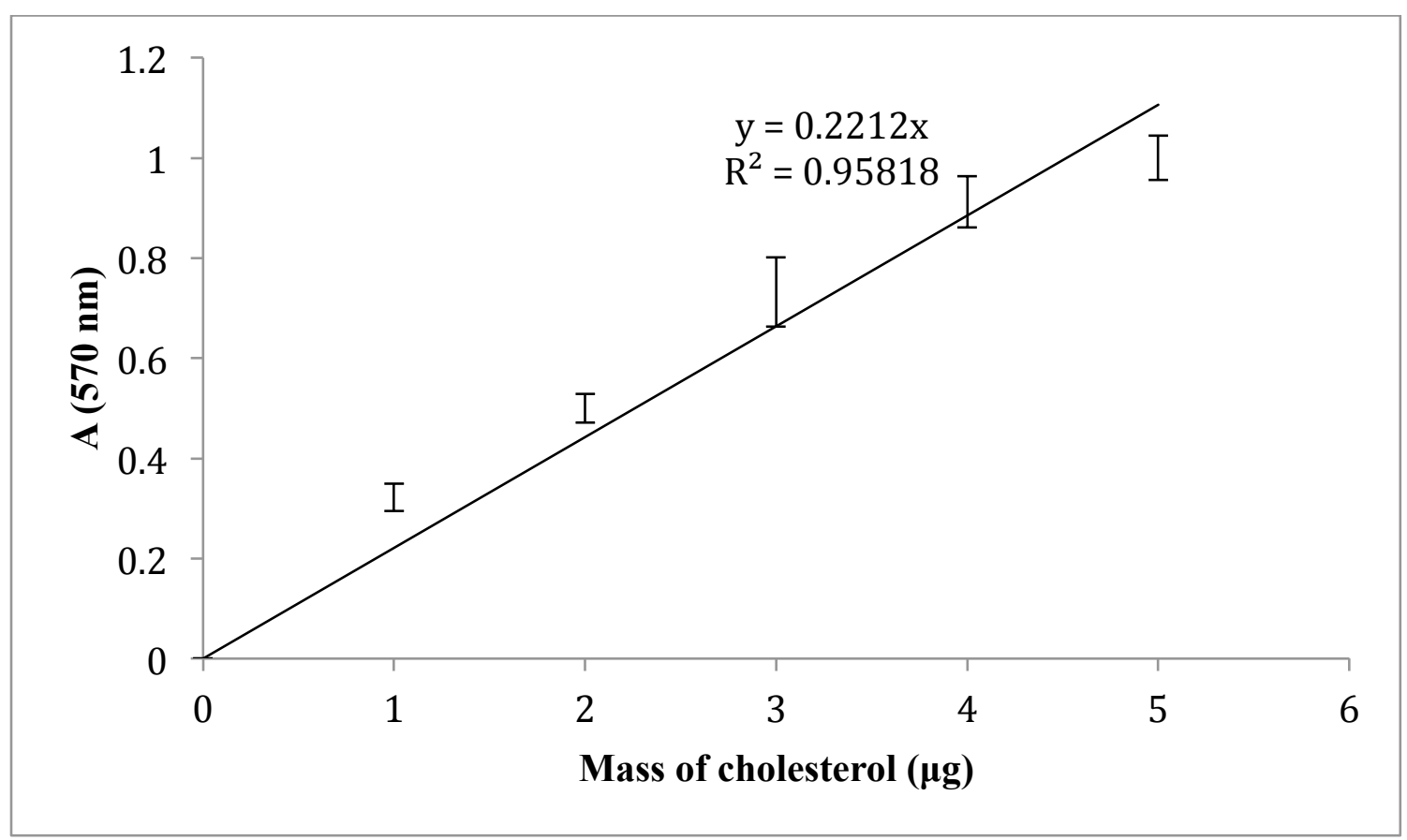

Figure 34. Calibration curve for abcam cholesterol quantitation kit.

\subsubsection{Cholesterol Degradation Profiles}

\subsubsection{Degradation Rate Calculations}

Shown in Fig. 35 is a sample cholesterol degradation rate plot for atomized bacteria for an initial cell count of $\mathrm{N}=4.53 \times 10^{8}$. As mentioned in the Methods section destructive sampling was conducted at days 2, 5 and 8 corresponding to the lag, log and stationary phases of the growth curve presented in Fig 26. Since the bulk of glycolipid growth occurs within the first 2 days according to Fig. 29, for analytical purposes it will 
be assumed that the 0-2 day interval corresponds to the period of free cholesterol diffusion (period 1) through the capsule membrane and the 2-8 day period (period 2) corresponds to the glycolipid-mediated transport period. Although degradation rates for both periods were analyzed, emphasis was placed on the free diffusion period. Furthermore since the Stokes' radius of cholesterol $(\mathrm{a}=0.54 \mathrm{~nm})$ is an order of magnitude smaller than the microcapsules pores $(\mathrm{a}=5 \mathrm{~nm}$ for atomized and $\mathrm{a}=8 \mathrm{~nm}$ for inkjet) (Simpliciano, 2012), diffusion resistance will not be taken into account in rate calculations. The rate equations, kinetic constants (when applicable) and regression coefficients for free and immobilized bacteria are presented in Tables 11 and 12.

Table 11. Degradation rates of cholesterol by free, atomized, and inkjet bacteria for the free diffusion phase at $N_{\text {low }}\left(4.53 \times 10^{8}\right)$.

\begin{tabular}{|c|c|c|c|}
\hline $\begin{array}{c}\text { Bacteria } \\
\text { Immobilization State }\end{array}$ & Free & Atomized & Inkjet \\
\hline Rate Equation & $\begin{array}{c}\mathrm{dC} / \mathrm{dt}= \\
-0.1502[\mathrm{C}]^{0}\end{array}$ & $\begin{array}{c}\mathrm{dC} / \mathrm{dt}= \\
-0.1109[\mathrm{C}]^{0}\end{array}$ & $\begin{array}{c}\mathrm{dC} / \mathrm{dt}= \\
-0.6025[\mathrm{C}]^{0}\end{array}$ \\
\hline $\begin{array}{l}\text { Zero Order Kinetic } \\
\text { Constant }\left(\mathrm{mg} \mathrm{mL}^{-1}\right. \\
\left.\text { day }^{-1}\right)\end{array}$ & 0.1502 & 0.1109 & 0.6025 \\
\hline
\end{tabular}

Table 12. Degradation rates of free, atomized, and inkjet bacteria for the glycolipidmediated transport phase at $N_{\text {low. }}\left(4.53 \times 10^{8}\right)$.

\begin{tabular}{|c|c|c|c|}
\hline $\begin{array}{c}\text { Bacteria } \\
\text { Immobilization } \\
\text { State }\end{array}$ & Free & Atomized & Inkjet \\
\hline Rate Equation & $\begin{array}{c}\mathrm{dC} / \mathrm{dt}= \\
-0.0313[\mathrm{C}]^{0}\end{array}$ & $\begin{array}{c}\mathrm{dC} / \mathrm{dt}= \\
-0.0901[\mathrm{C}]^{0}\end{array}$ & $\begin{array}{c}\mathrm{dC} / \mathrm{dt}= \\
-0.0259[\mathrm{C}]^{0}\end{array}$ \\
\hline $\begin{array}{c}\text { Regression } \\
\text { Coefficient }\end{array}$ & 0.933 & 0.999 & 0.866 \\
\hline
\end{tabular}


Since the profiles for both period were linear by design or regression analysis, the reaction order, $\mathrm{n}$, is equal to zero, thereby rendering them as zero-order equation.

\subsubsection{Effect of Initial Cell Count on Cholesterol Degradation}

Prior to the encapsulation experiments statistical significance testing using a student t-test (Dalgaard, 2008) was conducted on free bacteria to determine the effect of initial cell count on cholesterol degradation. In this case, the null hypothesis $\left(\mathrm{H}_{0}\right)$ was that there is no significant difference between initial free bacteria cell count and amount of cholesterol degraded. The alternate hypothesis $\left(\mathrm{H}_{1}\right)$ was that there would be a difference in cholesterol concentration as cell number was varied. For all t-test studies, $95 \%$ confidence was assumed, thus rendering $\alpha=0.05$. The same followed for the atomized bacteria (Table 13). Metabolite degradation plots at $\mathrm{N}_{\text {low }}\left(4.53 \times 10^{8}\right), \mathrm{N}_{\text {med }}$ $\left(6.90 \times 10^{8}\right)$, and $\mathrm{N}_{\text {high }}\left(1.76 \times 10^{9}\right)$ are presented in Fig. 36 . The reduction in the mass of cholesterol during the $0-2$ day period (period 1) was used to conduct the significance testing. As shown in the graphical trends, more specifically the super-imposition of the plots and results of the significance testing shown in Table 13, the null hypothesis $\left(\mathrm{H}_{0}\right)$ failed to be rejected for all 3 pairwise comparisons because of $p$-values being greater than $\alpha$. 


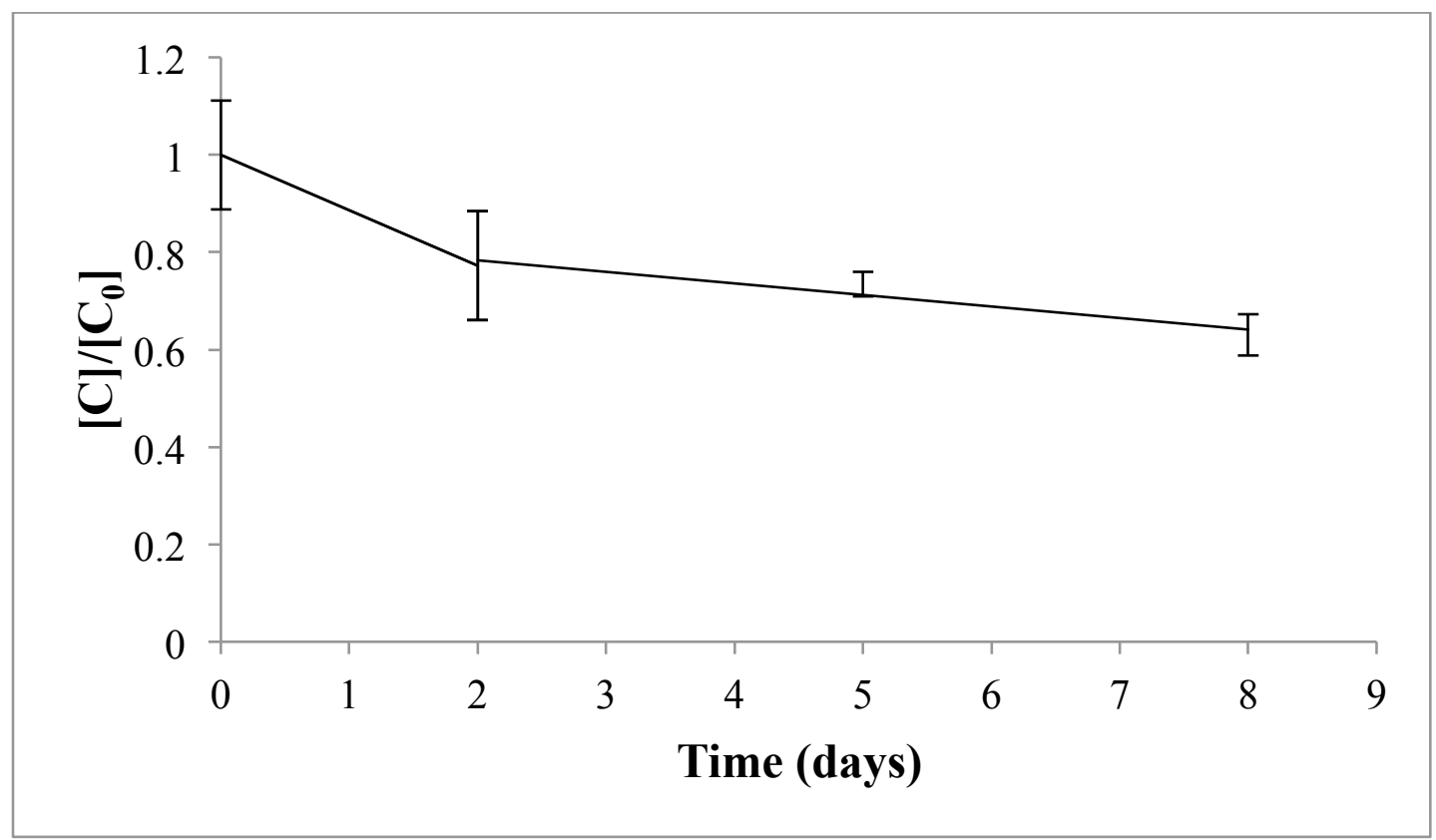

Figure 35. Normalized cholesterol concentration profile as a function of time for free bacteria $\left(\mathrm{N}_{\text {Low }}\right)$.

Table 13. Significance testing summary comparing the effect of cell count to cholesterol degradation for the free bacteria.

\begin{tabular}{|c|c|c|c|}
\hline Scenario & $\begin{array}{c}\mathrm{N}_{\text {low }} \text { Vs. } \\
\mathrm{N}_{\text {med }}\end{array}$ & $\begin{array}{c}\mathrm{N}_{\text {low }} \text { Vs. } \\
\mathrm{N}_{\text {high }}\end{array}$ & $\begin{array}{c}\mathrm{N}_{\text {med }} \text { Vs. } \\
\mathrm{N}_{\text {high }}\end{array}$ \\
\hline$\alpha$ & 0.05 & 0.05 & 0.05 \\
\hline T-value & -0.55 & 0.24 & 1.65 \\
\hline p-value & 0.635 & 0.83 & 0.242 \\
\hline
\end{tabular}

\subsubsection{Cholesterol Degradation for Immobilized Bacteria}

As proven above, since the effect of initial cell count was negligible on cholesterol degradation rate, it was decided to conduct bacterial immobilization at lower cell count to prevent nozzle blockage during the jetting portion of the microencapsulation processes. Metabolite degradation plots at $\mathrm{N}_{\text {low }}\left(4.53 \times 10^{8}\right)$ are presented for the atomized and inkjet-printed bacteria Fig. 36. The profiles can be described by the same 
two regions used to describe free bacteria behavior. The first is delimited by the $0-2$ day and the second by the 2-8 day time periods. The reduction in the mass of cholesterol during period 1 was used to conduct the significance testing between the two types of immobilization methods. The null hypothesis, $\mathrm{H}_{0}$ was that there would be no significant difference in cholesterol removal at day 2 between the atomized and inkjet-immobilized bacteria. The alternate hypothesis, $\mathrm{H}_{1}$, was that there would be a difference in cholesterol removal at day 2 between the atomized and inkjet-immobilized bacteria. As seen in Table 14, the reduction in capsule diameter has a significant effect on cholesterol degradation rate.

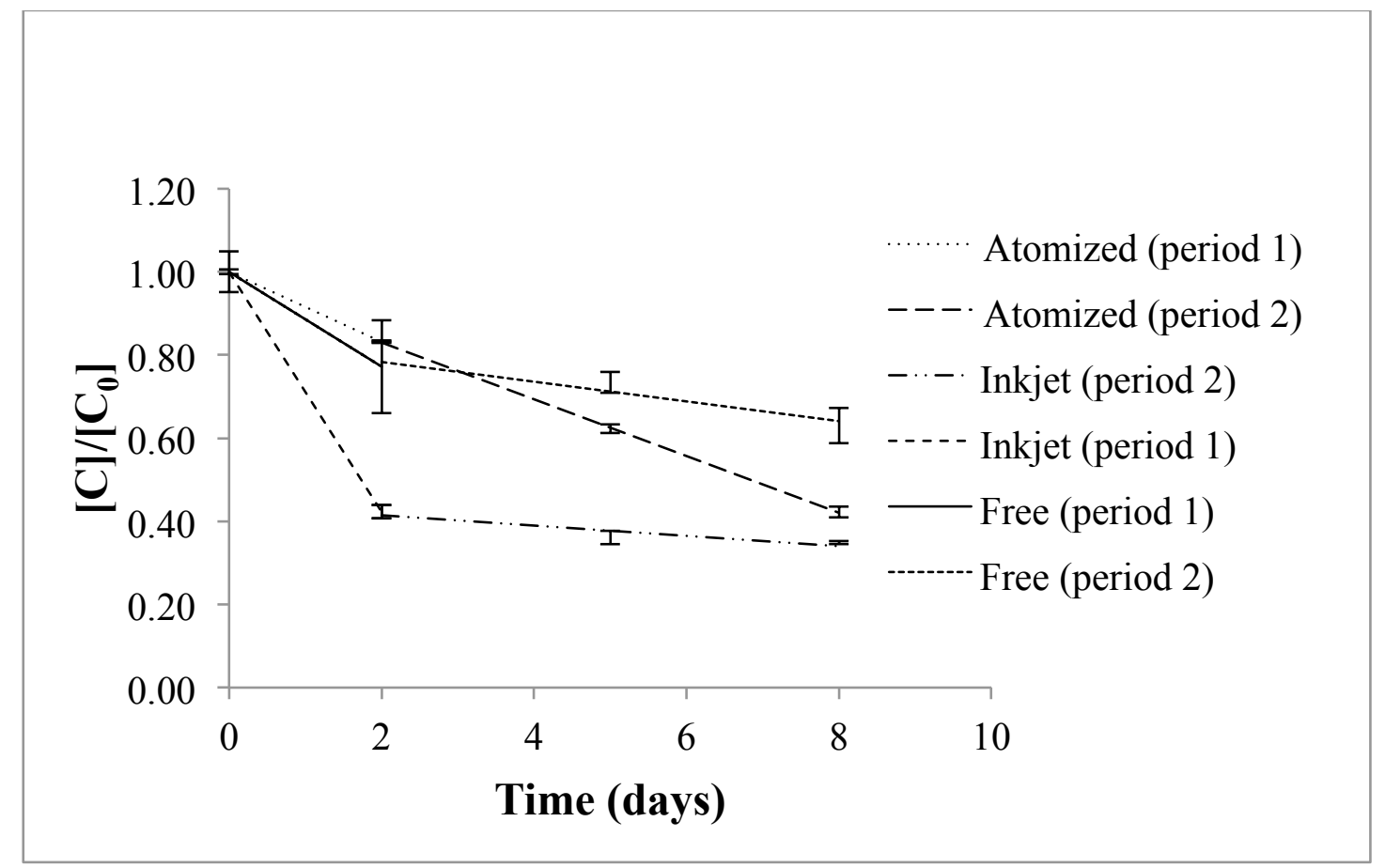

Figure 36. Cholesterol degradation profiles for free and immobilized bacteria as a function of time for $\mathrm{N}_{\text {low }}=4.53 \times 10^{8}$. 
Table 14. Summary of t-test significance testing for the effect of capsule miniaturization on cholesterol degradation rates at $N_{\text {low }}=4.53 \times 10^{8}$.

\begin{tabular}{|c|c|}
\hline Scenario & Atomized vs. Inkjet \\
\hline T-value & 5.9 \\
\hline p-value & 0.028 \\
\hline Accepted Hypothesis & $\mathrm{H}_{1}$ \\
\hline
\end{tabular}

\subsubsection{Synopsis of Cholesterol Degradation Results}

A synopsis of cholesterol degradation results in terms of percent decrease as a function of bacterial immobilization state is presented in Table 15. A monotonous decrease in metabolite was observed for all initial cells counts and immobilization states. Focusing on the low cell count $\left(\mathrm{N}_{\text {low }}\right)$ category, throughout sampling intervals, the percent decrease was greatest for the inkjet-printed bacteria.

Table 15. Percentage degradation of cholesterol mass for free, atomized, and inkjet bacteria in optimized medium.

\begin{tabular}{|c|c|c|c|c|c|}
\hline & \multicolumn{3}{|c|}{ Free Bacteria } & Atomized & Inkjet \\
\hline $\begin{array}{c}\text { Time } \\
\text { (days })\end{array}$ & $\mathrm{N}_{\text {Low }}$ & $\mathrm{N}_{\text {Med }}$ & $\mathrm{N}_{\text {High }}$ & $\mathrm{N}_{\text {Low }}$ & $\mathrm{N}_{\text {Low }}$ \\
\hline 0 & - & - & - & - & - \\
\hline 2 & $22.8 \% \pm 0.62 \%$ & $19.9 \% \pm 0.07 \%$ & $23.6 \% \pm 0.46 \%$ & $16.8 \% \pm 0.19 \%$ & $57.7 \% \pm 0.21 \%$ \\
\hline 5 & $26.6 \% \pm 0.25 \%$ & $39.6 \% \pm 0.65 \%$ & $31.1 \% \pm 0.69 \%$ & $37.8 \% \pm 0.83 \%$ & $63.9 \% \pm 0.15 \%$ \\
\hline 8 & $37.0 \% \pm 0.42 \%$ & $52.0 \% \pm 0.66 \%$ & $54.6 \% \pm 0.41 \%$ & $57.8 \% \pm 0.04 \%$ & $65.1 \% \pm 0.01 \%$ \\
\hline
\end{tabular}

5.4.2.5 Prediction of Cholesterol Removal in Plaque Based on the Current Models

Shown in Table 16 is the estimated percentage of cholesterol removed from plaque within 8 days, assuming that the lesion is composed of $22 \%$ cholesterol (Kaiz, 1976) and that the combined degradation rate equations in Tables 11 and 12 are used in 
Table 16 for the atomized and inkjet bacteria were calculated per $\mathrm{mL}$ of alginate. As can be seen, the inkjet case resulted in the highest degradation of cholesterol in plaque within the 8-day duration.

Table 16. Estimated time to fully degrade cholesterol from intermediate-stage plaque lesion.

\begin{tabular}{|c|c|c|c|c|c|c|c|}
\hline & \multicolumn{3}{|c|}{ Free Bacteria } & \multicolumn{3}{c|}{ Atomized } & Inkjet \\
\cline { 2 - 8 } & $\mathrm{N}_{\text {Low }}$ & $\mathrm{N}_{\text {Med }}$ & $\mathrm{N}_{\text {High }}$ & $\mathrm{N}_{\text {Low }}$ & $\mathrm{N}_{\text {Med }}$ & $\mathrm{N}_{\text {High }}$ & $\mathrm{N}_{\text {Low }}$ \\
\hline $\begin{array}{c}\text { \% Cholesterol } \\
\text { Removed }\end{array}$ & $22.19 \%$ & $34.65 \%$ & $31.23 \%$ & $41.51 \%$ & $32.70 \%$ & $38.53 \%$ & $61.80 \%$ \\
\hline
\end{tabular}

\subsection{Partition Coefficient Determination}

Shown in Table 17 and Fig. 37, are the partition coefficients of cholesterol extracted from water into chloroform according to the scheme in Fig. 5 at various sampling times. Theoretically, the partition coefficient is a constant and should not vary unless a new component is introduced in the mixture or there is a change in $\mathrm{pH}$ or temperature, thus shifting the solubilities (Harrison, 2003). A decrease in $\mathrm{K}$ values is observed for the free and immobilized bacteria as a function of time. Two hypotheses could be formulated to justify this observation: 1) The biosurfactant is amphipathic and thus the cholesterol has adsorbed upon to the bio-surfactant itself and was not stripped off by the chloroform during extraction, and/or, 2) The hydrophobic cholesterol adsorbed to the alginate membrane was not stripped off during the same extraction process. Both hypotheses lead to the presence of residual amounts of solute due non-ideal efficiency of extraction procedures. Since the same monotonous trend is observed in all scenarios, it is safe to attribute the root cause of the $\mathrm{K}$ value decrease to a systematic error. The average 
partition coefficient for the inkjet-immobilized bacteria is lower during the entire sampling interval. This could be due to the presence of chitosan in the immobilized matrix, absent in case of the atomized alginate. The extraction protocol needs to be further optimized to take the presence of this additional bio-polymer coating into account.

Table 17. Average partition coefficients of cholesterol extracted from water into chloroform $(N=3)$.

\begin{tabular}{|c|c|c|c|c|c|}
\hline \multicolumn{7}{|c|}{ Partition Coefficient (K) } \\
\hline $\begin{array}{c}\text { Time } \\
\text { (days) }\end{array}$ & $\begin{array}{c}\mathrm{N}_{\text {Low }} \\
\text { Free }\end{array}$ & $\begin{array}{c}\mathrm{N}_{\text {Low }} \\
\text { Atomized }\end{array}$ & $\begin{array}{c}\mathrm{N}_{\text {Med }} \\
\text { Free }\end{array}$ & $\begin{array}{c}\mathrm{N}_{\text {High }} \\
\text { Free }\end{array}$ & Inkjet \\
\hline 0 & $1.64 \mathrm{E}+01$ & $1.64 \mathrm{E}+01$ & $1.64 \mathrm{E}+01$ & $1.64 \mathrm{E}+01$ & $5.12 \mathrm{E}+00$ \\
\hline 2 & $4.74 \mathrm{E}+00$ & $6.10 \mathrm{E}+00$ & $5.34 \mathrm{E}+00$ & $4.58 \mathrm{E}+00$ & $3.20 \mathrm{E}+00$ \\
\hline 5 & $4.08 \mathrm{E}+00$ & $2.70 \mathrm{E}+00$ & $2.53 \mathrm{E}+00$ & $3.43 \mathrm{E}+00$ & $2.25 \mathrm{E}+00$ \\
\hline 8 & $2.78 \mathrm{E}+00$ & $1.32 \mathrm{E}+00$ & $1.63 \mathrm{E}+00$ & $1.49 \mathrm{E}+00$ & $2.11 \mathrm{E}+00$ \\
\hline
\end{tabular}

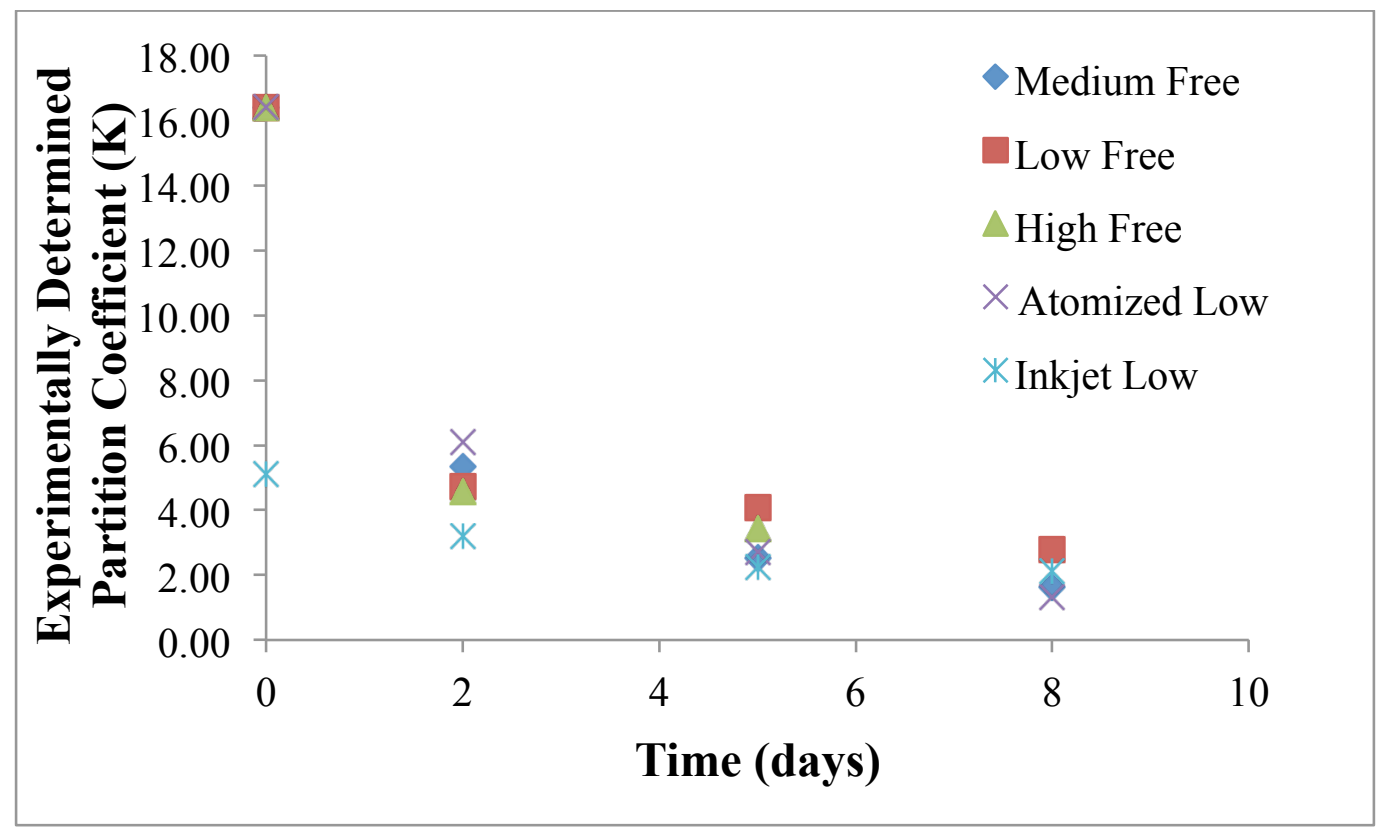

Figure 37. Experimentally determined partition coefficient of cholesterol extracted from water into chloroform. 


\subsection{DISCUSSION}

The studies from the literature that compared most closely with this study were those of Goetschel, et al and Bianchi, et al. Goetschel, et al, reported a 33\% degradation of cholesterol in $24 \mathrm{~h}$ in aqueous medium by free bacteria. Bianchi, et al reported that free and chitin-encapsulated $R$. erythropolis converted nearly all and $97 \%$ of total cholesterol, respectively, within 3 days.

The percentage degradation data reported in Table 15 for the first $48 \mathrm{~h}$ were slightly lower but not significantly different from the 33\% reported by Goetschel, et al. The percentage degradation reported by Bianchi, et al, however, was much greater than that of the data reported in this study. Several factors may have contributed to these differences. The first thing to note is that Bianchi, et al did not specify the initial amount of cholesterol that they used. Assuming the rate of cholesterol degradation did not change with the amount of cholesterol present within the system, if a small initial amount of cholesterol was used, less time would be required for it to be degraded. Second, Bianchi, et al used a BHI growth medium, whereas LB Broth, PBS, and BSA were used in this study. Hence, growth characteristics were expected to be different. Changes in growth characteristics would include differences in the enzyme production and cell survivability. Perhaps, the most important thing to consider is that the optimized medium in this study was designed to decrease the amount of biosurfactant being produced. Since the biosurfactant is amphipathic, it is possible that it played a role in cholesterol degradation. With regards to the case of encapsulated bacteria, Bianchi, et al worked 
with chitin polymer as opposed to Ca-alginate, which was used in this study. Hence, there is no baseline from which a conclusion may be reached.

Prior to the bio-surfactant minimization efforts, it was initially hypothesized that cholesterol diffusion could be described using Fick's Second Law of Diffusion. However, due to bio-surfactant growth the extent of diffusive and kinetic mechanisms contributing to cholesterol degradation was considered as a lump degradation mechanism. It is possible that the biosurfactant may have aided in some type of cotransport mechanism whereby hydrophobic cholesterol was physically transported from the medium into the capsule where it could have been degraded by bacteria. More studies would need to be conducted in order to understand the interaction of biosurfactant with cholesterol degradation. Due to the enhanced metabolic capability of the miniaturized inkjet capsules immobilizing the bacteria, the above-stated hypothesis is partially validated. This observation is in alignment with the results of a recent study on fluorescent MW markers demonstration a 4-fold diffusivity increase across miniaturized alginate beads (Mobed-Miremadi, 2012).

The following hypotheses justifying the higher degradation rates for the bacteria immobilized using the inkjet process could be formulated:

i. The $\mathrm{S} / \mathrm{V}$ ratio of inkjet bacteria was 26 times higher than that of the atomized bacteria; ii. Hydrophobic cholesterol adsorbs onto the surface of the capsules;

iii. The pore size range for both capsules has been measured to be approximately $6 \mathrm{~nm}$. The Stoke's radius of cholesterol is a $=0.54 \mathrm{~nm}$, hence the metabolite can freely diffuse. 
iv. The presence of the chitosan membrane may have also had some interaction with the cholesterol, which would require further investigation.

Cholesterol degradation using the low bacterial cell count condition during the lag phase may have mostly occurred by way of the intracellular enzyme from $t=0$ to $t=5$ days. It is likely that by the time the last measurement was taken at $\mathrm{t}=8$ days, the bacteria were beginning to produce the extracellular enzyme. Encapsulating bacteria harvested from the plateau phase by way of inkjet bioprinting followed by a cholesterol degradation study would confirm this hypothesis. Furthermore, the molecular weight of the cholesterol oxidase enzyme is below the molecular weight cut-off of alginate, which is approximately $70 \mathrm{kDa}$, so it is possible that the extracellular enzyme had diffused out of the capsules and degraded cholesterol in the medium. More studies would need to be conducted in order to confirm this postulated hypothesis. 


\subsection{POSSIBLE CONTRIBUTIONS TO KNOWLEDGE}

- The composition of bacteria growth medium was optimized in order to minimize the production of biosurfactant. Without this optimization, the cholesterol degradation studies would have been hindered.

- To date, the only membranes used to encapsulate $R$. erythropolis (ATCC 25544) were chitin and liposomes as compared to Ca-alginate, which was used in this study. Studies of cholesterol degradation with encapsulated bacteria have not been characterized for the case of miniaturization, which has been proven to be the most effective alternative for medical applications.

- One of the major feats of this research was overcoming the hydrophobic nature of the cholesterol powder suspended in the aqueous medium. It was the hydrophobicity of the cholesterol that necessitated the use of destructive sampling throughout experimentation. Custom extraction layer identification and protocols have been developed. 


\subsection{CONCLUSIONS AND FUTURE WORK}

\subsection{Conclusion}

Initially, bacterial cell growth was hindered due to biosurfactant production as a metabolic by-product. The constituents of the growth medium were optimized using an $\mathrm{L}_{16}$ Taguchi design in order to minimize the production of biosurfactant with the intention of characterizing growth data for free and atomized bacteria. The validity of the biosurfactant minimization efforts was proven by the stabilization of the amount of trehalose-glycolipid produced, measured post-optimization, in conjunction with the growth curves.

Detailed extraction methods were developed for cholesterol and biosurfactant from free and encapsulated bacteria systems. Simple extraction by use of $(2: 1, \mathrm{v} / \mathrm{v})$ chloroform:methanol mixture resulted in biphasic separation through which cholesterol and biosurfactant were chemically separated and subsequently quantified using colorimetric methods. By overcoming the challenge of the hydrophobicity of cholesterol characterization in aqueous media, the colorimetric quantification of cholesterol was made possible.

It was empirically shown that there was no significant difference in cholesterol degradation rate as cell number was varied. It was also empirically shown that cell number did not have a significant effect on cholesterol degradation rate for immobilized bacteria. It was shown that the highest cholesterol degradation rate was obtained using lag phase bacteria immobilized by inkjet bioprinting. 


\subsection{Future Work}

A recommended future step for this research study would be to increase the sampling frequency to between 0 and 2 days in order to obtain a better understanding of the cholesterol degradation profile. Furthermore, the study could be advanced through the genetic engineering of the bacterium in order to accelerate the cholesterol degradation rate by way of transfecting mammalian stem cells.

Another suggested area of study would be the examination of interaction(s) between cholesterol and biosurfactant in order to confirm the presence of co-transport

mechanisms. Mathematical models could then be derived for co-transport mechanisms of various substances by biosurfactants.

Also, the use of more sensitive measurement methodologies should be considered to obtain more accurate metabolite degradation rates. One such example would be to quantify the amount of 4-cholesten-3-one using gas chromatography and mass spectrometry (GC-MS) techniques in order to confirm the extent of cholesterol conversion. 


\section{REFERENCES}

1. Moses, J., et al. The SIRIUS-DIRECT Trial: A Multi-Center Study of Direct Stenting Using the Sirolimus-Eluting Stent in Patients With De Novo Native Coronary Artery Lesions, Catheter Cardiovasc. Interv., 2007, 70, 505-512.

2. Fontos, G. Drug eluting coronary stents, Orv. Hetil., 2006, 147, 2059-2066.

3. Sutton, A.G.C., et al. One year results of the Middlesborough early revascularization to limit infarction (MERLIN) trial, Heart (British Cardiac Society), 2005, 91, 1330-1337.

4. Arjomand, H., et al. Percutaneous coronary intervention: historical perspectives, current status, and future direction, Am. Heart J., 2003, 146, 787-796.

5. Jenkins, N.P., et al. Drug eluting coronary stents, BMJ, 2002, 325, 1315-1316.

6. Bitl, J.A., et al. Coronary-Stent placement compared with balloon angioplasty, $N$. Engl. J. Med., 1995, 332, 536-538.

7. Serruys, P.W., et al. A comparison of balloon-expandable stent implantation with balloon angioplasty in patients with coronary artery disease, N. Engl. J. Med., 1994, 331, 489-495.

8. Rosamund, W.D., et al. Trends in the Incidence of Myocardial Infarction and in Mortality Due to Coronary Heart Disease, 1987 to 1994, N. Eng. J. Med., 1998, 339, 861-867.

9. Murray, C.J.L., and Lopez, A.D. Mortality by cause for eight regions of the world: Global Burden of Disease Study, Lancet, 1997, 349, 1269-1276.

10. Jain, K.S., et al. The biology and chemistry of hyperlipidemia, Bioorganic \& Medicinal Chemistry, 2007, 15, 4674-4699.

11. McGill, H.C., and Strong, J.P. Geographical Pathology of Atherosclerosis, Annals of the New York Academy of Sciences, 1968, 149, 923-927.

12. American Heart Association. Heart and Stroke Statistical Update [Online]. http://www.americanheart.org/statistics (Accessed 10 Jun 2010).

13. Yusuf, S., et al. Effect of Potentially Modifiable Risk Factors Associated with Myocardial Infarction in 52 Countries (The INTERHEART Study): Case-Control Study, Lancet, 2004, 364, 937-952. 
14. George, S.J., and Johnson, J. Atherosclerosis: Molecular and Cellular Mechanisms, Wiley-Blackwell, Bristol, UK, 2010, pp 1-14.

15. du Souich, P., et al. The IUPHAR Compendium of Basic Principles For Pharmacological Research in Humans, IUPHAR, Irvine, CA, 2004, pp 119.

16. WHO. Cardiovascular Disease Fact sheet $\mathrm{N}^{\circ} 317$ [Online]. http://www.who.int/mediacentre/factsheets/fs317/en/print.html (Accessed 19 May 2010).

17. Hearing on Gainsharing, Hearing Before the Subcommittee on Health, Committee on Ways and Means. U.S. House of Representatives, $109^{\text {th }}$ Congress, $1^{\text {st }}$ session [Online]. http://www.gpo.gov/fdsys/pkg/CRPT109hrpt736/html/CRPT-109hrpt736.htm (Accessed 10 Dec 2010).

18. Ong, A.T.L., et al. Sirolimus-Eluting Stents Remain Superior to Bare-Metal Stents at Two Years, Journal of the American College of Cardiology, 2006, 47, 1356-1360.

19. Maisel, W.H. Unanswered questions - drug-eluting stents and the risk of late thrombosis, N. Engl. J. Med., 2007, 356, 981-984.

20. Mensah, G., and Brown, D. An overview of cardiovascular disease burden in the United States, Health Aff, 2007, 26, 38-48.

21. Bischof, M., et al. Cost-Effectiveness of Drug-Eluting Stents in a US Medicare Setting, A Cost-Utility Analysis with 3-Year Clinical Follow-Up Data, Value in Health, 2009, 12, 649-656.

22. Ross, R., and Glomset, J.A. The Pathogenesis of Atherosclerosis, N. Engl. J. Med., 1976, 295, 369-377.

23. Brown, M.S., and Goldstein, J.L. Lipoprotein Metabolism in the Macrophage: Implications for Cholesterol Deposition in Atherosclerosis, Ann. Review Biochem, 1983, 52, 223-261.

24. Moubayed, S.P., et al. Anti-inflammatory drugs and atherosclerosis, Current Opinion in Lipidology, 2007, 18, 638-644.

25. Imhof, B.A., and Aurrand-Lions, M. Adhesion mechanisms regulating the migration of monocytes, Nat. Rev. Immunol., 2004, 4, 432-444.

26. Ley, K., et al. Getting to the site of inflammation: the leukocyte adhesion cascade updated, Nat. Rev. Immunol., 2007, 7, 678-689. 
27. Woollard, K.J., and Geissmann, F. Monocytes in atherosclerosis: subsets and functions, Nature, 2010, 7, 77-86.

28. Tacke, F., and Randolph, G.J. Migratory fate and differentiation of blood monocyte subsets, Immunobiology, 2006, 211, 609-618.

29. Varol, C., et al. Origins and tissue-context-dependent fates of blood monocytes, Immunol. Cell Biol., 2009, 87, 30-38.

30. Goldstein, J.L., et al. Binding site on macrophages that mediates uptake and degradation of acetylated low density lipoprotein, producing massive cholesterol deposition, Proc. Natl. Acad. Sci. USA, 1979, 76, 333-337.

31. Basu, S.K., et al. Degradation of low density lipoprotein-dextran sulfate complexes associated with deposition of cholesteryl esters in mouse macrophages, J. BioI. Chem., 1979, 254, 7141-7146.

32. Goldstein, J.L., et al. Cholesteryl ester accumulation in macrophages resulting from receptor-mediated uptake and degradation of hypercholesterolemic canine bvery low density lipoproteins, J. Biol. Chem., 1980, 255, 1839-1848.

33. Goldstein, J.L., et al. Stimulation of cholesteryl ester synthesis in macrophages by extracts of atherosclerotic human aortas and complexes of albumin/cholesteryl esters. Arteriosclerosis, 1981, 1, 210 -226.

34. Greaves, D.R., and Gordon, S. The macrophage scavenger receptor at 30 years of age: current knowledge and future challenges, J. Lipid Res., 2009, 50, S282-S286.

35. Brown, M.S., et al. Cholesterol ester cycle in macrophage foam cells, J. BioI. Chem., 1980, 255, 9344-9352.

36. Galkina, E., and Ley, K. Immune and inflammatory mechanisms of atherosclerosis, Annu. Rev. Immunol., 2009, 27, 165-197.

37. Hahn, C., and Schwartz, M.A. Mechanotransduction in vascular physiology and atherogenesis, Nat. Rev. Mol. Cell Biol., 2009, 10, 53-62.

38. Fuster, V., et al. Atherothrombosis and high-risk plaque: part I: evolving concepts, J. Am. Coll.Cardiol., 2005, 46, 937-954.

39. The Heart and Vascular Institute of Florida. The various phases of atherosclerosis [Online]. http://www.hvif.com/angina.asp (Accessed 10 Dec 2010). 
40. Athyros, V.G., et al. Pleiotropic Effects of Statins - Clinical Evidence, Current Pharmaceutical Design, 2009, 15, 479-489.

41. Schouten, O., et al. Effect of statin withdrawal on frequency of cardiac events after vascular surgery, Am. J. Cardiol., 2007, 100, 316-320.

42. Ernst, E. Chelation therapy for coronary heart disease: An overview of all clinical investigations, Am. Heart J., 2000, 140, 139-141.

43. Ernst, E. Chelation therapy for peripheral arterial occlusive disease: a systematic review. Circulation, 1997, 96, 1031-1033.

44. Lewin, M.R. Chelation therapy for cardiovascular disease. Review and commentary, Tex. Heart Inst. J., 1997, 24, 81-89.

45. Knudtson, M.L., et al. Chelation therapy for ischemic heart disease: a randomized controlled trial, JAMA, 2002, 287, 481-486.

46. Lamas, G.A., and Ackermann, A. Clinical evaluation of chelation therapy: is there any wheat amidst the chaff? Am. Heart J., 2000, 140, 4-5.

47. Camenzind, E., et al. Stent thrombosis late after implantation of first-generation drug-eluting stents: a cause for concern, Circulation, 2007, 115, 1440-1455.

48. Pfisterer, M., et al. Late clinical events after clopidogrel discontinuation may limit the benefit of drug-eluting stents: an observational study of drug-eluting versus bare-metal stents, J. Am. Coll. Cardiol., 2006, 48, 2584-2591.

49. Tsimikas, S. Drug-eluting stents and late adverse clinical outcomes lessons learned, lessons awaited, J. Am. Coll. Cardiol., 2006, 47, 2112-2115.

50. Rajagopal, V., and Rockson, S.G. Coronary Restenosis: A Review of Mechanisms and Management, The American Journal of Medicine, 2003, 115, 547-553.

51. Glagov, S., et al. Compensatory enlargement of human atherosclerotic coronary arteries, N. Engl. J. Med., 1987, 316, 1371-1375.

52. Pakala, R., et al. Effect of serotonin, thromboxane A2, and specific receptor antagonists on vascular smooth muscle cell proliferation, Circulation, 1997, 96, 2280-2286.

53. Dorn II, G.W. Role of thromboxane A2 in mitogenesis of vascular smooth muscle cells, Agents Actions Suppl., 1997, 48, 42-62. 
54. Doyle, B., and Holmes, D.R. Next generation drug-eluting stents: focus on bioabsorbable platforms and polymers, Medical Devices: Evidence and Research, 2009, 2, 47-55.

55. Joner, M., et al. Pathology of drug-eluting stents in humans: delayed healing and late thrombotic risk, J. Am. Coll. Cardiol., 2006, 48, 193-202.

56. John, M.C., et al. Differential healing responses in polymer- and nonpolymerbased sirolimus-eluting stents, JACC Cardiovas.c Interv., 2008, 1, 535-544.

57. Virmani, R., et al. Localized hypersensitivity and late coronary thrombosis secondary to a sirolimus-eluting stent: should we be cautious? Circulation, 2004, 109, 701-705.

58. Carter, A.J., et al. Long-term effects of polymer-based, slow-release, sirolimuseluting stents in a porcine coronary model, Cardiovasc. Res., 2004, 63, 617-624.

59. Finn, A.V., et al. Differential response of delayed healing and persistent inflammation at sites of overlapping sirolimus- or paclitaxel-eluting stents, Circulation, 2005, 112, 270-278.

60. Hoye, A., et al. Long-term outcomes after stenting of bifurcation lesions with the "crush" technique: predictors of an adverse outcome, J. Am. Coll. Cardiol., 2006, 47, 1949-1958.

61. Kuchulakanti, P.K., et al. Correlates and long-term outcomes of angiographically proven stent thrombosis with sirolimus- and paclitaxel-eluting stents, Circulation, 2006, 113, 1108-1113.

62. Takano, M., et al. Angioscopic differences in neointimal coverage and in persistence of thrombus between sirolimus-eluting stents and bare metal stents after a 6-month implantation, Eur. Heart J., 2006, 27, 2189-2195.

63. Byrne, R.A., et al. A polymer-free dual drug-eluting stent in patients with coronary artery disease: a randomized trial vs polymer-based drug-eluting stents, Eur. Heart J., 2009, 30, 923-931.

64. Finn, A.V., et al. Vascular responses to drug eluting stents: importance of delayed healing, Arterioscler. Thromb. Vasc. Biol., 2007, 27, 1500-1510.

65. American Type Culture Collection. Bacteria and Phages [Online]. http://www.atcc.org (Accessed 10 Dec. 2010). 
66. Franzetti, A., et al. Production and applications of trehalose lipid biosurfactants, Eur. J. Lipid Sci. Technol., 2010, 112, 617-627.

67. Li, Y.Z., et al. Formation And Identification Of Interfacial-Active Glycolipids From Resting Microbial Cells Of Athrobacter Sp. And Potential Use In Tertiary Oil Recovery, Appl. Environ. Microbiol., 1984, 48, 610-617.

68. Rapp, P., et al. Formation, Isolation And Characterization Of Trehalose Dimycolates From Rhodococcus erythropolis Grown On n-alkanes, J. Gen. Microbiol., 1979, 115, 491-503.

69. Kretschmer, A., et al. Chemical And Physical Characterization Of Interfacial Active Lipids from Rhodococcus erythropolis Grown on n-alkane, Appl. Environ. Microbiol., 1982, 44, 864-870.

70. Sojo, M., et al. Cell-linked and extracellular cholesterol oxidase activities from Rhodococcus erythropolis. Isolation and physiological characterization, Appl. Microbiol. Biotechnol., 1997, 47, 583-589.

71. Kreit J, et al. Cholesterol oxidase: physiological functions. FEBS Journal, 2009, 276, 6844-6856.

72. Wilmanska D, et al. The kinetics of biosynthesis and some properties of an extracellular cholesterol oxidase produced by Arthrobacter sp. IM 79, Acta Microbiol. Polon., 1988, 37, 45-51.

73. Shirokane Y, et al. Purification and some properties of an extracellular 3hydroxysteroid oxidase produced by Corynebacterium cholesterolicum, Journal of Fermentation Technology, 1977, 55, 337-345.

74. Richmond W. Preparation and properties of a bacterial cholesterol oxidase from Nocardia sp. and its application to enzyme assay of total cholesterol in serum, Clin. Chem., 1973, 19, 1350-1356.

75. Atrat PG, et al. Localization of the cholesterol oxidase in Rhodococcus erythropolis IMET 7185 studied by immunoelectron microscopy, J. Steroid Biochem. Mol. Biol., 1992, 42, 193-200.

76. Buckland BC, et al. The kinetics of cholesterol oxidase synthesis by Nocardia rhodochrous. Biotech. and Bioeng., 1976, 18, 601-621.

77. Aihara $\mathrm{H}$, et al. Characterization of production of cholesterol oxidases in three Rhodococcus strains. J. Appl. Bacteriol., 1986, 61, 269. 
78. Cheetham PSJ, et al. Extraction of cholesterol oxidase from Nocardia rhodochrous. Enzyme Microbiol. Technol., 1980, 2, 201-205.

79. Cheetham PSJ, et al. The characterization and interconversion of three forms of cholesterol oxidase extracted from Nocardia rhodochrous, Biochem. J., 1982, 201, 512-521.

80. Cheetham PSJ. The identification properties and immobilisation of the 3hydroxysteroid oxidase and 3-oxosteroid $\Delta^{4}-\Delta^{5}$-isomerase components of cholesterol oxidase from Nocardia rhodochrous, J. Appl. Biochem., 1979, 1, 51.

81. Minuth $\mathrm{T}$, et al. A closed concept for the purification of the membrane bound cholesterol oxidase from Nocardia rhodochrous by surfactant-based, $J$.

Biotechnol., 1995, 38, 151-164

82. Schatz A, et al. The ability of soil microorganisms to decompose steroids, $J$. Bacteriol., 1949, 58, 117-125.

83. Smith M, et al. Growth and cholesterol oxidation by Mycobacterium species in Tween 80 medium, Appl. Environ. Microbiol., 1995, 59, 1425-1429.

84. Rhee H-I, et al. One step purification of cholesterol oxidase from culture broth of a Pseudomonas sp. using a novel affinity chromatography method, Journal of General Microbiology, 1991, 137, 1213-1214.

85. Fukuyama M, et al. Purification and some properties of cholesterol oxidase from Schizopyllum commune with covalently bound flavin, J. Biochem., 1979, 85, 1183-1193.

86. Uwajima T, et al. Isolation and crystallisation of extracellular 3-hydroxysteroid oxidase of Brevibacterium sterolicum, Agr. Biol. Chem., 1973, 37, 2345-2350.

87. Ohta $\mathrm{T}$, et al. Sequence of gene choB encoding cholesterol oxidase of Brevibacterium sterolicum: comparison with choA of streptomyces sp, SA-COO, Gene, 1991, 103, 93-96.

88. Inouye Y, et al. Purification and characterisation of extracellular $3 \beta$ hydroxysteroid oxidase produced by Streptoverticillium cholesterolicum, Chem. Pharm. Bull., 1982, 30, 951-958.

89. Ishizaki T, et al. Nucleotide sequence of the gene for cholesterol oxidase from a Streptomyces sp, J. Bacteriol., 1989, 171, 596-601. 
90. Lartillot $\mathrm{S}$, et al. Production, purification and some properties of cholesterol oxidase from a Streptomyces sp, Prep. Biochem., 1990, 20, 51-62.

91. Kamei T, et al. Purification of 3 $\beta$-hydroxysteroid oxidase of Streptomyces violascens origin by affinity chromatography on cholesterol, Chem. Pharm. Bull., 1978, 26, 2799-2804.

92. Watanabe $\mathrm{K}$, et al. Isolation and identification of cholesterol degrading Rhodococcus strains from food and animal origin and their cholesterol oxidase activities, Appl. Microbiol., 1986, 32, 137-147.

93. Kreit J, et al. Extracellular cholesterol oxidase from Rhodococcus sp. cells, $J$. Biotech., 1992, 24, 177-188.

94. Watanabe K, et al. Properties of the purified extracellular cholesterol oxidase from Rhodococcus equi No. 23, Agric. Food Chem., 1989, 37, 1178-1182.

95. Allain CC, et al. Enzymatic Determination of Serum Cholesterol, Clin. Chem., 1974, 20, 470-475.

96. Brooks CJW, et al. Selective reactions in the analytical characterisation of steroids by gas chromatography-mass spectrometry, J. Steroid Biochem., 1983, 19, 189-201.

97. Murata M, et al. Determination of cholesterol in sub-nanomolar quantities in biological fluids by high-performance liquid chromatography, J. Chromatogr., 1992, 579, 329-333.

98. Lapinleimu H, et al. Cholesterol measurement by reflotron dry chemistry in infants, children and adults, Scand. J. Clin. Lab. Invest., 1994, 54, 61-65.

99. Gray MC, et al. Microenzymatic fluorescence assay for serum cholesterol, Anal. Biochem., 1995, 224, 286-292.

100. Sugiuchi $\mathrm{H}$, et al. Homogeneous assay for measuring low-density lipoprotein cholesterol in serum with triblock copolymer and alpha-cyclodextrin sulfate, Clin. Chem., 1998, 44, 522-531.

101. Cobbaert C, et al. Reference standardization and triglyceride interference of a new homogeneous HDL-cholesterol assay compared with a former chemical precipitation assay, Clin. Chem., 1998, 44, 779-789.

102. Lange $\mathrm{Y}$, et al. Cholesterol oxidase susceptibility of the red cell membrane, Biochim. Biophys. Acta, 1984, 769, 551-562. 
103. Wei JS, et al. Simple enzymatic determination of total cholesterol in gallstones, Clin.Chem., 1989, 35, 2247-2249.

104. Aufenanger J, et al. Enzymatic determination of lipids in human bile without bilirubin interference: reliable assessment of the cholesterol saturation index (CSI), J. Clin. Chem. Clin. Biochem., 1989, 27, 605-611.

105. Bocos $\mathrm{C}$, et al. A rapid and sensitive method for HPLC cholesterol determination in bile, Rev. Esp. Fisiol., 1992, 48, 211-214.

106. Mike JH, et al. Temperature enhanced chemiluminescence for determination of cholesterol, Anal. Chim. Acta, 1992, 259, 73-78.

107. Sasamoto H, et al. Chemiluminescent enzymatic assay for cholesterol in serum using lucigenin, Anal. Chim. Acta, 1995, 310, 347-353.

108. Makino K, et al. Bioreactor system for the determination of cholesterol distribution in separated human serum lipoprotein classes, Nippon Kagaku Kaishi, 1987, 3, 524-530.

109. Shuler, M.L., and Kargi, F. Bioprocess Engineering: Basic Concepts; PrenticeHall: Upper Saddle River, NJ, 2002, pp 154.

110. Nunamaker, E.A., et al. In vivo stability and biocompatibility of implanted calcium alginate disks, Journal of Biomedical Materials Research Part A, 2007, 1128-1137.

111. Amsden, B., and Turner, N. Diffusion characteristics of calcium alginate gels, Biotechnol. Bioeng., 1999, 65, 605-610.

112. Smidsrod, O. The relative extension of alginates having different chemical composition, Carbohydr. Res., 1973, 27, 107-118.

113. Kong, H.J., et al. Controlling degradation of hydrogels via the size of cross-linked junctions, Adv. Mater., 2004, 16, 1917-1921.

114. Klein, J., et al. Pore size and properties of spherical Ca alginate biocatalysts, Eur. J. Microb. Biotechnol., 1983, 18, 86-91.

115. Stewart, W.W., and Swaisgood, H.E. Characterization of calcium alginate pore diameter by size-exclusion chromatography using protein standards, Enzyme Microb. Technol., 1993, 15, 922-927. 
116. Fritschy, W.M., et al. The capsular overgrowth on microencapsulated pancreatic islet grafts in streptozotocin and autoimmune diabetic rats, Transplant Int., 1994, 7, 264-271.

117. De Vos, et al. Improved biocompatibility but limited graft survival after purification of alginate for microencapsulation of pancreatic islets, Diabetologia, 1997, 40, 262-270.

118. De Vos, P., et al. Obstacles in the application of microencapsulation in islet transplantation, Int. J. Artif. Org., 1993, 16, 205-212.

119. De Vos, P., et al. Possible relationship between fibrotic overgrowth of alginatepolylysine-alginate microencapsulated pancreatic islets and the microcapsule integrity, Transplant Proc., 1994, 26, 782-783.

120. De Vos, P., et al. Effect of the alginate composition on the biocompatibility of alginate-polylysine microcapsules, Biomaterials, 1997, 18, 273-278.

121. Martin, G.D., et al. Inkjet printing - the physics of manipulating liquid jets and drops, J. Phys. Conf. Series, 2008, 105, 1-14.

122. Le, H.P. Progress and trends in ink-jet printing technology, J. Imaging Sci. Technol., 1998, 42, 49-62.

123. Brünahl, J., and Grishin, A.M. Piezoelectric shear mode drop-on-demand inkjet actuator, Sens. Actuat. A., 2002, 101, 371-382.

124. Dong, H., et al. Visualization of drop-on-demand inkjet: drop formation and deposition, Rev. Sci. Instrum., 2006, 77, 1-8.

125. Dohnal, J., and Štěpánek, F. Inkjet fabrication and characterization of calcium alginate microcapsules, Powder Technology, 2010, 200, 254-259.

126. Nakamura, M., et al. Biocompatible Inkjet Printing Technique for Designed Seeding of Individual Living Cells, Tissue Engineering, 2005, 11, 1658-1666.

127. Fournier, R.L. Basic Transport Phenomena in Biomedical Engineering, $2^{\text {nd }}$ ed.; Taylor \& Francis Group: New York, NY, 2007, pp 70.

128. Johnson, T.L., and Somkuti, G.A. Properties of Cholesterol Dissimilation by Rhodococcus equi, Journal of Food Protection, 1990, 53, 1-5.

129. Bianchi, G., et al. Rhodococcus sp. immobilized by adsorption on chitin, Elsevier, 1996, $11,126-131$. 
130. Tok, E., and Aslim, B. Cholesterol removal by some lactic acid bacteria that can be used as probiotic, Microbiol. Immunol., 2010, 54, 257-264.

131. Goetschel, R., et al. Microbial conversions in a liposomal medium. Part 2: Cholesterol oxidation by Rhodococcus erythropolis, Enzyme Microb. Technol., 1992, 14, 390-395.

132. Garofalo, F.A., and Chang, T.M.S. Immobilization of P. pictorum in Open Pore Agar, Alginate and Polylysine-Alginate Microcapsules for Serum Cholesterol Depletion, Biomat., Art. Cells, Art. Org., 1989, 17, 271-289.

133. Gilliland, S.E., et al. Assimilation of Cholesterol by Lactobacillus acidophilus, Applied and Environmental Microbiology, 1985, 49, 377-381.

134. Rasic, J.L., et al. Assimilation of Cholesterol by Some Cultures of Lactic Acid Bacteria and Bifidobacteria, Biotechnology Letters, 1992, 14, 39-44.

135. Noh, D.O., et al. Incorporation of Cholesterol into the Cellular Membrane of Lactobacillus acidophilus ATCC 43121, J. Dairy Sci., 1997, 80, 3107-3113.

136. Tahri, K., et al. Bifidobacteria Strain Behavior Toward Cholesterol: Coprecipitation with Bile Salts and Assimilation, Current Microbiology, 1996, 33, 187-193.

137. Tahri, K., et al. Effects of three strains of bifidobacteria on cholesterol, Letters in Applied Microbiology, 1995, 21, 149-151.

138. Lin, M-Y., and Chen, T-W. Reduction of Cholesterol by Lactobacillus acidophilus in Culture Broth. Journal of Food and Drug Analysis, 2000, 8, 97 102.

139. Medical Breakthroughs. Drano for Clogged Arteries [Online]. http://www.wndu.com $/ \mathrm{mmm} /$ headlines/Clogged_arteries_cleared_by_new_treatm ent_117670088.html (Accessed 12 Jul. 2012).

140. Ebbing, D.D., and Gammon, S.D. General Chemistry, $9^{\text {th }}$ ed.; Cengage Learning: Belmont, CA, 2010, pp 560-568.

141. Salva, T.J.G., et al. Some Enzymatic Properties of Cholesterol Oxidase Produce by Brevibacterium sp, Revista de Microbiologia, 1999, 30, 315-323.

142. Roy, R.K. Design of Experiments Using the Taguchi Approach: 16 Steps to Product and Process Improvement; John Wiley \& Sons, Inc: New York, NY, 2001, pp 433-459. 
143. Ristau, E., and Wagner, F. Formation Of Novel Anionic Trehalose tetraesters from Rhodococcus erythropolis Under Growth Limiting Conditions, Biotechnology Letters, 1983, 5, 95-100.

144. Nigam, A., and Ayyagari, A. Lab Manual in Biochemistry, Immunology and Biotechnology; Tata McGraw Hill: New Delhi, India, 2007, pp 33-35.

145. Mobed-Miremadi, M., et al. High Throughput Miniaturization of Artificial Cells, Art. Cells, Blood Substitutes \& Biotech., 2011, 39, 310-316.

146. Romley, C., and Wright, A. Animal and vegetable fixed oils, fats, butters, and waxes, $3^{\text {rd }}$ ed.; Charles Griffin \& Co.'s Publications: London, England, 1903, pp 516.

147. Simpliciano, C, and Asi, B. Pore size determination and validation using AFM and spectrophotometry. Presented at Third Bay Area Biomedical Devices Conference, San Jose State University [Online], San Jose, CA, 28 March 2012. http://www.engr.sjsu.edu/ bmes/BMDConf2012/abstract4.html (Accessed 27 Dec. 2012)

148. Dalgaard, P. Introductory Statistics with R, $2^{\text {nd }}$ ed.; Springer, New York, NY, 2008, pp 95-106.

149. Kaiz, S.S., et al. Physical Chemistry Of The Lipids Of Human Atherosclerotic Lesions. Demonstration Of A Lesion Intermediate Between Fatty Streaks And Advanced Plaques, J. Clin. Invst., 1976, 58, 200-211.

150. Harrison, R.G., et al. Bioseparations Science and Engineering, $1^{\text {st }}$ ed.; Oxford University Press: New York, NY, 2003, pp 31-38.

151. Mobed-Miremadi, M., et al. Comparative Diffusivity Measurements for AlginateBased Atomized and Inkjet-Bioprinted Artificial Cells using Fluorescence Microscopy. Art. Cells. Blood Substitutes \& Biotech, 2012. [Online early access], DOI:10.3109/10731199.2012.716064. Publoshed online: Sept 9, 2012. http://www.ncbi.nlm.nih.gov/pubmed/22992197 (accessed Mar 8, 2013). 


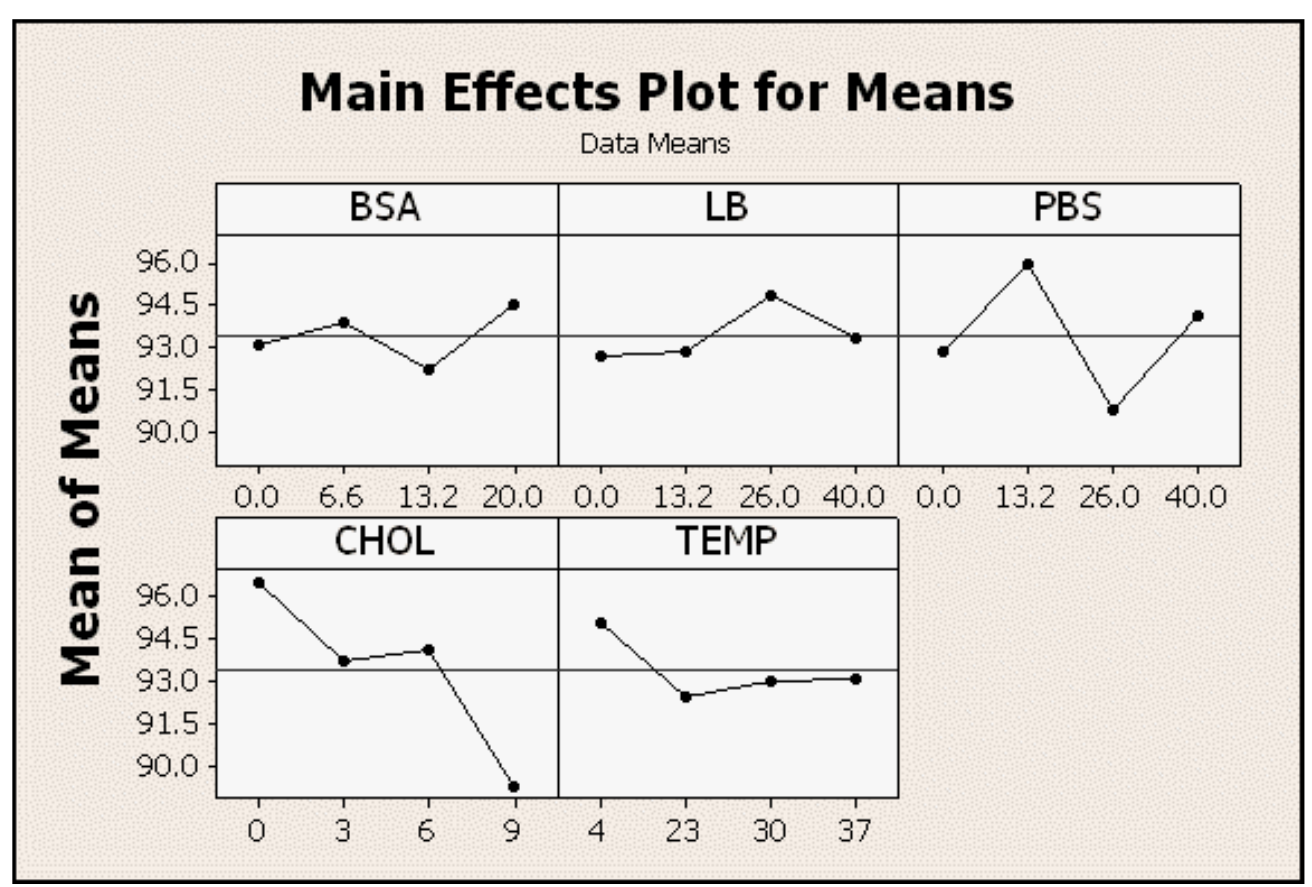

Figure 38. Main effects plot for means for bacteria growth for $\mathrm{t}=24 \mathrm{~h}$.

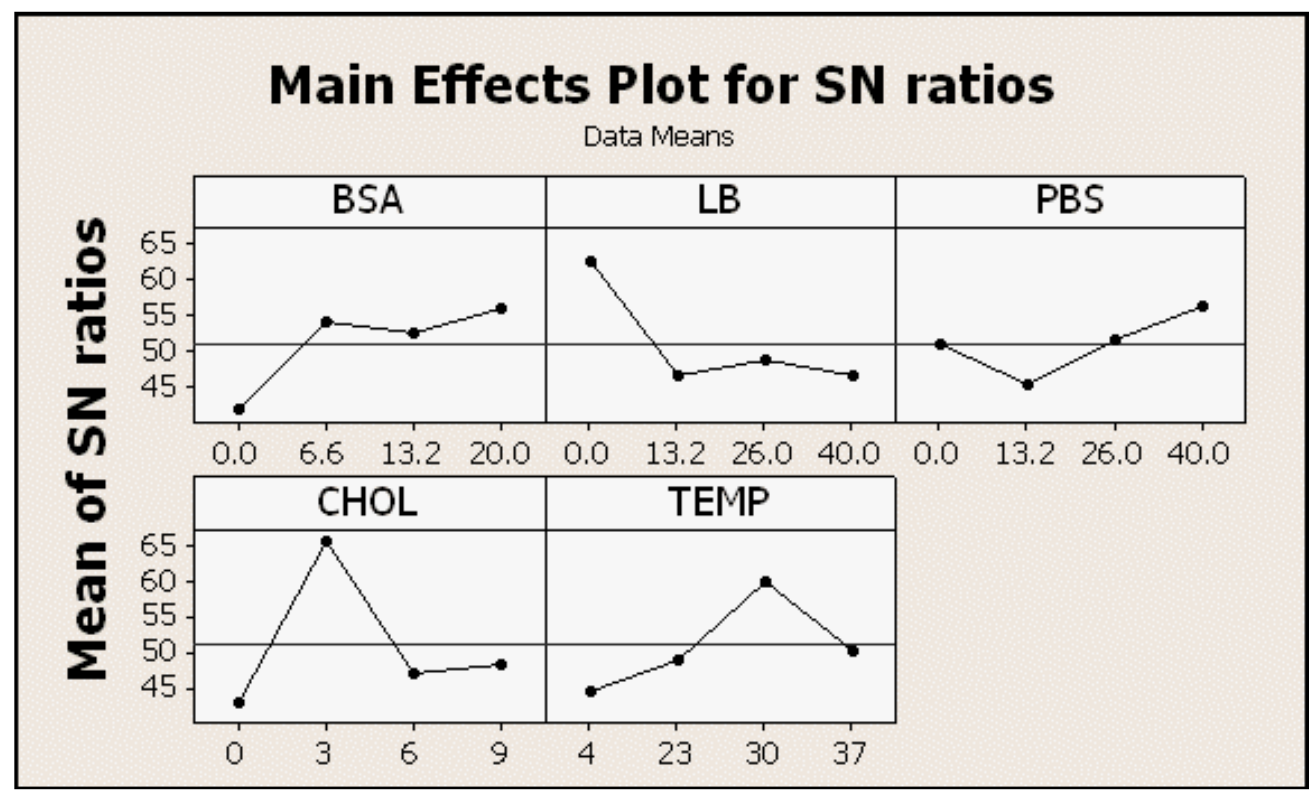

Figure 39. Main effects plot for signal-to-noise ratios for $\mathrm{t}=24 \mathrm{~h}$. 


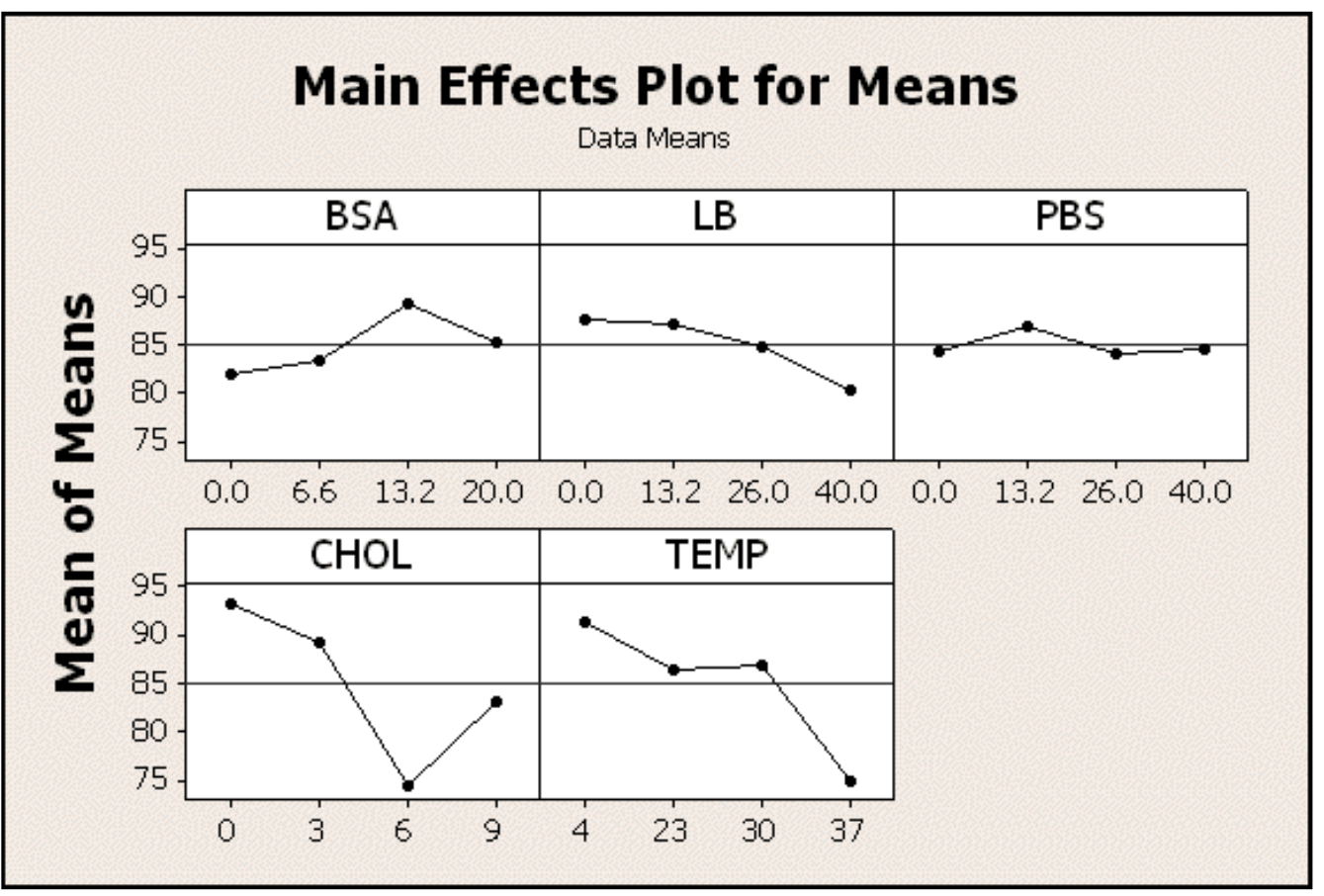

Figure 40. Main effects plot for means for bacteria growth for $\mathrm{t}=48 \mathrm{~h}$.

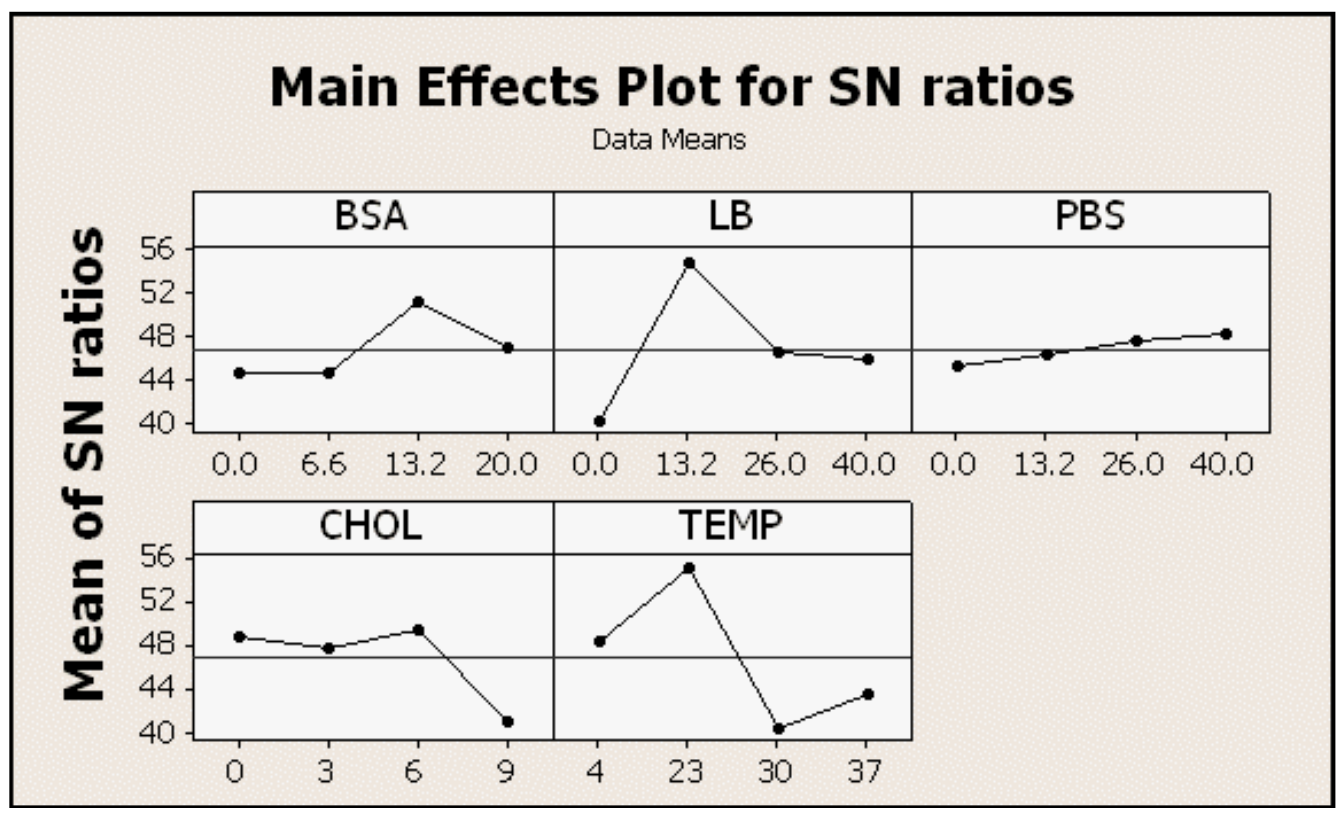

Figure 41. Main effects plot for signal-to-noise ratios for bacteria growth for $\mathrm{t}=48 \mathrm{~h}$. 


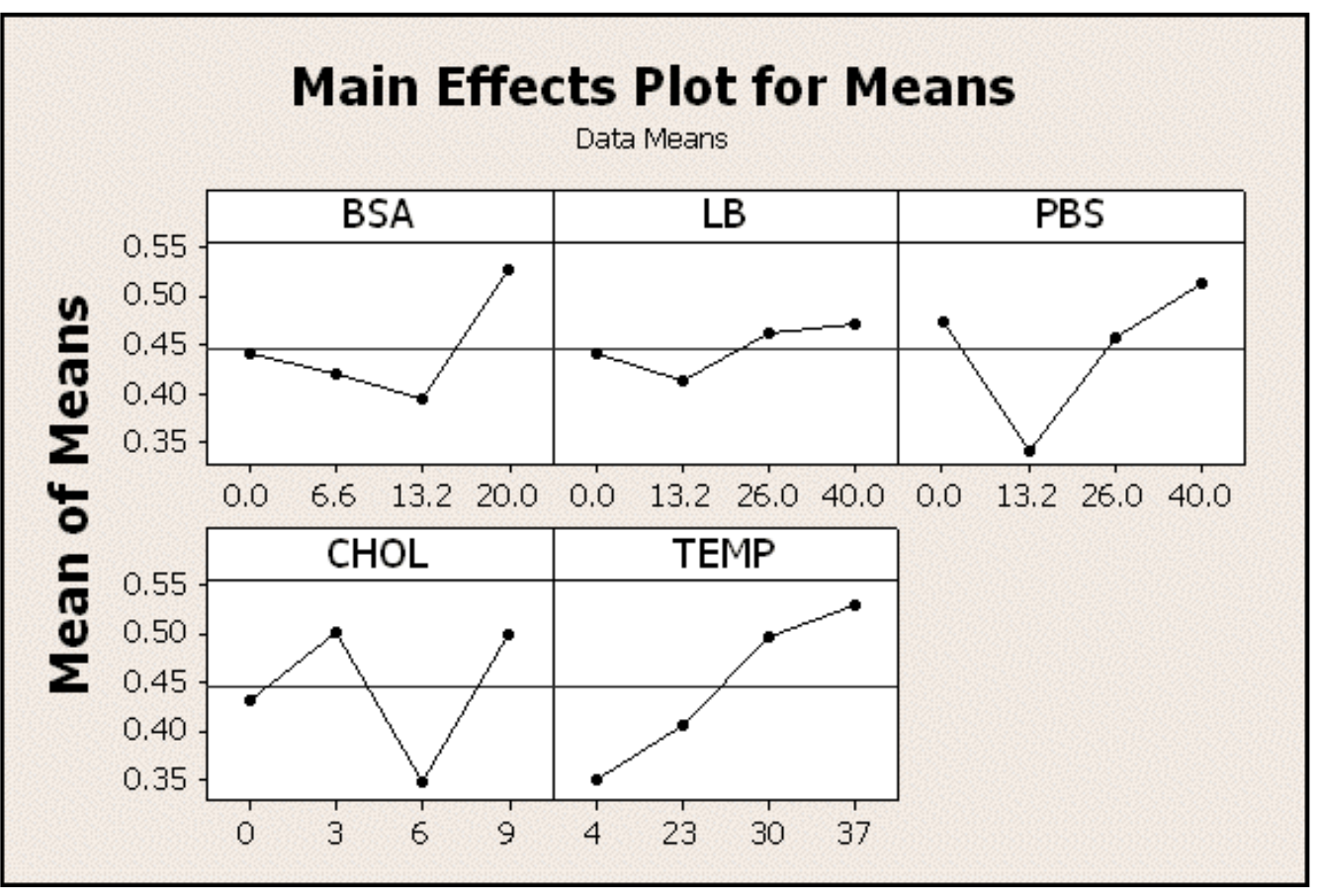

Figure 42. Main effects plot for means for glycolipid biosurfactant for $\mathrm{t}=24 \mathrm{~h}$.

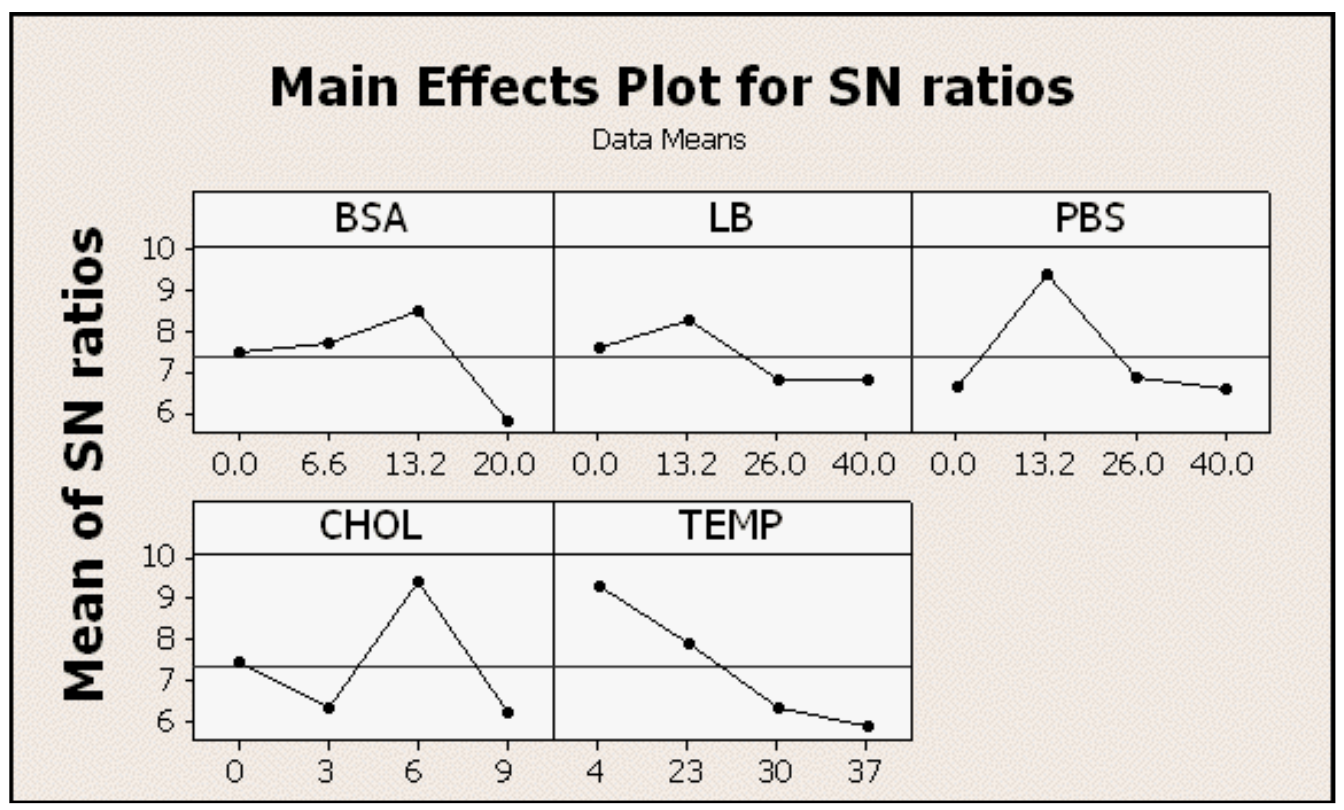

Figure 43. Main effects plot for signal-to-noise ratios for glycolipid biosurfactant for $\mathrm{t}=$ $24 \mathrm{~h}$. 
Table 18. DOE raw data for biosurfactant mass and bacteria growth at $t=48 \mathrm{~h}$.

\begin{tabular}{|c|c|c|}
\hline Experiment No. & $\begin{array}{l}\text { Mass of Biosurfactant in mg } \\
\qquad(\mathrm{t}=48 \mathrm{~h})\end{array}$ & $\begin{array}{c}\text { Bacteria Growth } \\
\text { in } \% \mathrm{~T} \\
(\mathrm{t}=48 \mathrm{~h})\end{array}$ \\
\hline 1 & 10.81 & 98.25 \\
\hline 2 & 22.51 & 91.78 \\
\hline 3 & 34.53 & 71.73 \\
\hline 4 & 26.80 & 64.07 \\
\hline 5 & 23.03 & 66.47 \\
\hline 6 & 25.28 & 84.11 \\
\hline 7 & 19.35 & 92.63 \\
\hline 8 & 16.85 & 88.17 \\
\hline 9 & 27.90 & 90.61 \\
\hline 10 & 17.09 & 86.89 \\
\hline 11 & 26.71 & 82.49 \\
\hline 12 & 16.21 & 97.07 \\
\hline 13 & 22.69 & 92.82 \\
\hline 14 & 26.31 & 84.74 \\
\hline 15 & 21.74 & 91.26 \\
\hline 16 & 23.28 & 70.94 \\
\hline 1 & 10.34 & 99.77 \\
\hline 2 & 23.06 & 93.87 \\
\hline 3 & 29.41 & 72.75 \\
\hline 4 & 25.53 & 67.73 \\
\hline 5 & 21.38 & 67.94 \\
\hline 6 & 24.66 & 87.71 \\
\hline 7 & 19.83 & 95.05 \\
\hline 8 & 24.01 & 90.94 \\
\hline 9 & 30.64 & 93.34 \\
\hline 10 & 16.40 & 87.08 \\
\hline 11 & 25.05 & 85.24 \\
\hline 12 & 17.22 & 96.45 \\
\hline 13 & 26.44 & 97.11 \\
\hline 14 & 25.81 & 87.18 \\
\hline 15 & 22.25 & 94.51 \\
\hline 16 & 24.39 & 70.88 \\
\hline
\end{tabular}




\subsection{APPENDIX B: CHOLESTEROL DEGRADATION PROFILES}

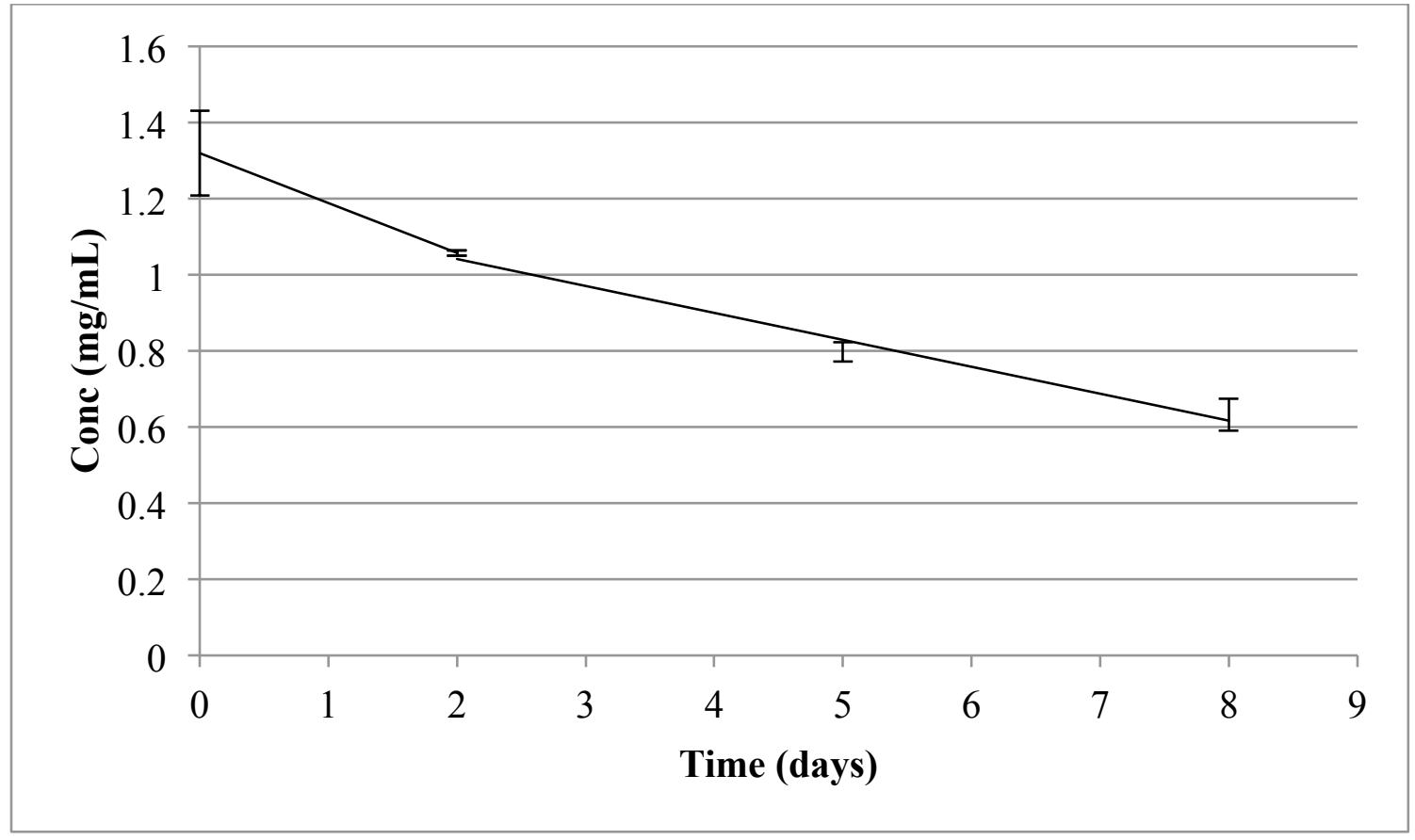

Figure 44. Cholesterol profile of free bacteria with medium cell count.

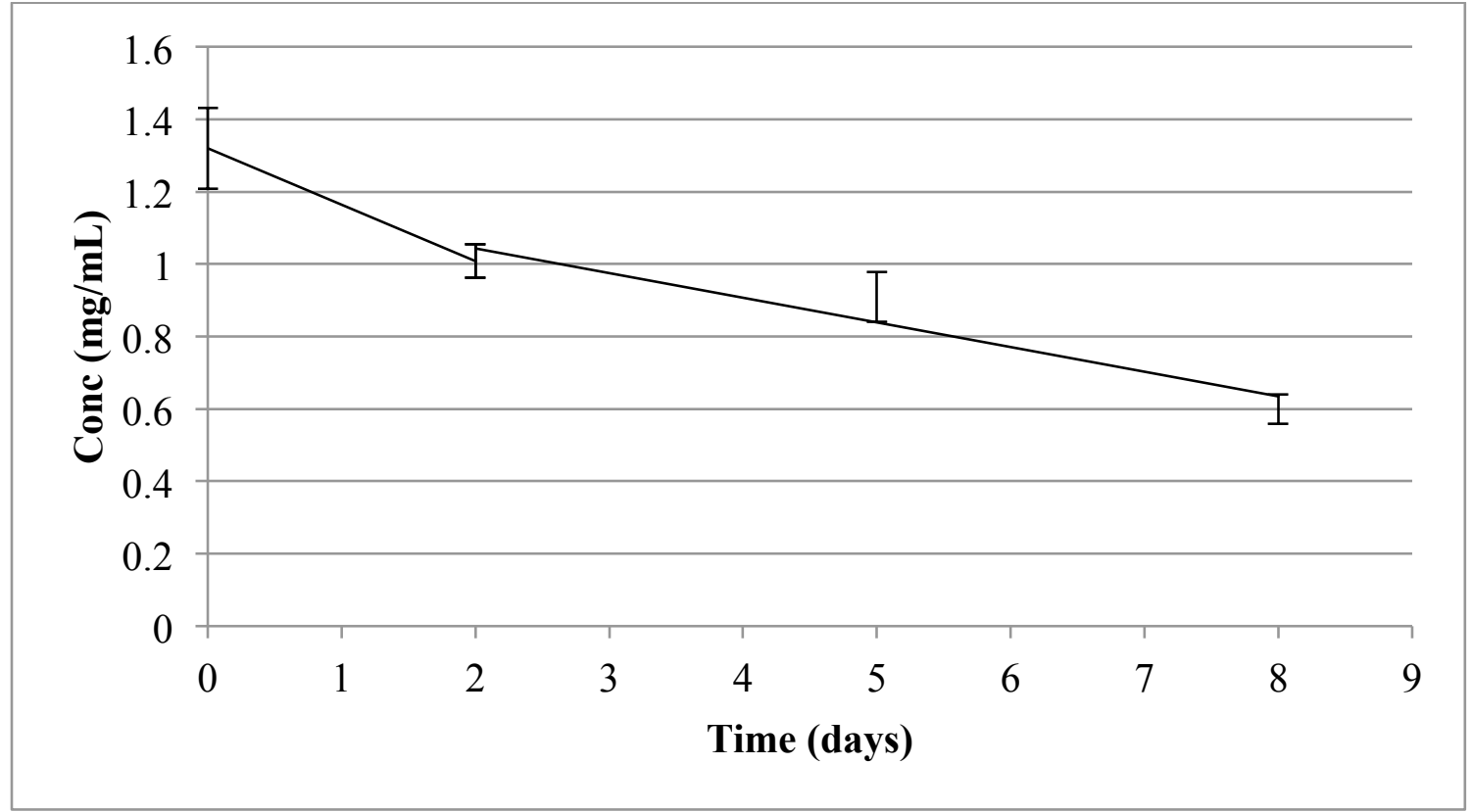

Figure 45. Cholesterol profile of free bacteria with high cell count. 


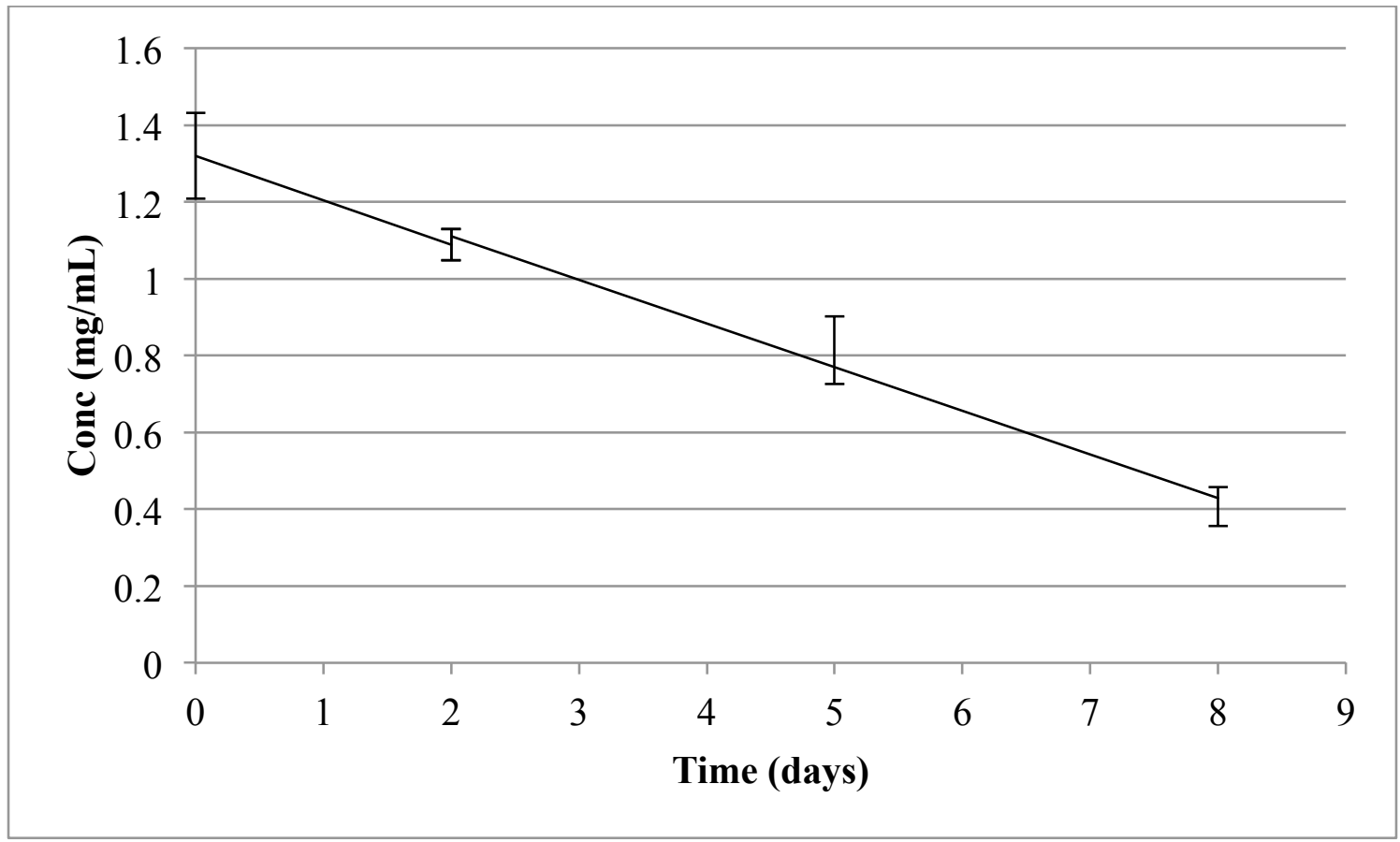

Figure 46. Cholesterol profile of atomized bacteria with medium cell count.

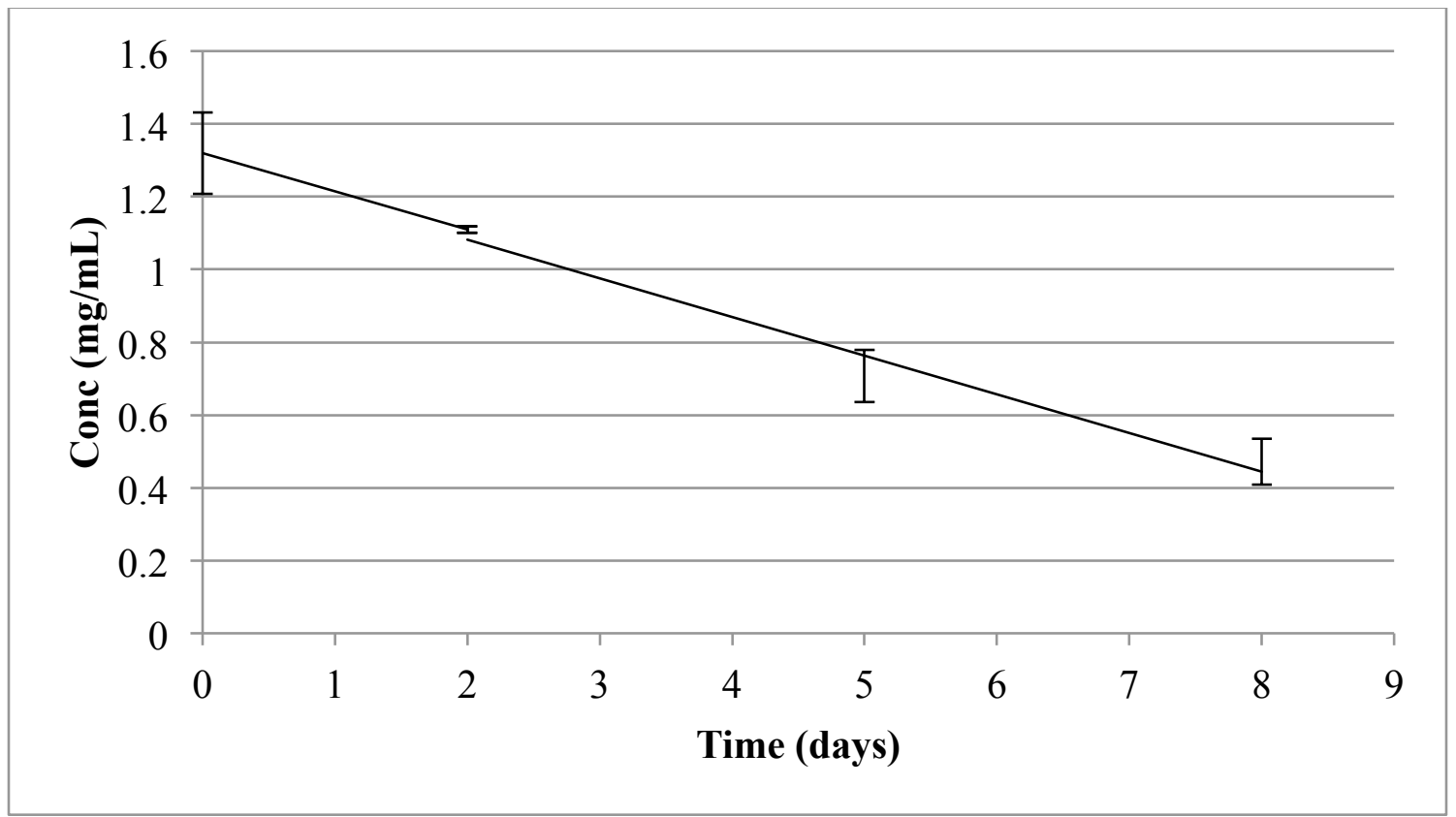

Figure 47. Cholesterol profile of atomized bacteria with high cell count. 